\title{
Multivalent Peptide-functionalized Bioreducible Polymers for Cellular Delivery of Various RNAs
}

Dong-Chu Yang, Alex Eldredge, Collin Hickey, Hurik Muradyan, Zhibin Guan*

\section{Supporting Information}

\section{Table of Contents}

\section{Supplemental Figures and Table}

Figure S1. Gel electrophoresis study of MPBP-siRNA complexation.

Figure S2. Gel electrophoresis study of MPBP-eGFP mRNA complexation.

Figure S3. Gel electrophoresis study to determine mRNA degradation and protection.

Figure S4. DLS measurement of different MPBP-siRNA complexes ( $\mathrm{N} / \mathrm{P}=10)$.

Figure S5. DLS measurement of different MPBP-Fluc mRNA complexes $(\mathrm{N} / \mathrm{P}=10)$.

Figure S6. Stability of different MPBP-Fluc mRNA complexes in PBS buffer $(\mathrm{pH}=7.4)$ as determined by DLS.

Figure S7. TEM images and size distribution of representantive MPBP-RNA nanoparticle complexes stained with $2 \%$ wt uranyl acetate.

Figure S8. Transfection screening of G0-100LP-siRNA complexes at various N/P ratios $(3-80)$ in firefly luciferase-expressing HEK-293 cells. [siRNA] $=60 \mathrm{nM}$.

Figure S9. Transfection screening of different MPBP-siRNA complexes in firefly luciferaseexpressing HEK-293 cells.

Figure S10. Transfection screening of G0-100LP-Fluc mRNA complexes in NIH 3T3 cells at 
various $\mathrm{N} / \mathrm{P}$ ratios $(5-30)$.

Figure S11. Transfection screening of G1-100LP-Fluc mRNA complexes in NIH 3T3 cells at various $\mathrm{N} / \mathrm{P}$ ratios $(5-50)$.

Figure S12. Cytotoxicity of the MPBP vectors against NIH 3T3 cells assayed using a LDH assay.

Figure S13. Cellular uptake of MPBP-Cy5 Fluc mRNA complexes as observed by confocal fluorescence microscopy.

Figure S14. Cellular uptake of MPBP-Cy5 Fluc mRNA complexes in NIH 3T3 cells quantified by flow cytometry.

Figure S15. Endosomal escape by intracellular trafficking for MPBP-Cy5 siRNA complexes.

Figure S16. Preliminary linear peptide sequence screen from Fluc mRNA delivery.

Table S1. DLS measurements of size and Zeta potential of complexes between MPBPs and siRNA.

Table S2. DLS measurements of size and Zeta potential of complexes between MPBPs and Fluc mRNA.

\section{General Information}

3. MPBP Vector Synthesis and Characterization

4. MPBP/RNA Binding Studies

5. Biological Studies

6. Flow Cytometry Output

7. ${ }^{1} \mathrm{H}$ NMR Spectra

8. References 


\section{Supplemental Figures and Table}

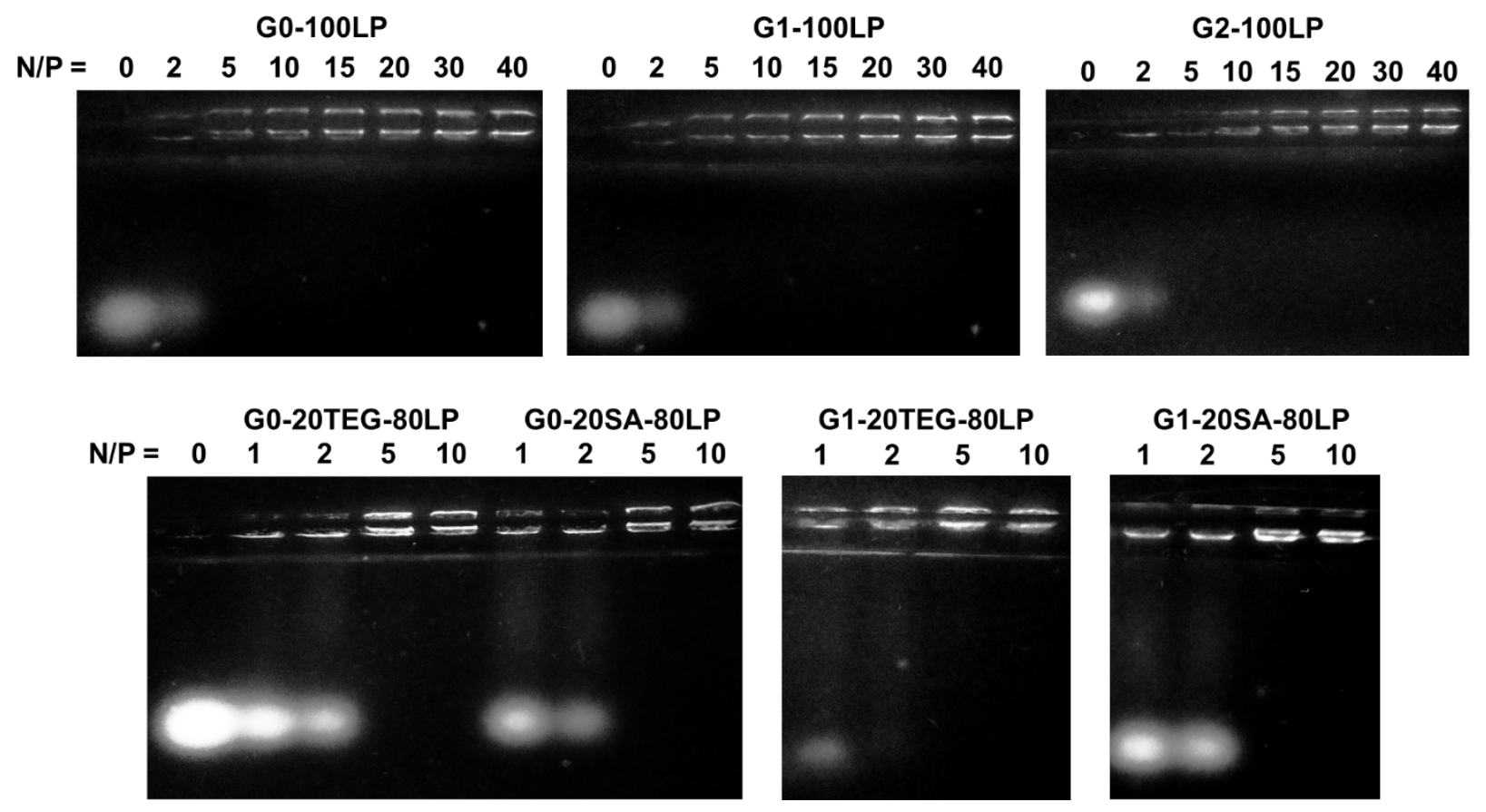

Figure S1. Gel electrophoresis study of MPBP-siRNA complexation. All vectors surveyed bound siRNA by N/P = 5.

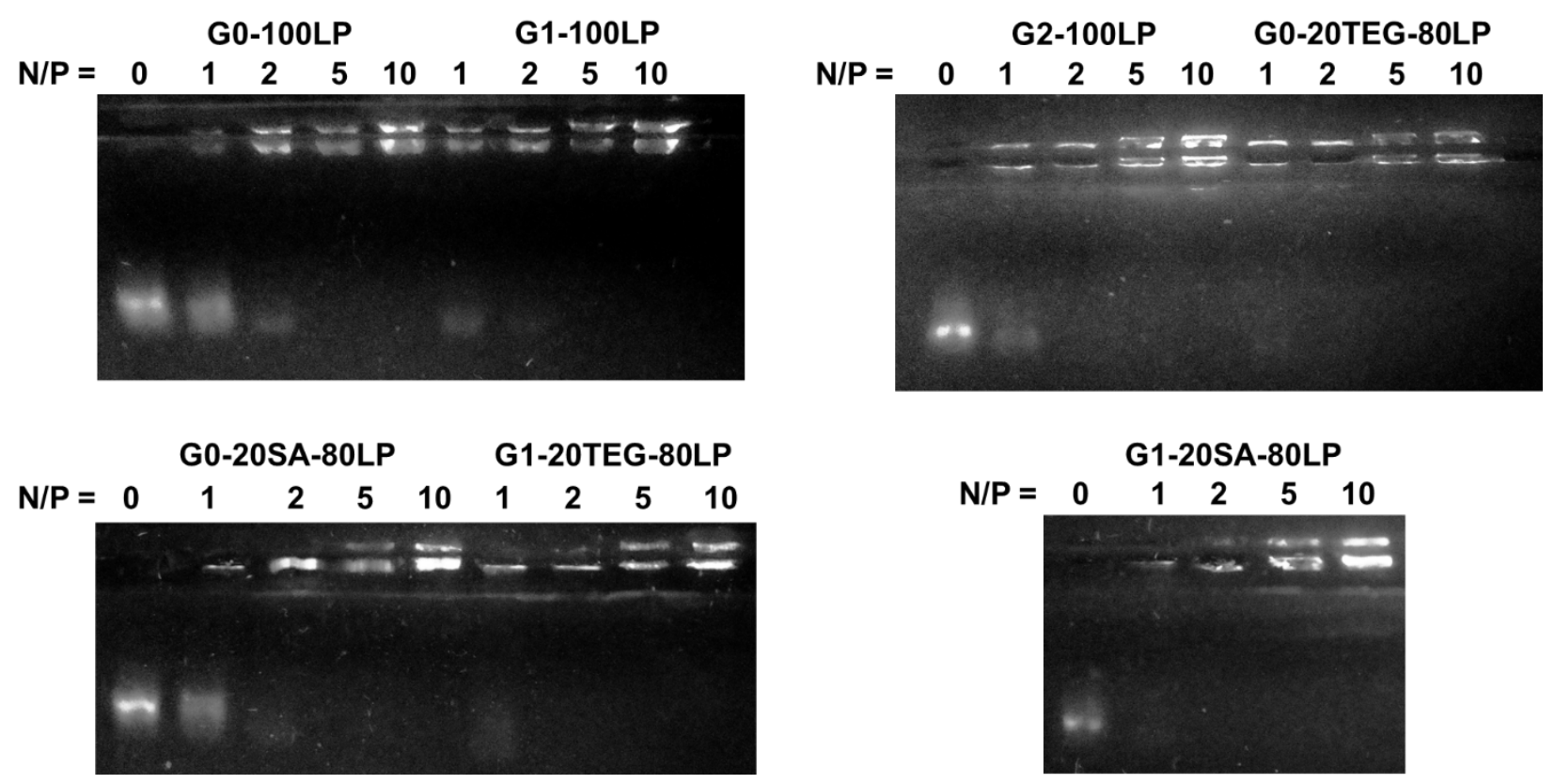

Figure S2. Gel electrophoresis study of MPBP-eGFP mRNA complexation. All vectors surveyed bound eGFP mRNA by $\mathrm{N} / \mathrm{P}=5$. 


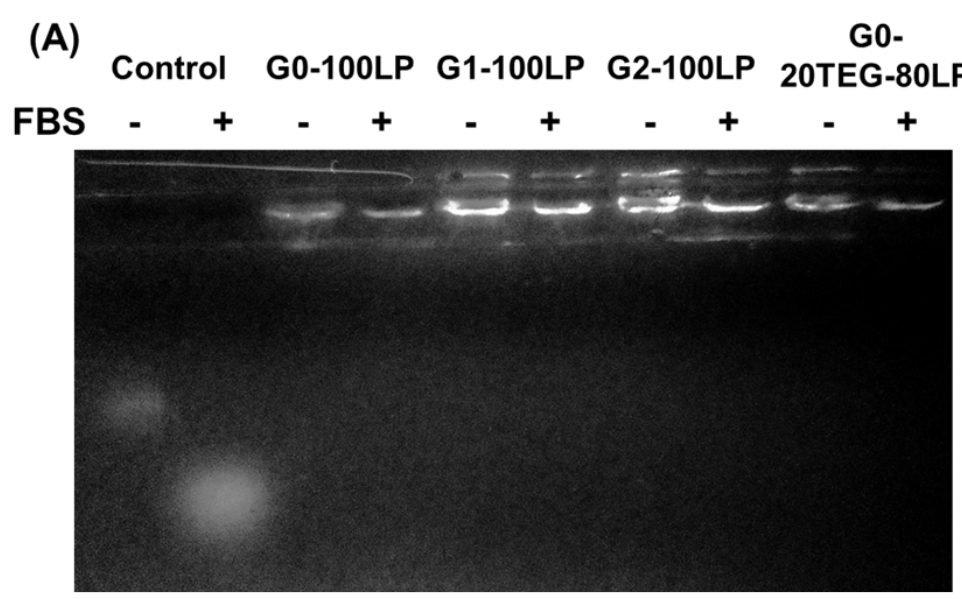

(B)

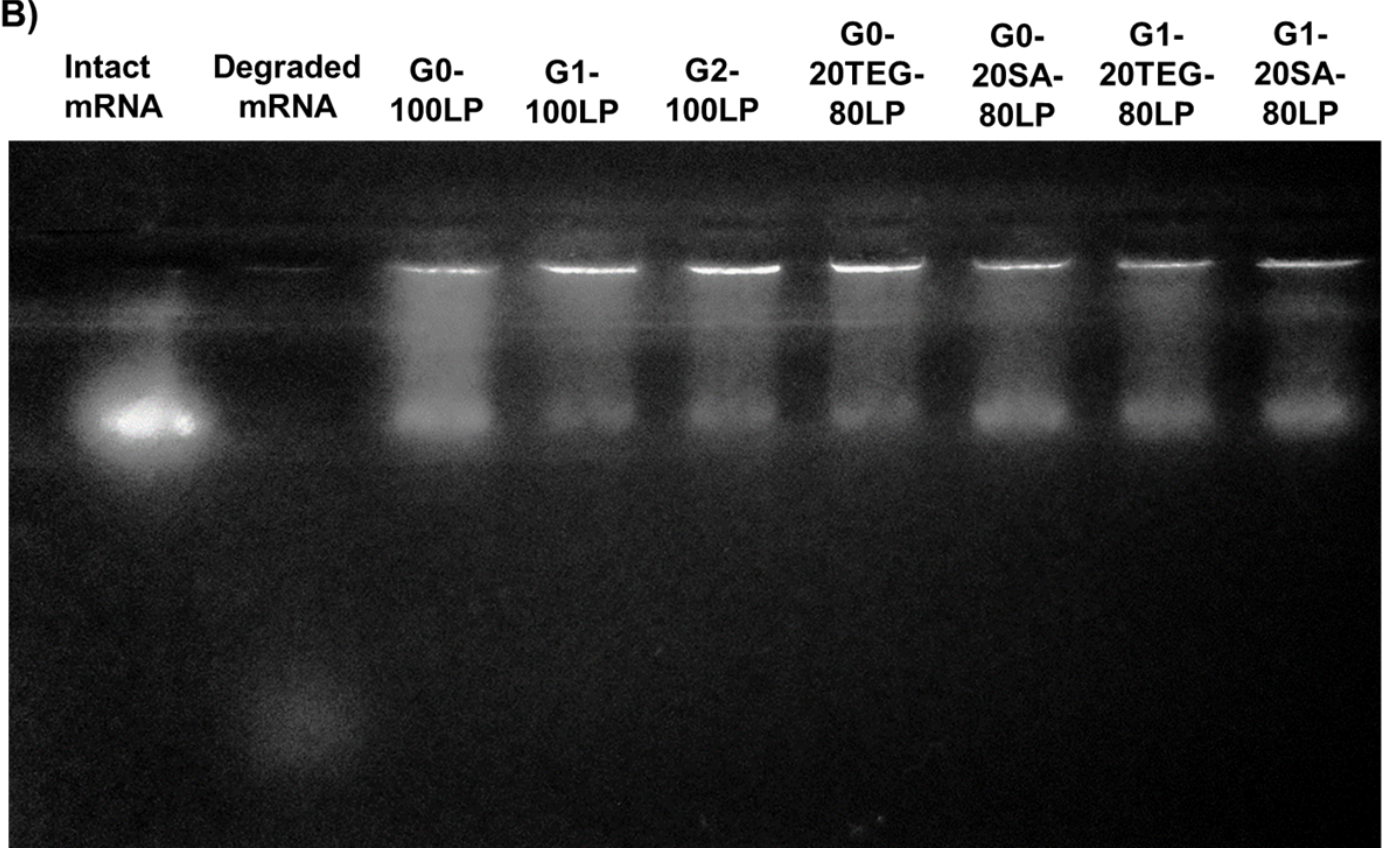

Figure S3. Gel electrophoresis study to determine mRNA degradation and protection. (A) Gel binding assays of MPBP-Fluc mRNA complexes $(\mathrm{N} / \mathrm{P}=10)$ with/without $10 \%$ FBS incubation (20 min). Naked mRNA was fully degraded after FBS incubation, while mRNAs in MPBPmRNA complexes remained bounded and intact after FBS incubation. (B) Dextran sulfate competition $(\mathrm{S} / \mathrm{P}=80)$ with different MPBP-Fluc mRNA complexes $(\mathrm{N} / \mathrm{P}=10)$ after $\mathrm{FBS}$ incubation to release any bound RNA. The released RNAs from MPBP-mRNA complexes were still intact indicating that the MPBP protected the RNA from degradation, while the blank RNA was fully degraded. 
Table S1. DLS measurements of size and Zeta potential of complexes between MPBPs and siRNA $(\mathrm{N} / \mathrm{P}=10$, PBS buffer $(\mathrm{pH}=7.4)$, [siRNA] $=150 \mathrm{nM})$. The Z-Average size is reported as an average value of 3 different measurements.

\begin{tabular}{cccc}
\hline Sample & $\begin{array}{c}\text { Z-Average } \\
\text { Size }(\mathbf{n m})\end{array}$ & PDI & Zeta potential $(\mathbf{m V})$ \\
\hline G0-100LP & $170 \pm 10$ & 0.27 & 8.4 \\
G1-100LP & $140 \pm 14$ & 0.14 & 28.2 \\
G2-100LP & $133 \pm 14$ & 0.15 & 22.1 \\
G0-20TEG-80LP & $201 \pm 6$ & 0.12 & 4.2 \\
G0-20SA-80LP & $198 \pm 9$ & 0.17 & 5.4 \\
G1-20TEG-80LP & $186 \pm 6$ & 0.15 & 17.1 \\
G1-20SA-80LP & $137 \pm 5$ & 0.17 & 17.6 \\
\hline
\end{tabular}

Table S2. DLS measurements of size and Zeta potential of complexes between MPBPs and Fluc mRNA (N/P $=10$, PBS buffer $(\mathrm{pH}=7.4)$, $[\mathrm{mRNA}]=2 \mathrm{ng} / \mu \mathrm{L})$. The Z-Average size is reported as an average value of 3 different measurements.

\begin{tabular}{cccc}
\hline Sample & $\begin{array}{c}\text { Z-Average } \\
\text { Size (nm) }\end{array}$ & PDI & Zeta Potential (mV) \\
\hline G0-100LP & $245 \pm 11$ & 0.06 & 26.5 \\
G1-100LP & $125 \pm 2$ & 0.11 & 25.4 \\
G2-100LP & $128 \pm 2$ & 0.12 & 28.0 \\
G0-20TEG-80LP & $245 \pm 13$ & 0.08 & 28.2 \\
G0-20SA-80LP & $281 \pm 8$ & 0.09 & 29.6 \\
G1-20TEG-80LP & $169 \pm 4$ & 0.08 & 26.0 \\
G1-20SA-80LP & $138 \pm 3$ & 0.12 & 28.4 \\
\hline
\end{tabular}


Size Distribution by Intensity

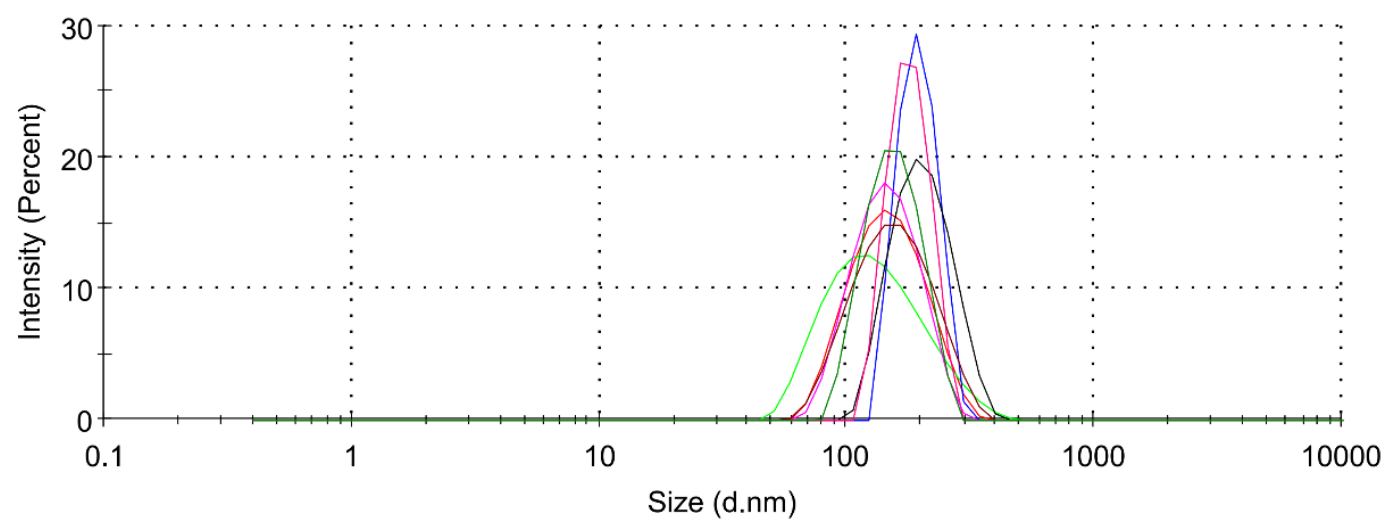

$\begin{array}{lll}\text { Record 7: G1-100LP 1 } & & \text { Record 13: G2-100LP 1 } \\ \text { Record 18: G0-20TEG-80LP 1 } & \text { Record 24: G0-20SA-80LP 1 } \\ \text { Record 30: G1-20TEG-80LP 1 } & & \text { Record 37: G1-20SA-80LP 3 } \\ \text { Record 42: G1-20OA-80LP 3 } & & \text { Record 46: G0-100LP 1 }\end{array}$

Figure S4. DLS measurement of different MPBP-siRNA complexes (N/P = 10, PBS buffer ( $\mathrm{pH}$ $=7.4)$, $[$ siRNA $]=150 \mathrm{nM})$.

Size Distribution by Intensity

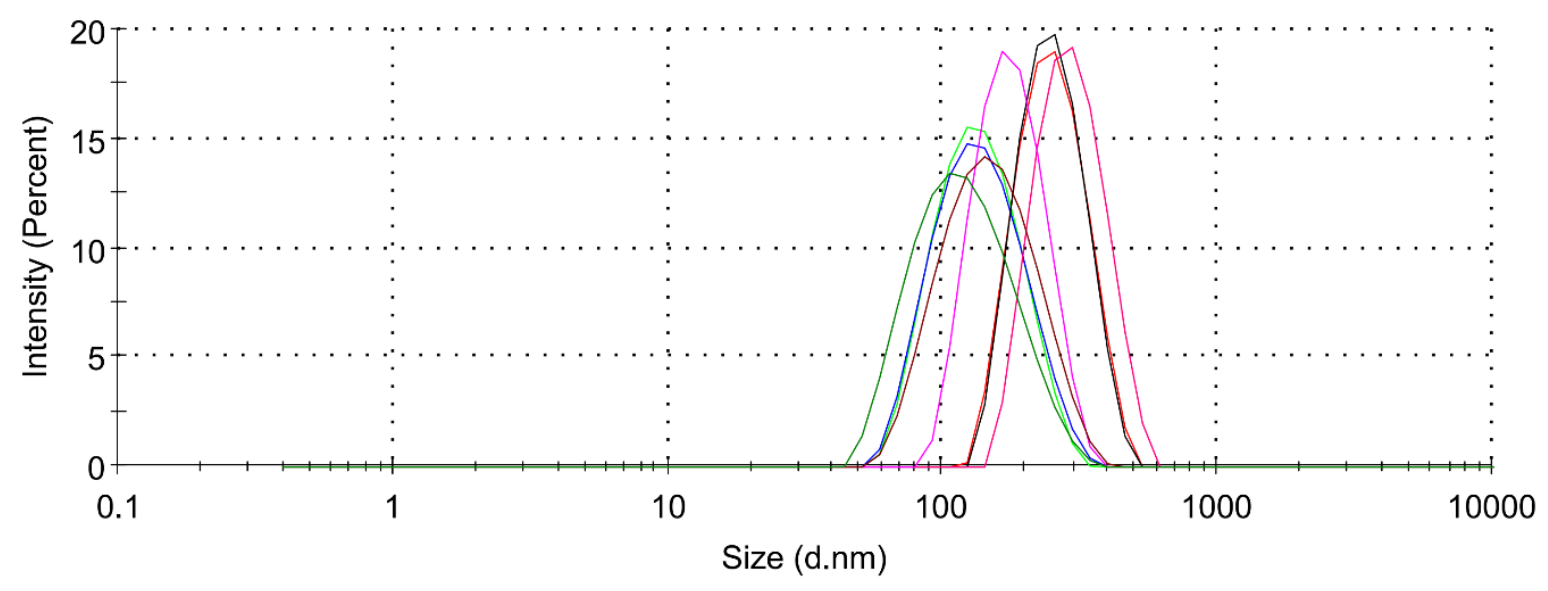

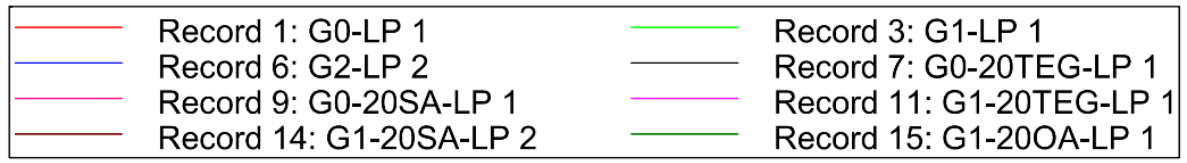

Figure S5. DLS measurement of different MPBP-Fluc mRNA complexes (N/P = 10, PBS buffer $(\mathrm{pH}=7.4),[\mathrm{mRNA}]=2 \mathrm{ng} / \mu \mathrm{L})$. 


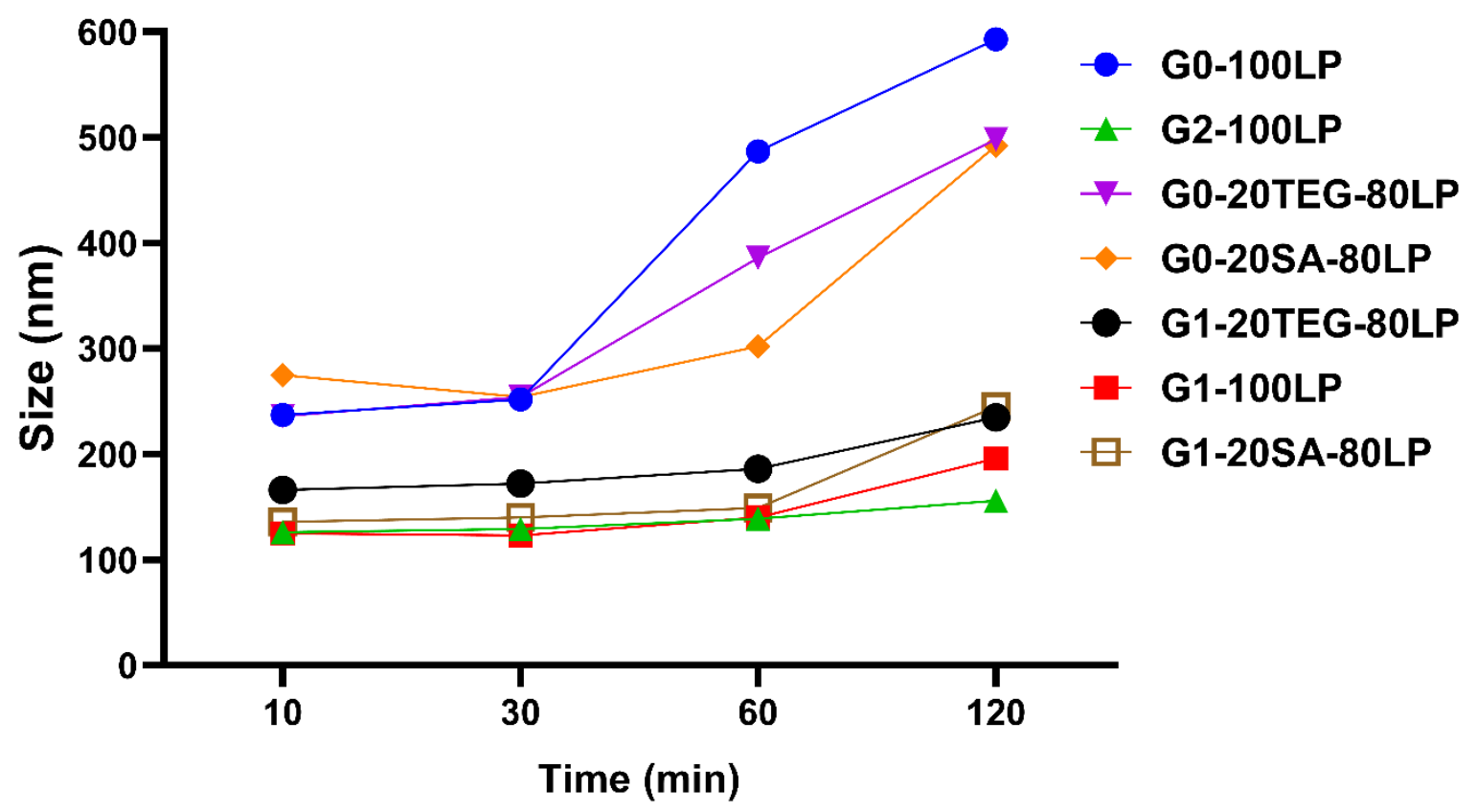

Figure S6. Stability of different MPBP-Fluc mRNA complexes in PBS buffer $(\mathrm{pH}=7.4)$ as determined by DLS. All measurements reported as Z-average (nm). 
(A)
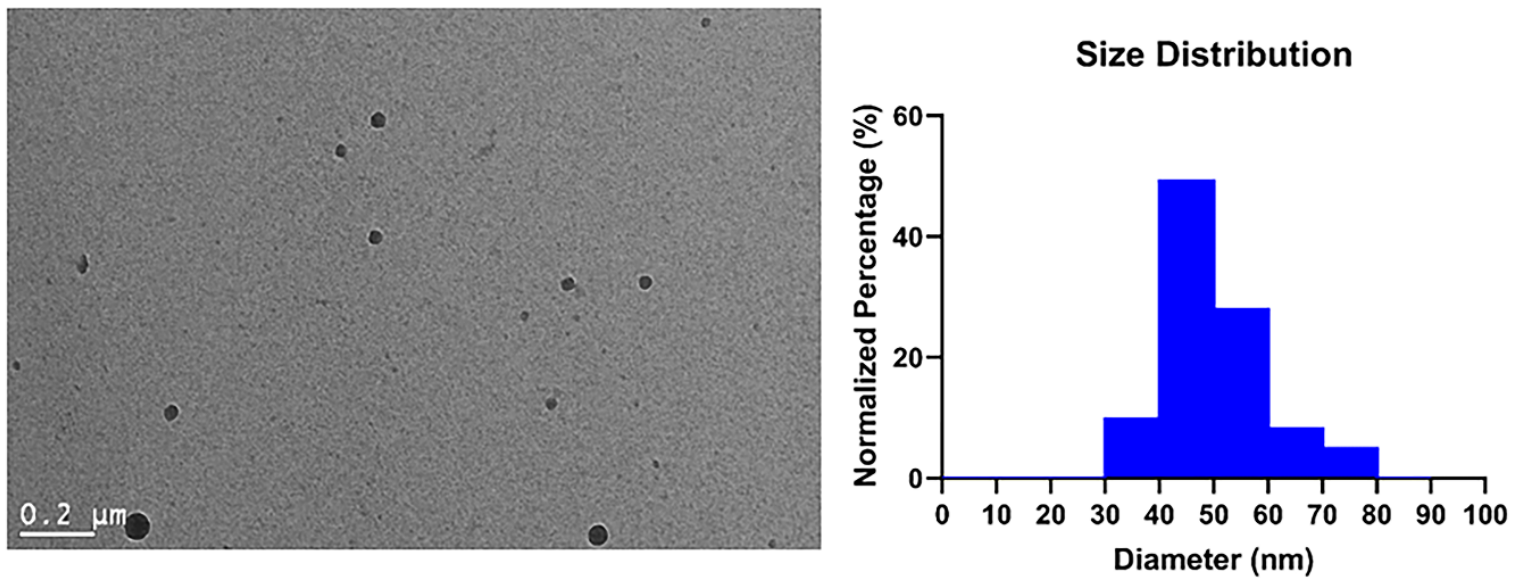

(B)
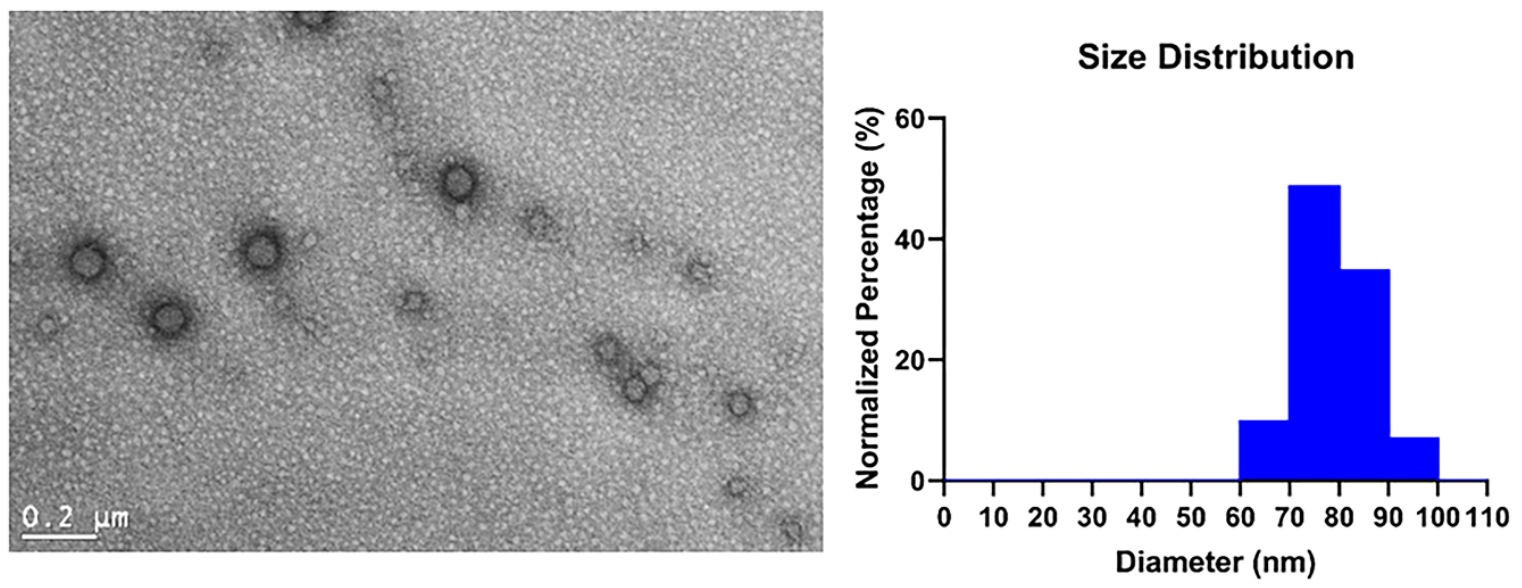

Figure S7. TEM images and size distribution $(\mathrm{n}=70)$ of representantive MPBP-RNA nanoparticle complexes stained with $2 \%$ wt uranyl acetate. (A) G0-100LP-siRNA complexes at $\mathrm{N} / \mathrm{P}=10$. [siRNA] $=10 \mu \mathrm{M}$. (B) G1-100LP-Fluc mRNA complexes at $\mathrm{N} / \mathrm{P}=10 .[\mathrm{mRNA}]=0.1$ $\mu \mathrm{g} / \mu \mathrm{L}$. 


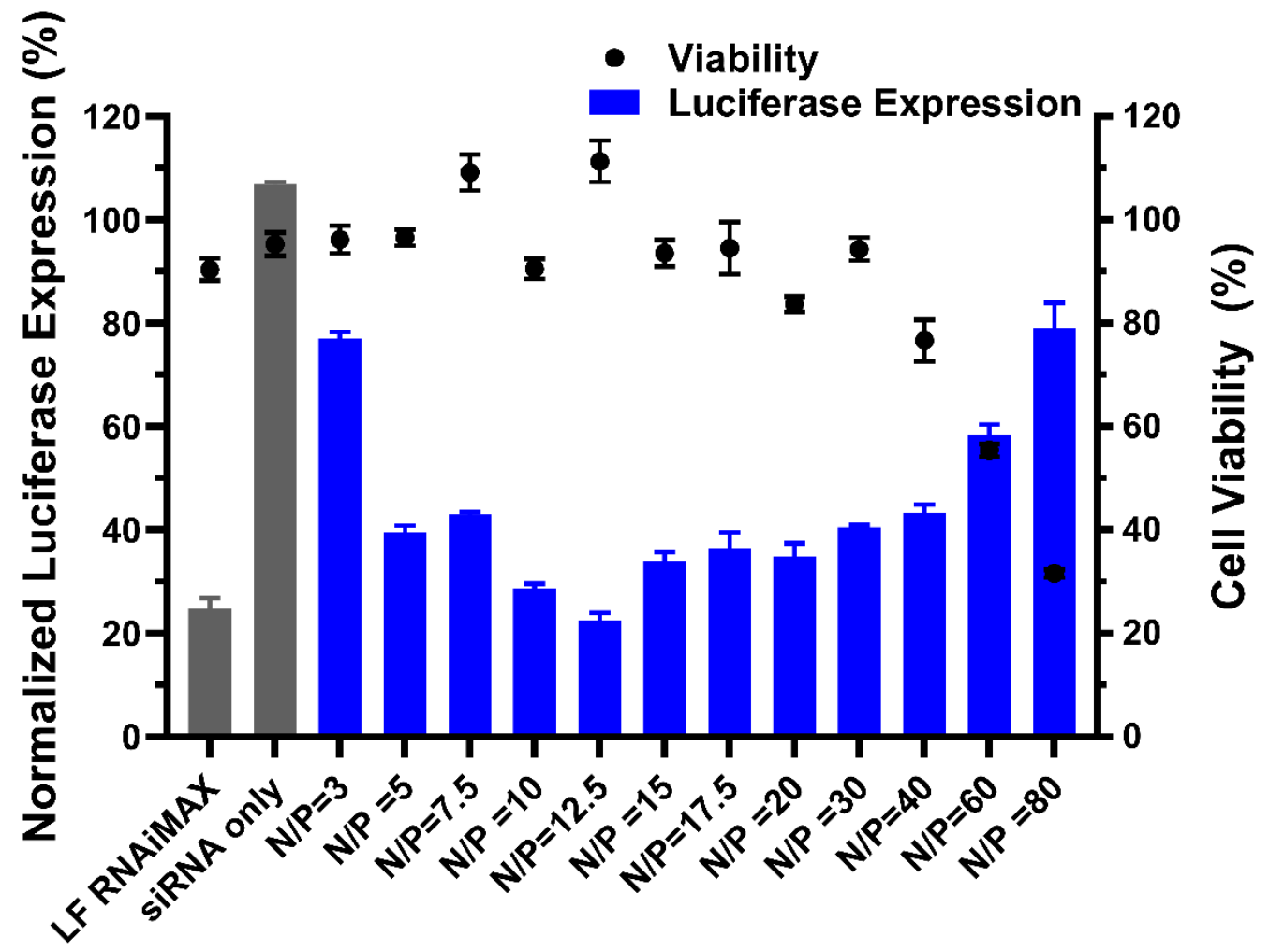

Figure S8. Transfection screening of G0-100LP-siRNA complexes at various N/P ratios $(3-80)$ in firefly luciferase-expressing HEK-293 cells. [siRNA] $=60 \mathrm{nM}$. 
(A)

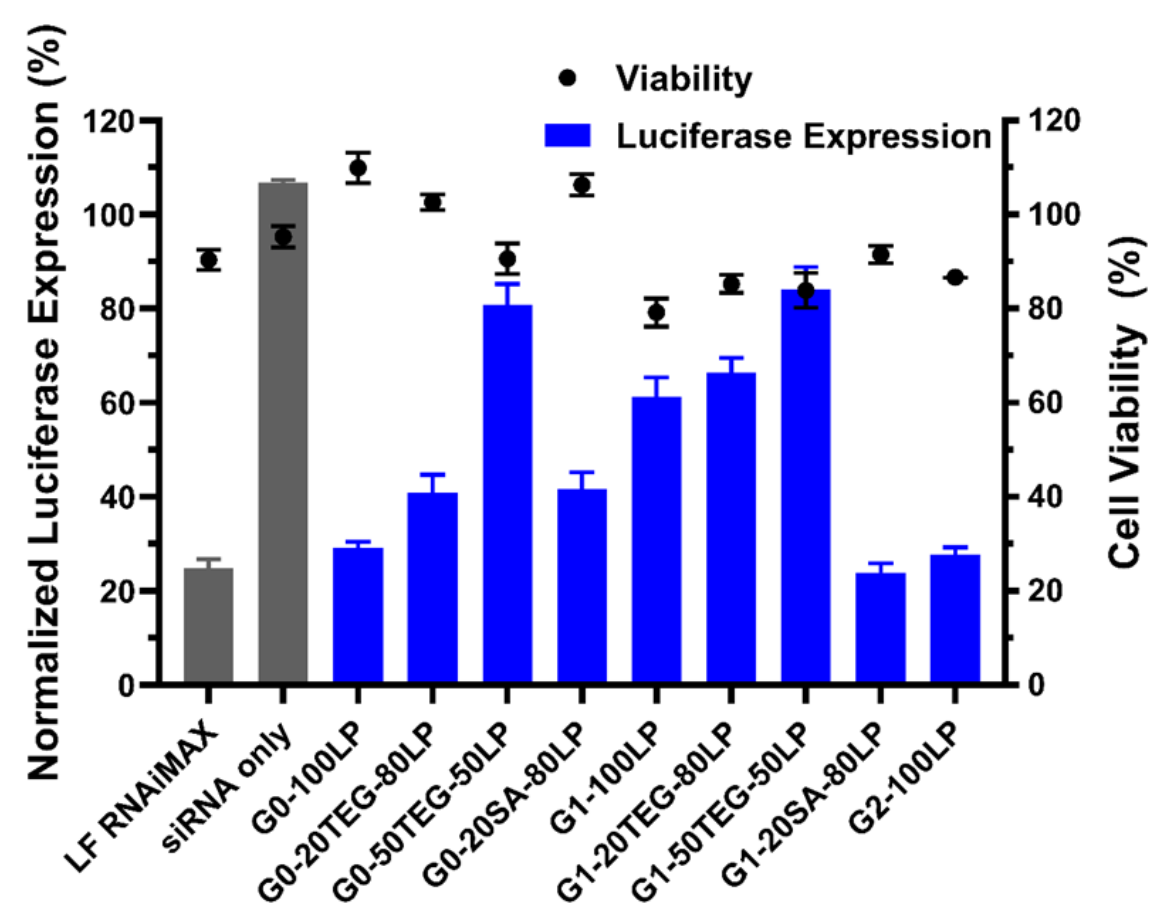

(B)

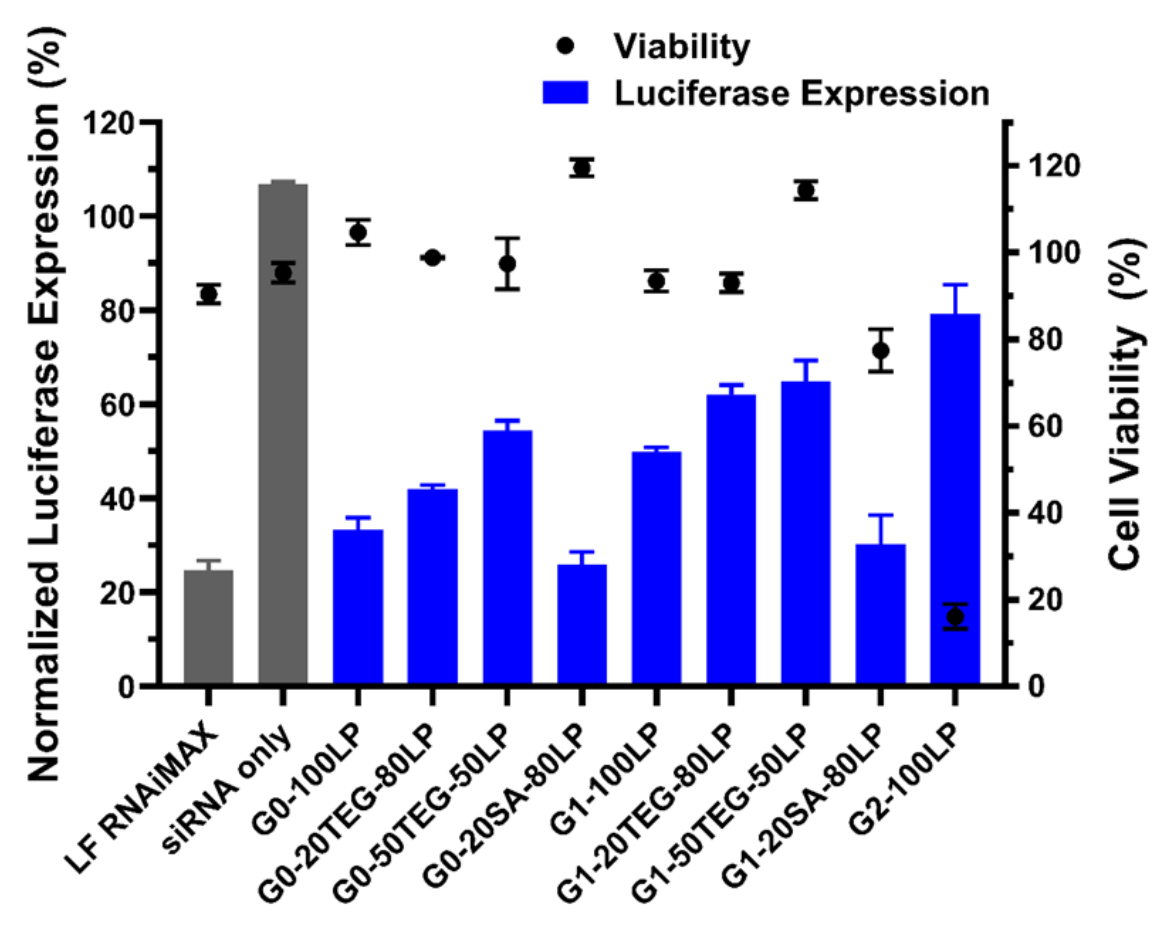

Figure S9. Transfection screening of different MPBP-siRNA complexes in firefly luciferaseexpressing HEK-293 cells. (A) N/P $=10$, [siRNA] $=60 \mathrm{nM}$. (B) $\mathrm{N} / \mathrm{P}=15$, [siRNA] $=60 \mathrm{nM}$. 


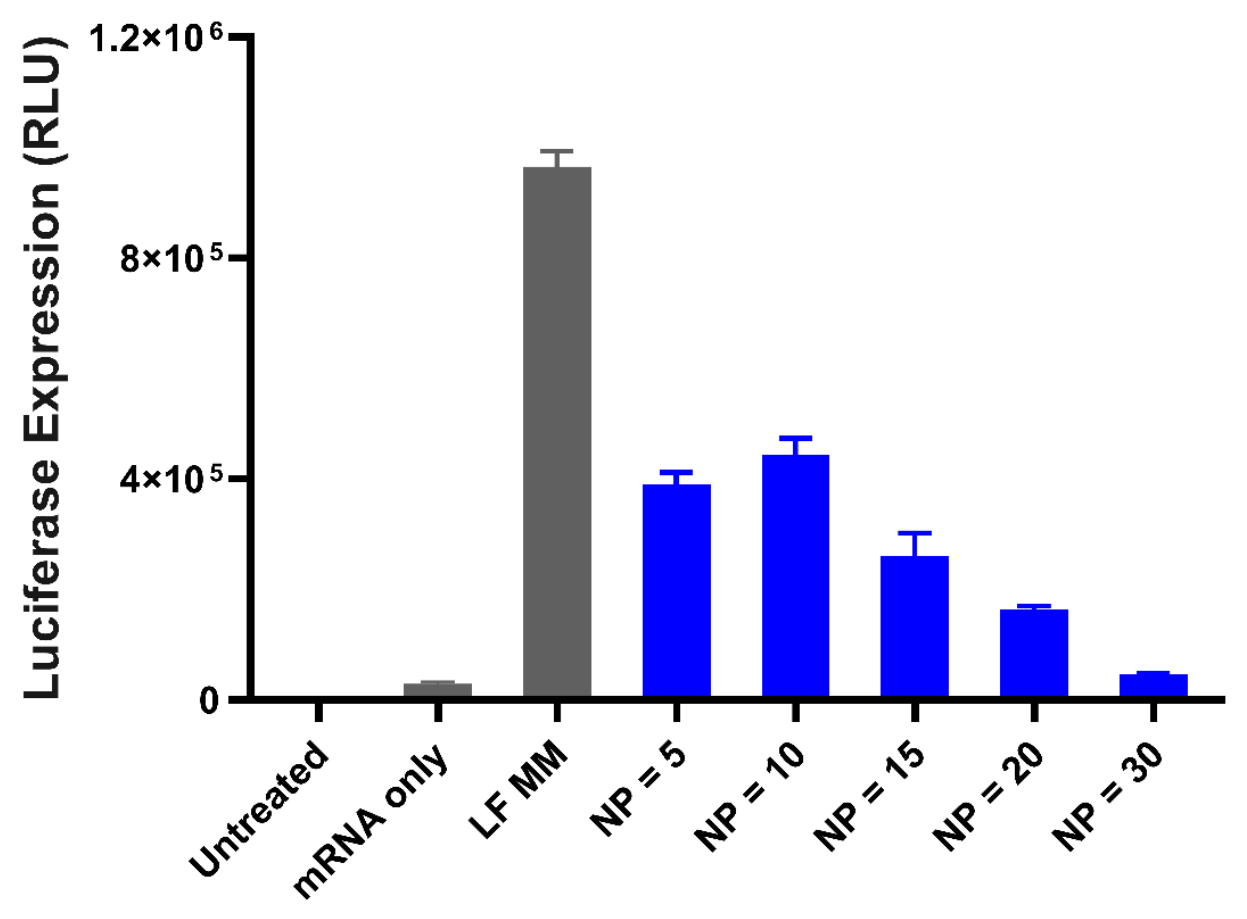

Figure S10. Transfection screening of G0-100LP-Fluc mRNA complexes in NIH 3T3 cells at various $\mathrm{N} / \mathrm{P}$ ratios $(5-30)$ (150 ng mRNA per well).

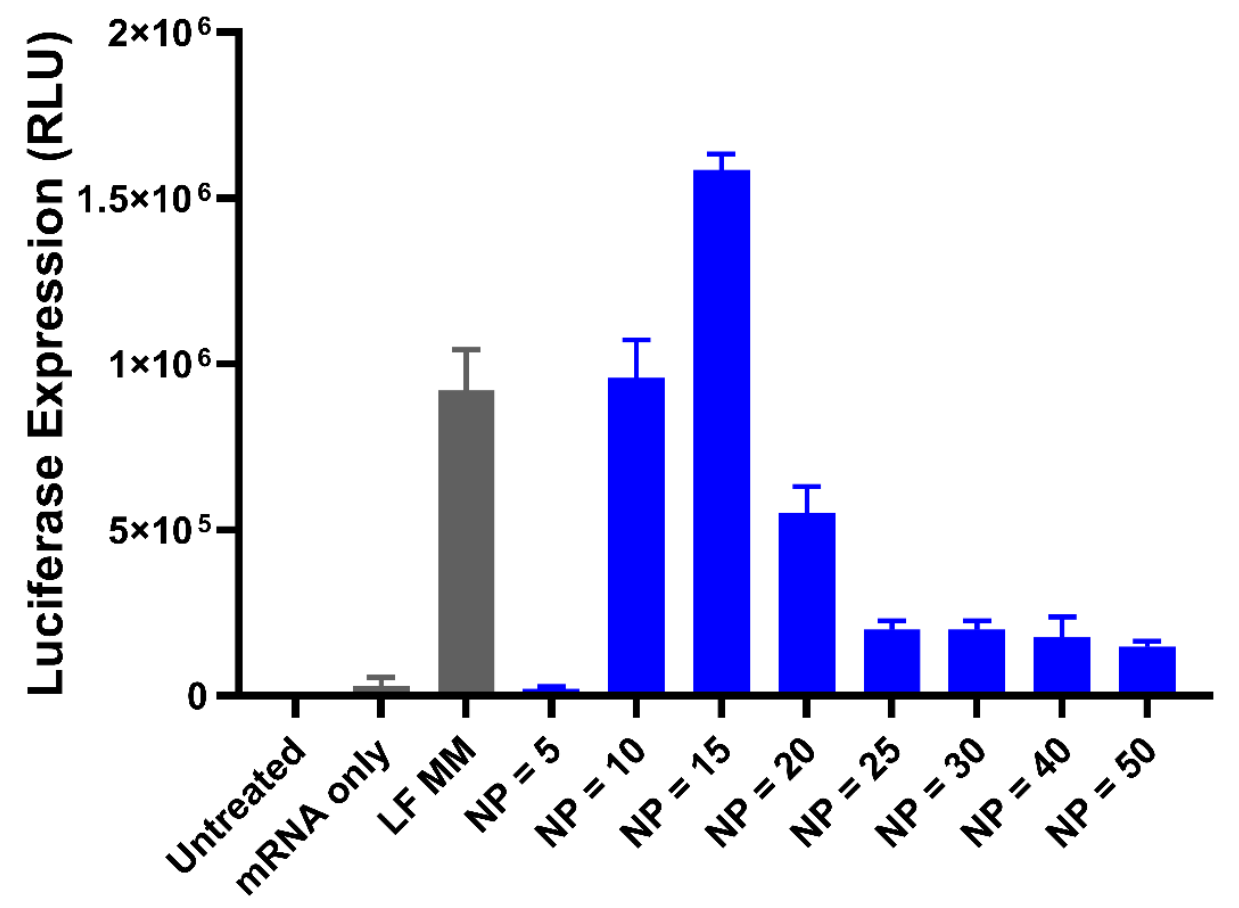

Figure S11. Transfection screening of G1-100LP-Fluc mRNA complexes in NIH 3 T3 cells at various $\mathrm{N} / \mathrm{P}$ ratios $(5-50)$ (150 ng mRNA per well). 
(A)

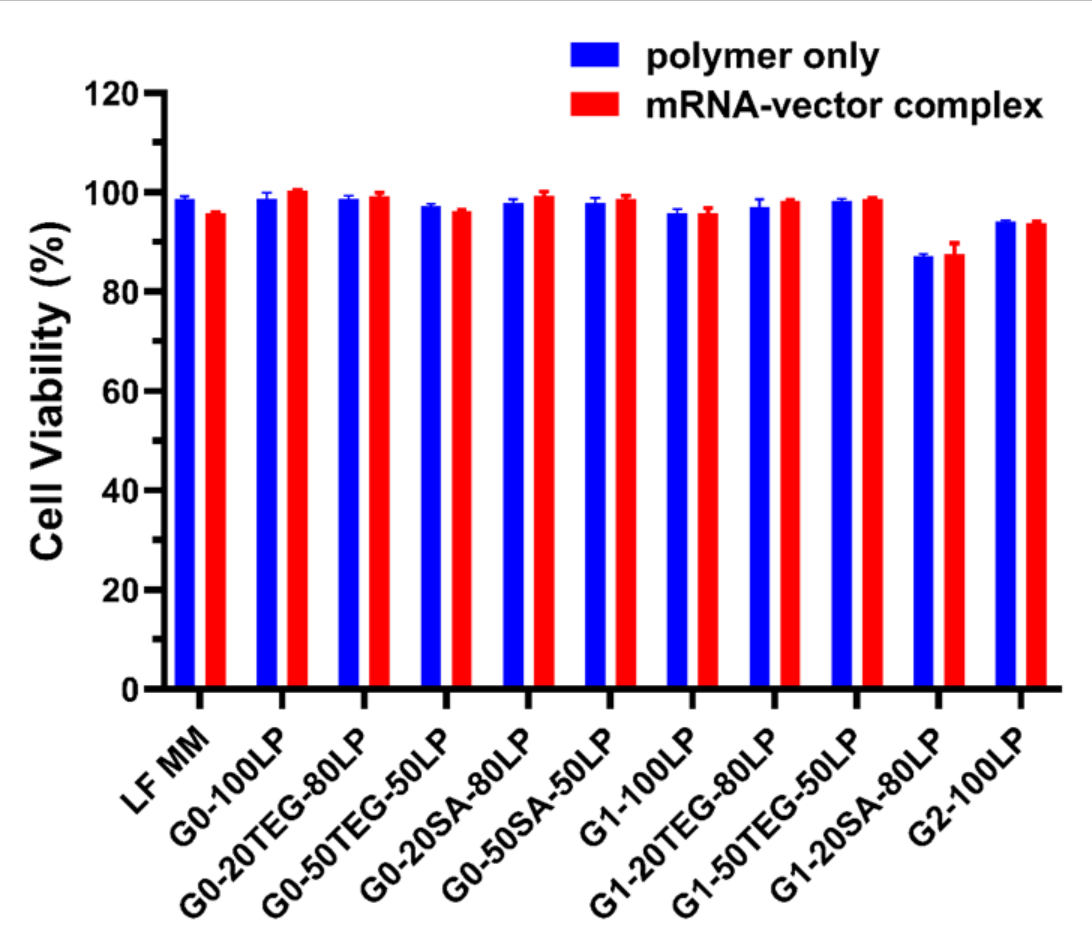

(B)

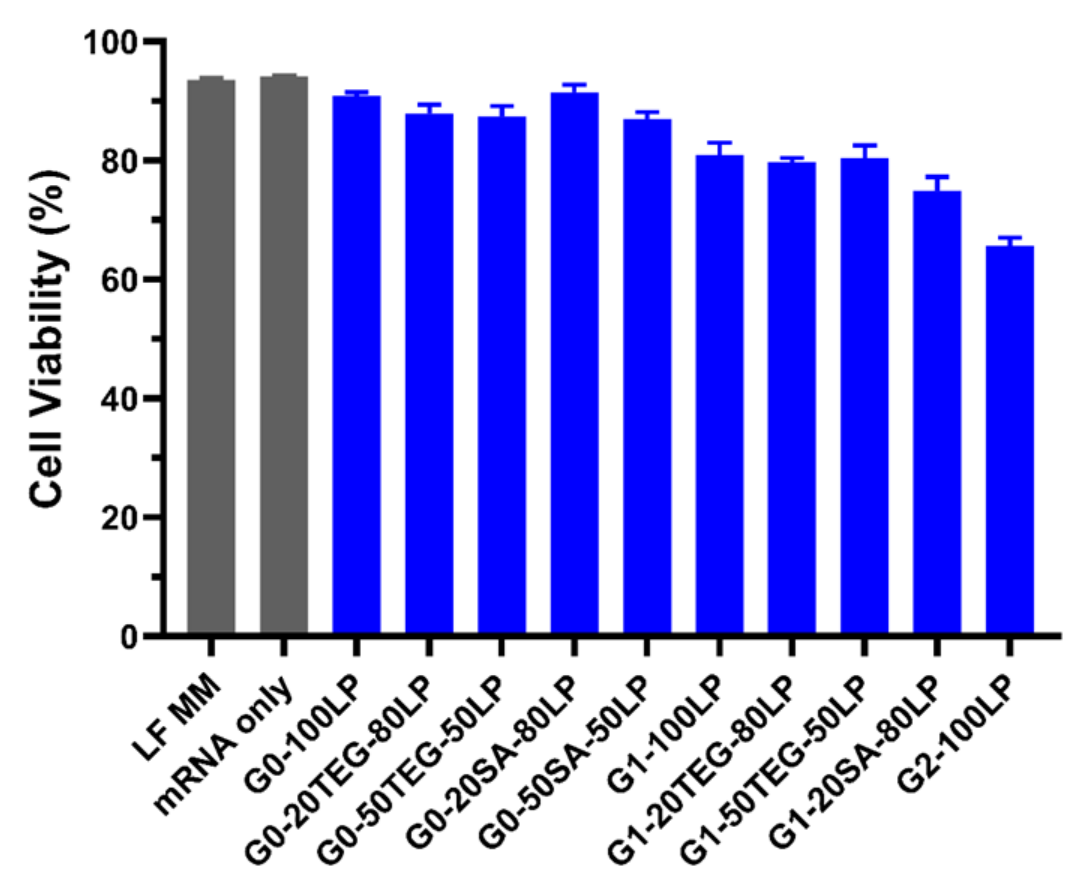

Figure S12. Cytotoxicity of the MPBP vectors against NIH 3T3 cells assayed using a LDH assay (150 ng Fluc mRNA per well). (A) Results summary of Fluc mRNA transfection in serumfree media, $\mathrm{N} / \mathrm{P}=10$ for $\mathrm{G} 0$ series of vectors and $\mathrm{N} / \mathrm{P}=15$ for $\mathrm{G} 1, \mathrm{G} 2$ series of vectors. (B) Results summary of Fluc mRNA transfection in $10 \%$ FBS-containing media, N/P $=50$ for all vectors. 

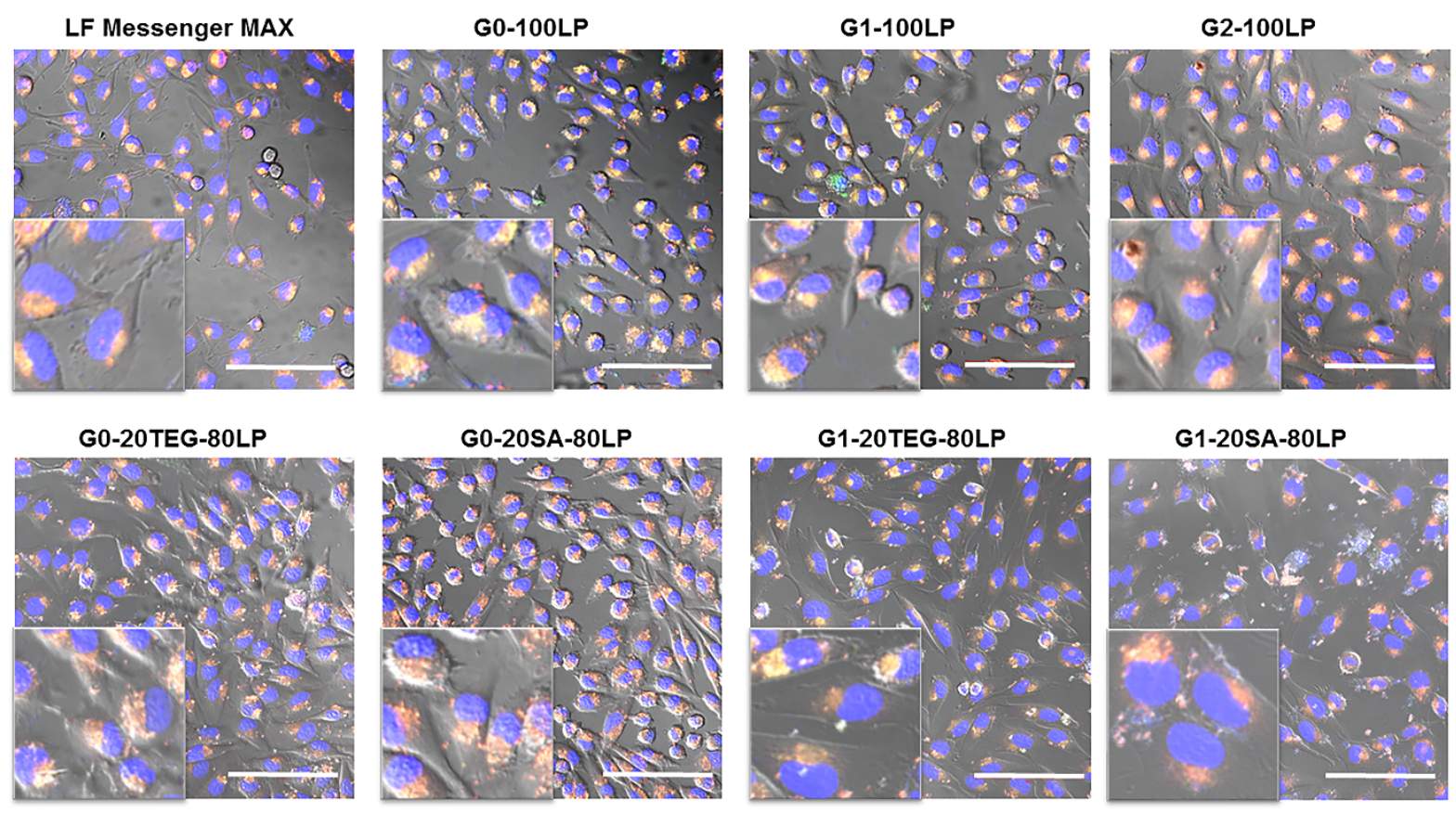

Scale bar $=100 \mu \mathrm{m}$

Figure S13. Cellular uptake of MPBP-Cy5 Fluc mRNA complexes as observed by confocal fluorescence microscopy. Confocal fluorescence images of NIH 3T3 cells $4 \mathrm{~h}$ post-transfection (nuclei were stained blue with Hoechst 33342 indicated in blue, lysosomes were stained with Lysotracker Deep Green indicated in green, Cy5 Fluc mRNA is indicated in red, all scale bars $=$ $100 \mu \mathrm{m})$. Zoomed in images are inserted for clear visualization of individual cells. Transfection conditions: 300 ng Cy5 Fluc mRNA per well, N/P = 15. 


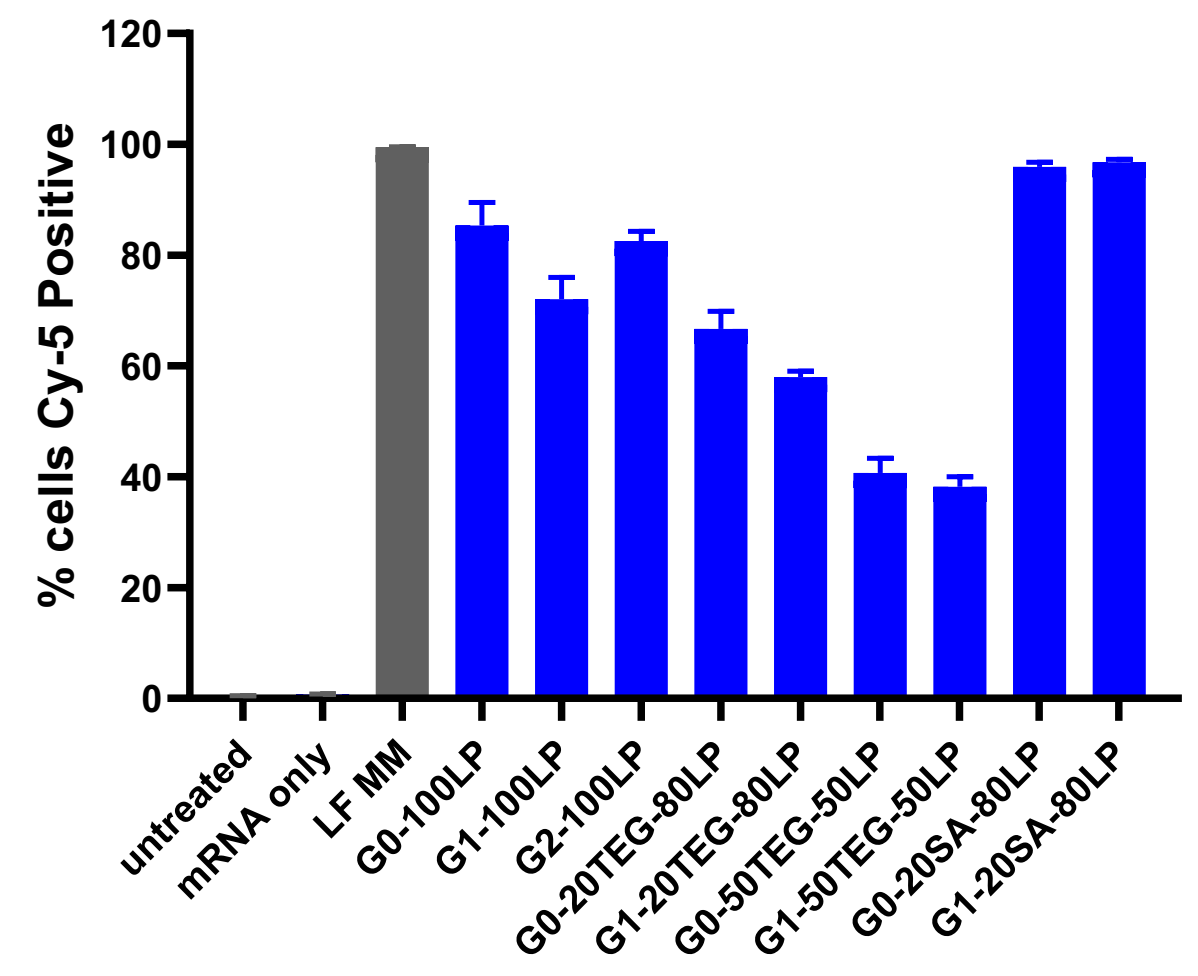

Figure S14. Cellular uptake of MPBP-Cy5 Fluc mRNA complexes in NIH 3 T3 cells quantified by flow cytometry. Fluorescence was measured $4 \mathrm{~h}$ post-transfection using a flow cytometer. Transfection conditions: 300 ng Cy5 Fluc mRNA per well, N/P $=15$. 

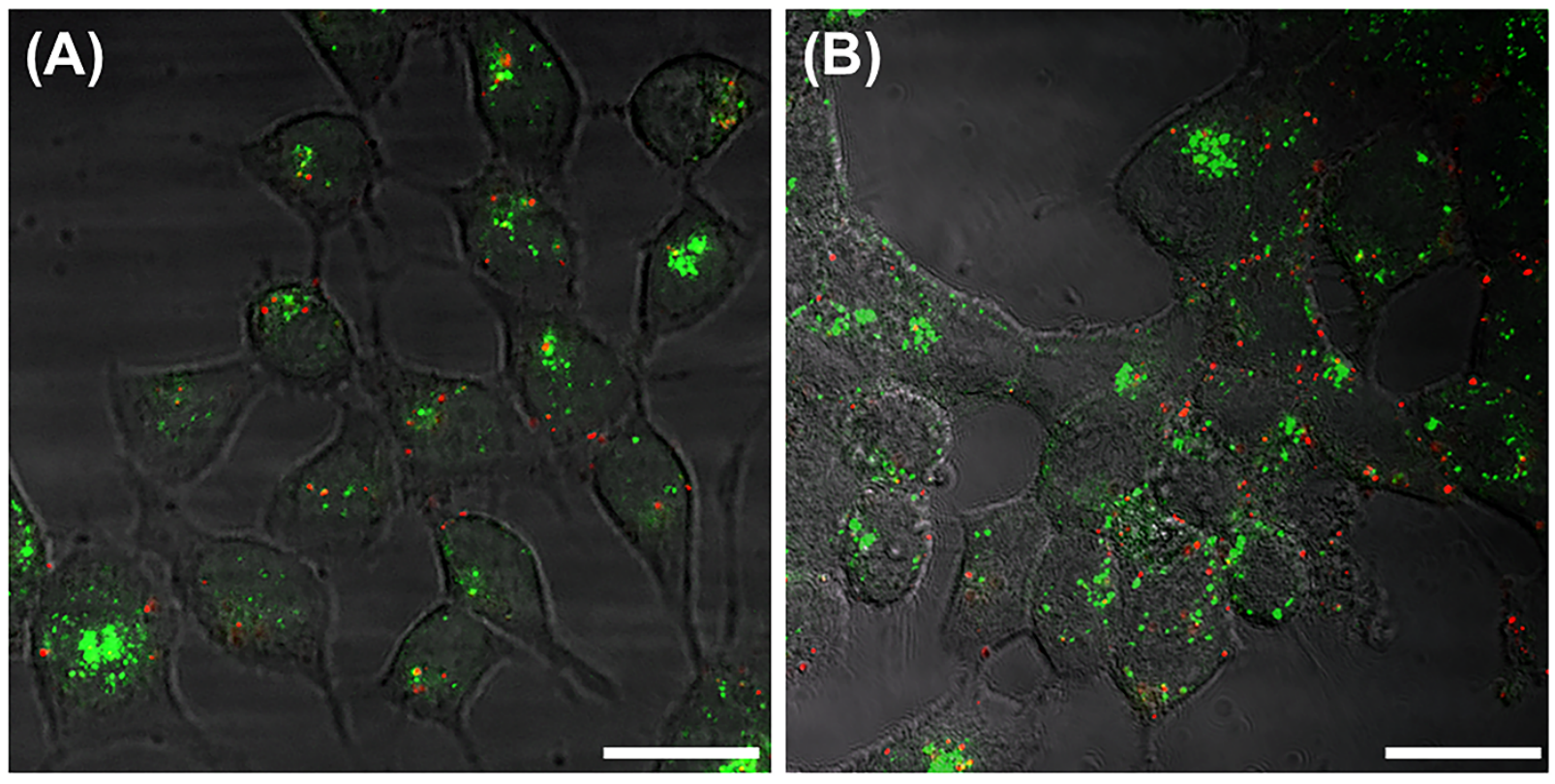

Figure S15. Endosomal escape by intracellular trafficking for MPBP-Cy5 siRNA complexes. Confocal fluorescence images of HEK-293T cells $24 \mathrm{~h}$ post-transfection of (A) G1-100LP and (B) G1-20SA-80LP. Lysosome was stained with LysoTracker Blue indicated in green, Cy5 negative control siRNA is indicated in red, scale bars $=20 \mu \mathrm{m}$. Transfection conditions: [siRNA] $=60 \mathrm{nM}, \mathrm{N} / \mathrm{P}=10$. 


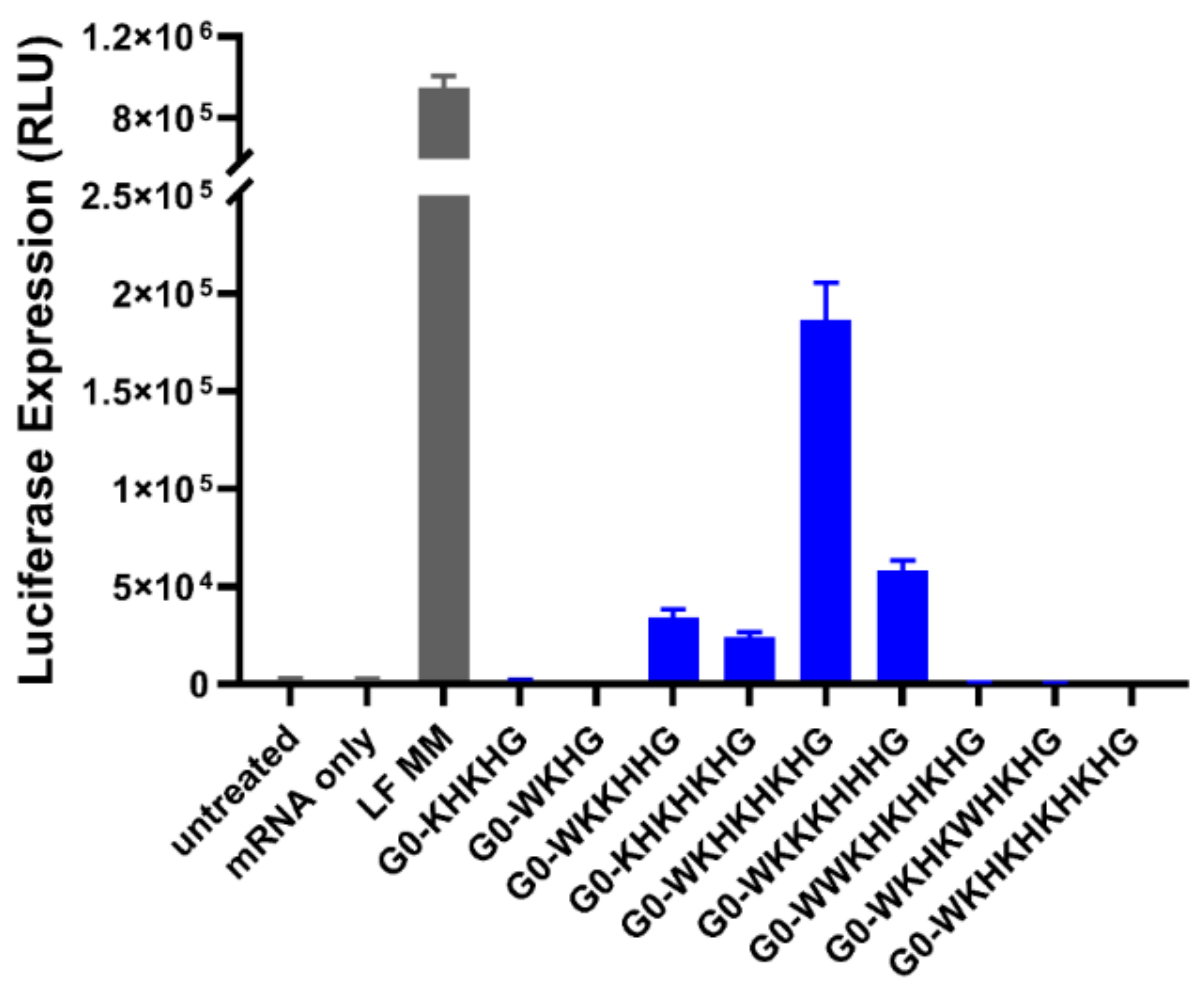

Figure S16. Initial Fluc mRNA delivery screening of different MPBPs functionalized with various linear peptides sequences. All MPBP polymers were complexed with Fluc mRNA at an $\mathrm{N} / \mathrm{P}=15$ and delivered to NIH 3T3 cells; $150 \mathrm{ng}$ of Fluc mRNA was administered per well. Linear peptide H-WKHKHKHG-OH was used in further experiments; other peptide sequences were not used in this study. 


\section{General Information}

Materials. All commercially available chemicals were used without further purification unless otherwise noted. Protected amino acids were purchased from Advanced ChemTech (Loiusville, KY) and Aroz Technologies, LLC. (Cincinnati, $\mathrm{OH})$. Coupling reagents were purchased from GL Biochem Ltd. (Shanghai, China). All siRNA used in this study was purchased from Thermo Fischer Life Technologies with Silencer ${ }^{\circledR}$ Select negative control siRNA and Silencer ${ }^{\circledR}$ Select Custom siRNA used for gel assays, DLS measurements, and transfection studies. The sequences for the anti-Luc siRNA are: 5'AGACUAUAAGAUUCAAUCUTT-3' (sense) and 5'AGAUUGAAUCUUAUAGUCUTG-3' (anti-sense). Mission ${ }^{\circledR}$ siRNA Fluorescent Universal Negative Control \#1 Cyanine 5 was obtained from Sigma-Aldrich. CleanCap ${ }^{\circledR}$ eGFP mRNA (5moU), Fluc mRNA (5moU), Cyanine 5 Fluc mRNA (5moU), Cyanine 5 eGFP mRNA (5moU), and Cas9 mRNA (5moU-modified) were obtained from TriLink Biotechnologies (Sorrento Mesa, CA). sgRNA was synthesized according to EnGen ${ }^{\circledR}$ sgRNA Synthesis Kit protocol. Lipofectamine RNAiMAX, Lipofectamine MessengerMAX, and Lipofectamine 2000 were purchased from Invitrogen (Carlsbad, CA) and used as positive controls following the manufacturer's protocol. Pierce ${ }^{\mathrm{TM}}$ LDH Cytotoxicity Assay Kit was purchased from Thermo Fisher (San Jose, CA). All reactions were performed using HPLC grade solvents unless otherwise noted. All water used in biological experiments was Nanopure water obtained from Barnstead Nanopure Diamond (Waltham, MA). Unmodified NIH 3 T3 cells were a generous gift from Professor Young Jik Kwon (Department of Chemical Engineering, UC Irvine, CA). Firefly luciferaseexpressing HEK cells were generously provided by Professor Jennifer Prescher (Department of Chemistry, UC Irvine, CA). GFP-expressing NIH 3T3 cells were 
obtained through lentiviral transduction. ${ }^{1}$ psPAX2 plasmid was a gift from Didier Trono (Addgene plasmid \#12260; RRID: Addgene_12260), pMD2.G was a gift from Didier Trono (Addgene plasmid \#12259; RRID: Addgene_12259), and pLJM1-EGFP was a gift from David Sabatini (Addgene plasmid \#19319; RRID: Addgene_19319). Dulbecco's modified Eagle's medium (DMEM), fetal bovine serum (FBS), and OptiMEM were purchased from Invitrogen (Carlsbad, CA).

Instruments. Nuclear Magnetic Resonance (NMR) spectra were recorded on 500 $\mathrm{MHz}$ or $600 \mathrm{MHz}$ Bruker spectrometers. Chemical shifts were reported in ppm. Coupling constants ( $J$ values) were reported in Hertz. ${ }^{1} \mathrm{H}$ NMR chemical shifts were referenced to $\mathrm{D}_{2} \mathrm{O}(\delta=4.79 \mathrm{ppm})$. The molecular weight and molecular weight distribution of the Denpol backbone was measured by gel permeation chromatography (GPC). GPC was performed on an Agilent 1100 SEC system using an OHpak SB-803 HQ column from Shodex. The molecular weight was determined with respect to poly(ethylene glycol) (PEG) S3 standards purchased from Aldrich. DMF with $0.1 \% \mathrm{LiBr}(\mathrm{wt} / \mathrm{v})$ was used as the eluent at a flow rate of $1.0 \mathrm{~mL} / \mathrm{min}$ with column temperature at $45^{\circ} \mathrm{C}$. The Z-average size and zeta potential of MPBP-RNA polyplexes were measured at $633 \mathrm{~nm}$ using Zetasizer (NanoZS) dynamic light scattering instrument (Malvern Instruments, Malvern, UK) at $25{ }^{\circ} \mathrm{C}$ with detection angle of $173^{\circ}$. The MPBP/RNA nanoparticles were visualized on a FEI/Philips CM-20 conventional TEM operated at an accelerating voltage of $200 \mathrm{kV}$. Confocal images were obtained using a Zeiss LSM 700 (Carl Zeiss AG, Oberkochen, Germany). Flow cytometry was performed on a BD ACCURI C6 flow cytometer (BD Biosciences, San Jose). Solid-phase peptide synthesis was performed on a Protein Technologies PS3 synthesizer.

\section{MPBP Vector Synthesis and Characterization}

Scheme 1. Synthetic scheme for MPBP vectors. Amounts of TEG, SA, OA, and linear 
peptide functionalization are specified in the procedures.

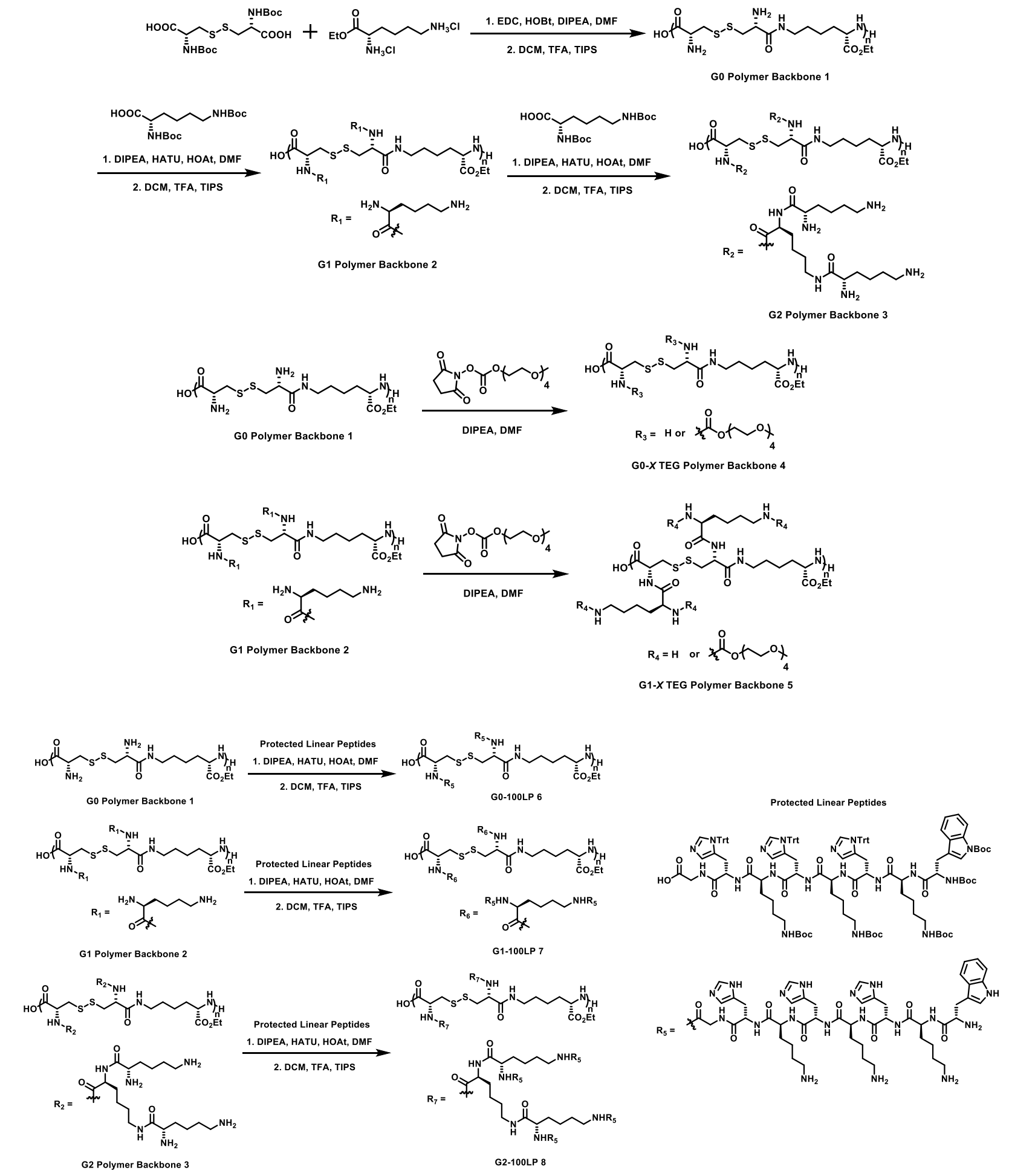





\section{G0 polymer backbone 1, G1 polymer backbone 2, G2 polymer backbone 3,} and NHS-TEG-OMe were obtained according to previous literature. ${ }^{2}$ The functionalization percentage $X$ and $Y$ are determined based on the total amount of primary amines on different polymers. All yields given refer to isolated yields.

The deprotected G0 polymer backbone 1 was characterized by analytical GPC with $0.1 \% \mathrm{LiBr}$ in DMF as the eluent and poly(ethylene glycol) (PEG) standards were used as the reference. The result was shown below: 


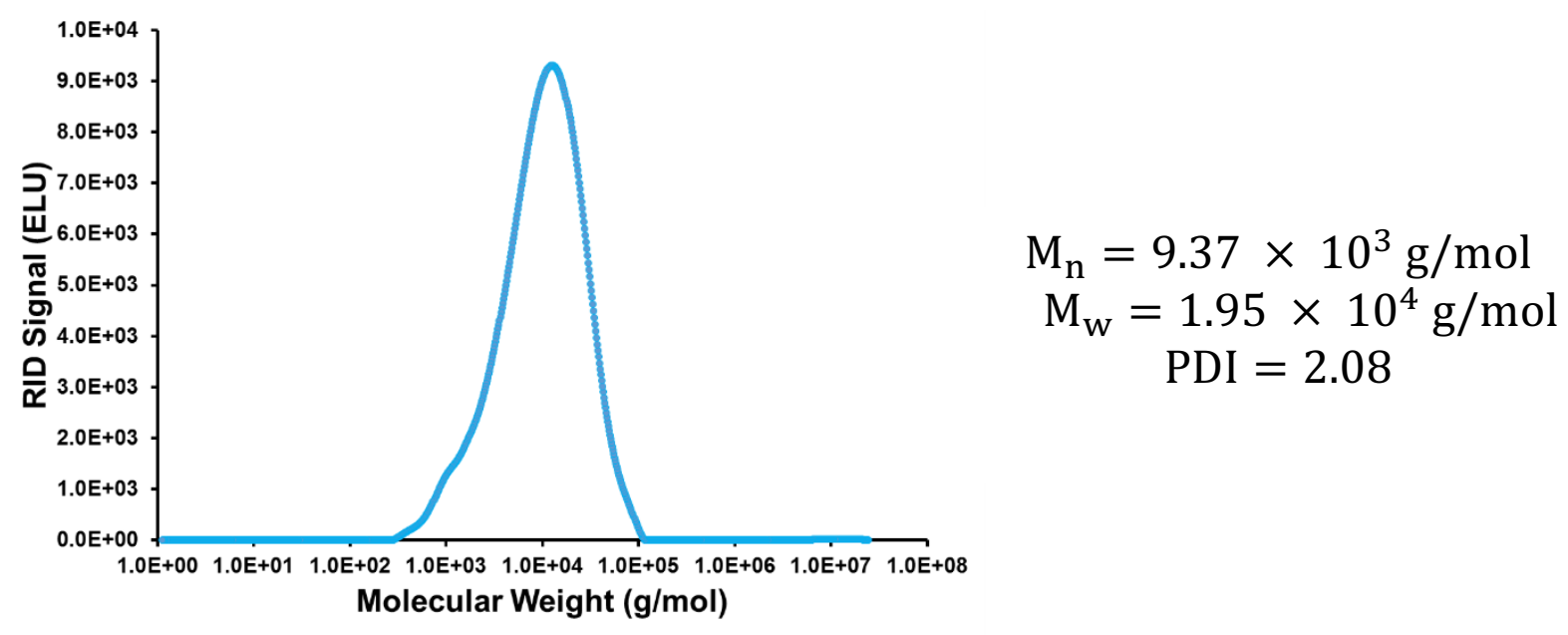

${ }^{1} \mathrm{H}$ NMR of the polymer samples used a 3 seconds d1 relaxation time to ensure chain relaxation and to help with resolution. Methanol, acetone and water were unable to be completely removed from the polymer samples. The integration ratios of ${ }^{1} \mathrm{H}$ NMR peaks are determined based on each repeating unit of the polymers. The integration of some peaks are not accurate due to the overlapping between sample signals and solvent signals.

Typical procedure for synthesis of G0-X TEG polymer backbone 4:

In a $25 \mathrm{~mL}$ round bottom flask equipped with a stir bar, G0 polymer backbone 1 (1.0 equiv.) was dissolved in $5 \mathrm{~mL}$ of anhydrous DMF and DIPEA (2.0 equiv.) was added. The reaction was cooled to $0{ }^{\circ} \mathrm{C}$ and the NHS-TEG-OMe was added in the corresponding amount of functionalization ratio $X(0.4$ equiv. for $20 \%$ and 1.0 equiv. for $50 \%$ ). After 30 minutes, the ice bath was removed and the reaction mixture was stirred under nitrogen at room temperature overnight. After removal of the solvent under reduced pressure, the residue was dissolved in $\mathrm{MeOH}$ and purified via dialysis $(\mathrm{MWCO}=6-8 \mathrm{kDa}$ ) against $\mathrm{MeOH}$ for $12 \mathrm{~h}$. Then $\mathrm{MeOH}$ was removed in vacuo to give G0-X TEG polymer backbone 4 as a colorless oil.

G0-20TEG polymer backbone (70\% isolated yield): ${ }^{1} \mathrm{H}$ NMR $\left(600 \mathrm{MHz}, \mathrm{D}_{2} \mathrm{O}\right.$, 
$298 \mathrm{~K}, \mathrm{ppm}): \delta 4.43-4.16(\mathrm{~m}, 6 \mathrm{H}), 3.78-3.63(\mathrm{~m}, 6 \mathrm{H}), 3.39(\mathrm{~s}, 1 \mathrm{H}), 3.29-3.02$ (m, 6H), $1.90-1.41(\mathrm{~m}, 6 \mathrm{H}), 1.29-1.27(\mathrm{~m}, 3 \mathrm{H})$.

G0-50TEG polymer backbone (65\% isolated yield): ${ }^{1} \mathrm{H}$ NMR $\left(600 \mathrm{MHz}, \mathrm{D}_{2} \mathrm{O}\right.$, $298 \mathrm{~K}, \mathrm{ppm}): \delta 4.54-4.22(\mathrm{~m}, 7 \mathrm{H}), 3.77-3.63(\mathrm{~m}, 14 \mathrm{H}), 3.39(\mathrm{~s}, 3 \mathrm{H}), 3.22-$ $3.02(\mathrm{~m}, 6 \mathrm{H}), 1.90-1.40(\mathrm{~m}, 6 \mathrm{H}), 1.29-1.26(\mathrm{~m}, 3 \mathrm{H})$.

Typical procedure for synthesis of G1-X TEG polymer backbone 5:

In a $25 \mathrm{~mL}$ round bottom flask equipped with a stir bar, G1 polymer backbone 2 (1.0 equiv.) was dissolved in $5 \mathrm{~mL}$ of anhydrous DMF and DIPEA (4.0 equiv.) was added. The reaction was cooled to $0{ }^{\circ} \mathrm{C}$ and the NHS-TEG-OMe was added in the corresponding amount of functionalization ratio $X(0.8$ equiv. for $20 \%$ and 2.0 equiv. for $50 \%$ ). After 30 minutes, the ice bath was removed and the reaction mixture was stirred under nitrogen at room temperature overnight. After removal of the solvent under reduced pressure, the residue was dissolved in $\mathrm{MeOH}$ and purified via dialysis $(\mathrm{MWCO}=6-8 \mathrm{kDa}$ ) against $\mathrm{MeOH}$ for $12 \mathrm{~h}$. Then $\mathrm{MeOH}$ was removed in vacuo to give G1-X TEG polymer backbone 5 as a colorless oil.

G1-20TEG polymer backbone (70\% isolated yield): ${ }^{1} \mathrm{H}$ NMR $\left(600 \mathrm{MHz}, \mathrm{D}_{2} \mathrm{O}\right.$, $298 \mathrm{~K}, \mathrm{ppm}): \delta 4.64-4.03(\mathrm{~m}, 9 \mathrm{H}), 3.76-3.63(\mathrm{~m}, 11 \mathrm{H}), 3.39(\mathrm{~s}, 2.4 \mathrm{H}), 3.21-$ $3.00(\mathrm{~m}, 10 \mathrm{H}), 1.92-1.34(\mathrm{~m}, 18 \mathrm{H}), 1.27(\mathrm{~m}, 3 \mathrm{H})$.

G1-50TEG polymer backbone (68\% isolated yield): ${ }^{1} \mathrm{H}$ NMR $\left(600 \mathrm{MHz}, \mathrm{D}_{2} \mathrm{O}\right.$, $298 \mathrm{~K}, \mathrm{ppm}): \delta 4.66-4.06(\mathrm{~m}, 11 \mathrm{H}), 3.76-3.63(\mathrm{~m}, 28 \mathrm{H}), 3.39(\mathrm{~s}, 6 \mathrm{H}), 3.20-$ $3.02(\mathrm{~m}, 10 \mathrm{H}), 2.01-1.39(\mathrm{~m}, 18 \mathrm{H}), 1.27(\mathrm{~m}, 3 \mathrm{H})$.

Protected linear peptide (Boc-WKHKHKHG-OH): 2-chlorotrityl chloride resin was first loaded with Fmoc-Gly-OH at the loading density of $0.484 \mathrm{mmol} / \mathrm{g}$. 
Following the sequence of HKHKHKW, Gly-loaded resin (400 mg, 1.0 equiv., $0.194 \mathrm{mmol}$ ) was coupled with 3 different side-chain protected amino acids on a PS3 solid-phase peptide synthesizer. For each coupling step, one amino acid was added for reaction: Fmoc-His(Trt)-OH (601 mg, 5.0 equiv., $0.97 \mathrm{mmol})$, FmocLys(Boc)-OH (455 mg, 5.0 equiv., $0.97 \mathrm{mmol}$ ), or Boc-Trp(Boc)-OH (392 mg, 5.0 equiv., $0.97 \mathrm{mmol}$ ). HATU (332 $\mathrm{mg}, 4.5$ equiv., $0.873 \mathrm{mmol}$ ) was utilized as coupling reagent and HOAt (119 $\mathrm{mg}, 4.5$ equiv., $0.873 \mathrm{mmol}$ ) was included to suppress the possible epimerization. 20\% collidine in DMF was used in the coupling reaction and $20 \%$ piperidine in DMF was used to deprotect the Fmoc group. After the synthesis was finished, the protected linear peptide was cleaved from the resin by using 20\% hexafluoroisopropanol in anhydrous $\mathrm{CH}_{2} \mathrm{Cl}_{2}$. After removal of the solvent under reduced pressure, the residue was obtained as a white solid to give $350 \mathrm{mg}$ (79\%) of protected linear peptide (Boc-WKHKHKHGOH). The synthesized linear peptide was purified by $\mathrm{C} 18$ reverse-phase chromatography $(\mathrm{MeOH}$ as the eluent) and utilized for the following coupling reactions. MALDI-TOF MS m/z: $2284.2156[\mathrm{M}+\mathrm{H}]^{+}$.
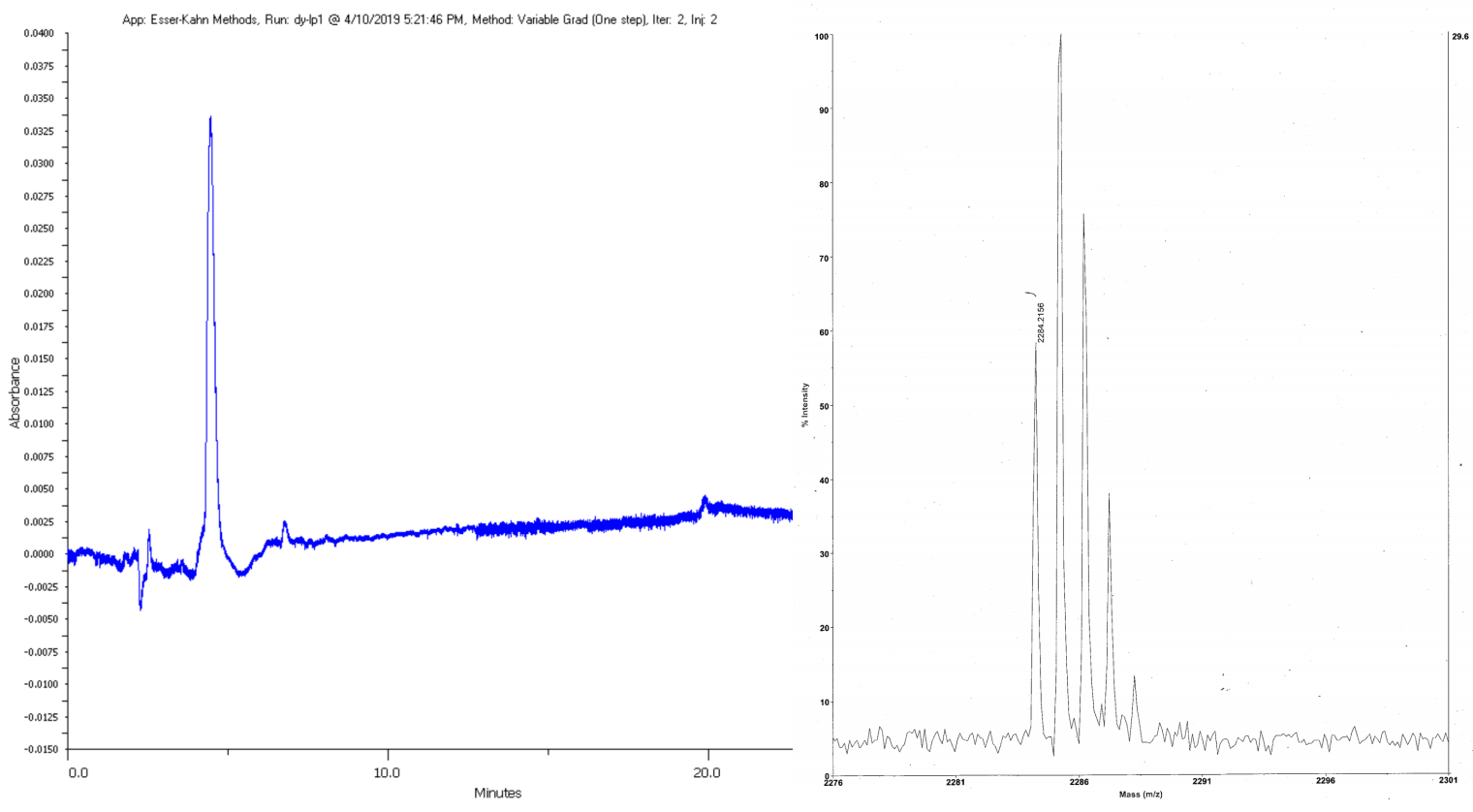
G0-100LP 6: In a $20 \mathrm{~mL}$ scintillation vial, G0 polymer backbone 1 (5.0 $\mathrm{mg}$, $0.016 \mathrm{mmol}$ ), protected linear peptide (56 mg, $0.024 \mathrm{mmol}$ ), HATU (12.5 mg, $0.032 \mathrm{mmol}$ ) and HOAt (4.5 $\mathrm{mg}, 0.032 \mathrm{mmol})$ was dissolved in $2 \mathrm{~mL}$ anhydrous DMF. After DIPEA (14 $\mu \mathrm{L}, 0.08 \mathrm{mmol})$ was added, the yellow reaction mixture was left to stir at room temperature overnight. The reaction mixture was then precipitated by adding the reaction solution into water. After centrifugation, the water was removed and the polymer was dissolved in a mixture of TFA $(3.0 \mathrm{~mL})$, $\mathrm{CH}_{2} \mathrm{Cl}_{2}(1.5 \mathrm{~mL})$, anisole $(1.5 \mathrm{~mL})$ and TIPS $(0.2 \mathrm{~mL})$. The deprotection reaction mixture was stirred at room temperature for $6 \mathrm{~h}$ under nitrogen. After removal of the solvents under reduced pressure, the residue was dissolved in $\mathrm{MeOH}$ and then precipitated in diethyl ether. After centrifugation, the supernatant was discarded and the white precipitate was dissolved in $\mathrm{MeOH}$ and purified via dialysis $(\mathrm{MWCO}=6-8 \mathrm{kDa})$ against $\mathrm{MeOH}$ for $24 \mathrm{~h}$. Then $\mathrm{MeOH}$ was removed in vacuo to give $44 \mathrm{mg}(82 \%)$ of G0-100LP 6 (TFA salt) as a white solid. ${ }^{1} \mathrm{H}$ NMR (600 $\left.\mathrm{MHz}, \mathrm{D}_{2} \mathrm{O}, 298 \mathrm{~K}, \mathrm{ppm}\right): \delta 8.63-8.58(\mathrm{~m}, 6 \mathrm{H}), 7.54-7.50(\mathrm{~m}, 4 \mathrm{H}), 7.30-7.13$ $(\mathrm{m}, 12 \mathrm{H}), 4.59-4.02(\mathrm{~m}, 21 \mathrm{H}), 3.80-3.74(\mathrm{~m}, 2 \mathrm{H}), 3.23-3.14(\mathrm{~m}, 17 \mathrm{H}), 3.06-$ $2.94(\mathrm{~m}, 17 \mathrm{H}), 1.83-1.24(\mathrm{~m}, 45 \mathrm{H})$.

G1-100LP 7: In a $20 \mathrm{~mL}$ scintillation vial, G1 polymer backbone 2 (10.0 mg, $9.17 \times 10^{-3} \mathrm{mmol}$ ), protected linear peptide (126 $\mathrm{mg}, 0.055 \mathrm{mmol}$ ), HATU (20.9 mg, $0.055 \mathrm{mmol}$ ) and HOAt (7.5 mg, $0.055 \mathrm{mmol}$ ) was dissolved in $2.5 \mathrm{~mL}$ anhydrous DMF. After DIPEA (34 $\mu \mathrm{L}, 0.19 \mathrm{mmol})$ was added, the reaction mixture was left to stir at room temperature overnight. The reaction mixture was then precipitated by adding the reaction solution into water. After centrifugation, the water was removed and the polymer was dissolved in a mixture of TFA $(3.0 \mathrm{~mL})$, $\mathrm{CH}_{2} \mathrm{Cl}_{2}(1.5 \mathrm{~mL})$, anisole $(1.5 \mathrm{~mL})$ and TIPS $(0.2 \mathrm{~mL})$. The deprotection reaction 
mixture was stirred at room temperature for $6 \mathrm{~h}$ under nitrogen. After removal of the solvents under reduced pressure, the residue was dissolved in $\mathrm{MeOH}$ and then precipitated in diethyl ether. After centrifugation, the supernatant was discarded, and the white precipitate was dissolved in $\mathrm{MeOH}$ and purified via dialysis ( $\mathrm{MWCO}=6-8 \mathrm{kDa}$ ) against $\mathrm{MeOH}$ for $24 \mathrm{~h}$. Then $\mathrm{MeOH}$ was removed in vacuo to give $47 \mathrm{mg}$ (78\%) of G1-100LP 7 (TFA salt) as a white solid. ${ }^{1} \mathrm{H}$ NMR (600 $\left.\mathrm{MHz}, \mathrm{D}_{2} \mathrm{O}, 298 \mathrm{~K}, \mathrm{ppm}\right): \delta 8.56-8.41(\mathrm{~m}, 12 \mathrm{H}), 7.52-7.05(\mathrm{~m}, 32 \mathrm{H}), 4.33-$ $3.72(\mathrm{~m}, 43 \mathrm{H}), 3.40-2.94(\mathrm{~m}, 66 \mathrm{H}), 1.96-1.17(\mathrm{~m}, 93 \mathrm{H})$.

G2-100LP 8: In a $20 \mathrm{~mL}$ scintillation vial, G2 polymer backbone 3 (10.0 mg, $\left.4.85 \times 10^{-3} \mathrm{mmol}\right)$, protected linear peptide (124 $\left.\mathrm{mg}, 0.054 \mathrm{mmol}\right)$, HATU (20.0 mg, $0.052 \mathrm{mmol}$ ) and HOAt (7.1 mg, $0.052 \mathrm{mmol}$ ) was dissolved in $2.5 \mathrm{~mL}$ anhydrous DMF. After DIPEA ( $14 \mu \mathrm{L}, 0.08 \mathrm{mmol})$ was added, the reaction mixture was left to stir at room temperature overnight. The reaction mixture was then precipitated by adding the reaction solution into water. After centrifugation, the water was removed and the polymer was dissolved in a mixture of TFA $(3.0 \mathrm{~mL})$, $\mathrm{CH}_{2} \mathrm{Cl}_{2}(1.5 \mathrm{~mL})$, anisole $(1.5 \mathrm{~mL})$ and TIPS $(0.2 \mathrm{~mL})$. The deprotection reaction mixture was stirred at room temperature for $6 \mathrm{~h}$ under nitrogen. After removal of the solvents under reduced pressure, the residue was dissolved in $\mathrm{MeOH}$ and then precipitated in diethyl ether. After centrifugation, the supernatant was discarded, and the white precipitate was dissolved in $\mathrm{MeOH}$ and purified via dialysis $(\mathrm{MWCO}=6-8 \mathrm{kDa}$ ) against $\mathrm{MeOH}$ for $24 \mathrm{~h}$. Then $\mathrm{MeOH}$ was removed in vacuo to give $39 \mathrm{mg}(61 \%)$ of G2-100LP 8 (TFA salt) as a white solid. ${ }^{1} \mathrm{H}$ NMR (600 $\left.\mathrm{MHz}, \mathrm{D}_{2} \mathrm{O}, 298 \mathrm{~K}, \mathrm{ppm}\right): \delta 8.57-8.43(\mathrm{~m}, 24 \mathrm{H}), 7.53-7.06(\mathrm{~m}, 64 \mathrm{H}), 4.33-$ $3.65(\mathrm{~m}, 83 \mathrm{H}), 3.24-2.94(\mathrm{~m}, 130 \mathrm{H}), 1.72-1.26(\mathrm{~m}, 189 \mathrm{H})$. 
Typical procedure for synthesis of G0-X TEG-Y LP 9:

In a $20 \mathrm{~mL}$ scintillation vial, G0-X TEG polymer backbone 4 (1.0 equiv.), protected linear peptide (quantity determined by the functionalization ratio $Y, 1.6$ equiv. for $80 \%$ and 1.0 equiv. for $50 \%$ ), HATU (1.6 equiv. for $80 \%$ and 1.0 equiv. for $50 \%$ ) and HOAt (1.6 equiv. for $80 \%$ and 1.0 equiv. for $50 \%$ ) was dissolved in 2 $\mathrm{mL}$ anhydrous DMF. After DIPEA (3.2 equiv. for $80 \%$ and 2.0 equiv. for $50 \%$ ) was added, the yellow reaction mixture was left to stir at room temperature overnight. The reaction mixture was then precipitated by adding the reaction solution into water. After centrifugation, the water was removed and the polymer was dissolved in a mixture of TFA $(3.0 \mathrm{~mL}), \mathrm{CH}_{2} \mathrm{Cl}_{2}(1.5 \mathrm{~mL})$, anisole $(1.5 \mathrm{~mL})$ and TIPS $(0.2$ $\mathrm{mL})$. The deprotection reaction mixture was stirred at room temperature for $6 \mathrm{~h}$ under nitrogen. After removal of the solvents under reduced pressure, the residue was dissolved in $\mathrm{MeOH}$ and then precipitated in diethyl ether. After centrifugation, the supernatant was discarded, and the white precipitate was dissolved in $\mathrm{MeOH}$ and purified via dialysis $(\mathrm{MWCO}=6-8 \mathrm{kDa}$ ) against $\mathrm{MeOH}$ for $24 \mathrm{~h}$. Then $\mathrm{MeOH}$ was removed in vacuo to give G0-X TEG-Y LP 9 (TFA salt) as a white solid.

G0-20TEG-80LP (75\% isolated yield): ${ }^{1} \mathrm{H}$ NMR (600 MHz, $\left.\mathrm{D}_{2} \mathrm{O}, 298 \mathrm{~K}, \mathrm{ppm}\right): \delta$ $8.58-8.39(\mathrm{~m}, 5 \mathrm{H}), 7.55-7.06(\mathrm{~m}, 13 \mathrm{H}), 4.68-4.61(\mathrm{~m}, 2 \mathrm{H}), 4.35-3.99(\mathrm{~m}$, $11 \mathrm{H}), 3.83-3.59(\mathrm{~m}, 6 \mathrm{H}), 3.41-2.96(\mathrm{~m}, 30 \mathrm{H}), 1.75-1.17(\mathrm{~m}, 38 \mathrm{H})$.

G0-50TEG-50LP (71\% isolated yield): ${ }^{1} \mathrm{H}$ NMR (600 MHz, $\left.\mathrm{D}_{2} \mathrm{O}, 298 \mathrm{~K}, \mathrm{ppm}\right): \delta$ $8.46-8.12(\mathrm{~m}, 3 \mathrm{H}), 7.54-7.06(\mathrm{~m}, 8 \mathrm{H}), 4.64-3.98(\mathrm{~m}, 20 \mathrm{H}), 3.73-3.59(\mathrm{~m}$, $13 \mathrm{H}), 3.20-2.94(\mathrm{~m}, 23 \mathrm{H}), 1.72-1.21(\mathrm{~m}, 27 \mathrm{H})$. 
Typical procedure for synthesis of G1- $X$ TEG-Y LP 10:

In a $20 \mathrm{~mL}$ scintillation vial, G1-X TEG polymer backbone 5 (1.0 equiv.), protected linear peptide (quantity determined by the functionalization ratio $Y, 3.2$ equiv. for $80 \%$ and 2.0 equiv. for $50 \%$ ), HATU (3.2 equiv. for $80 \%$ and 2.0 equiv. for $50 \%$ ) and HOAt (3.2 equiv. for $80 \%$ and 2.0 equiv. for $50 \%$ ) was dissolved in 2 $\mathrm{mL}$ anhydrous DMF. After DIPEA (6.4 equiv. for $80 \%$ and 4.0 equiv. for $50 \%$ ) was added, the yellow reaction mixture was left to stir at room temperature overnight. The reaction mixture was then precipitated by adding the reaction solution into water. After centrifugation, the water was removed and the polymer was dissolved in a mixture of TFA $(3.0 \mathrm{~mL}), \mathrm{CH}_{2} \mathrm{Cl}_{2}(1.5 \mathrm{~mL})$, anisole $(1.5 \mathrm{~mL})$ and TIPS $(0.2$ $\mathrm{mL})$. The deprotection reaction mixture was stirred at room temperature for $6 \mathrm{~h}$ under nitrogen. After removal of the solvents under reduced pressure, the residue was dissolved in $\mathrm{MeOH}$ and then precipitated in diethyl ether. After centrifugation, the supernatant was discarded, and the white precipitate was dissolved in $\mathrm{MeOH}$ and purified via dialysis $(\mathrm{MWCO}=6-8 \mathrm{kDa}$ ) against $\mathrm{MeOH}$ for $24 \mathrm{~h}$. Then $\mathrm{MeOH}$ was removed in vacuo to give G1-X TEG-Y LP 10 (TFA salt) as a white solid.

G1-20TEG-80LP (72\% isolated yield): ${ }^{1} \mathrm{H}$ NMR (600 MHz, $\left.\mathrm{D}_{2} \mathrm{O}, 298 \mathrm{~K}, \mathrm{ppm}\right): \delta$ $8.54-8.24(\mathrm{~m}, 10 \mathrm{H}), 7.53-7.06(\mathrm{~m}, 26 \mathrm{H}), 4.66-4.60(\mathrm{~m}, 2 \mathrm{H}), 4.33-4.13(\mathrm{~m}$, $22 \mathrm{H}), 4.01-3.64(\mathrm{~m}, 24 \mathrm{H}), 3.40-2.94(\mathrm{~m}, 57 \mathrm{H}), 1.86-1.20(\mathrm{~m}, 73 \mathrm{H})$.

G1-50TEG-50LP (68\% isolated yield): ${ }^{1} \mathrm{H}$ NMR (600 MHz, $\left.\mathrm{D}_{2} \mathrm{O}, 298 \mathrm{~K}, \mathrm{ppm}\right): \delta$ $8.52-8.28(\mathrm{~m}, 6 \mathrm{H}), 7.54-7.05(\mathrm{~m}, 16 \mathrm{H}), 4.67-4.60(\mathrm{~m}, 1 \mathrm{H}), 4.33-3.86(\mathrm{~m}$, $17 \mathrm{H}), 3.74-3.59(\mathrm{~m}, 34 \mathrm{H}), 3.41-2.95(\mathrm{~m}, 40 \mathrm{H}), 1.74-1.23(\mathrm{~m}, 60 \mathrm{H})$. 
Typical procedure for synthesis of G0-X SA-Y LP 11:

In a $20 \mathrm{~mL}$ scintillation vial, G0 polymer backbone 1 (1.0 equiv.), stearic acid (quantity determined by the functionalization ratio $X, 0.4$ equiv. for $20 \%$ and 1.0 equiv. for 50\%), protected linear peptide (quantity determined by the functionalization ratio $Y, 1.6$ equiv. for $80 \%$ and 1.0 equiv. for $50 \%$ ), HATU (2.0 equiv.) and HOAt (2.0 equiv.) was dissolved in $2 \mathrm{~mL}$ anhydrous DMF. After DIPEA (4.0 equiv.) was added, the yellow reaction mixture was left to stir at room temperature overnight. The reaction mixture was then precipitated by adding the reaction solution into water. After centrifugation, the water was removed and the polymer was dissolved in a mixture of TFA $(3.0 \mathrm{~mL}), \mathrm{CH}_{2} \mathrm{Cl}_{2}(1.5 \mathrm{~mL})$, anisole $(1.5 \mathrm{~mL})$ and TIPS $(0.2 \mathrm{~mL})$. The deprotection reaction mixture was stirred at room temperature for $6 \mathrm{~h}$ under nitrogen. After removal of the solvents under reduced pressure, the residue was dissolved in $\mathrm{MeOH}$ and then precipitated in diethyl ether. After centrifugation, the supernatant was discarded, and the white precipitate was dissolved in $\mathrm{MeOH}$ and purified via dialysis $(\mathrm{MWCO}=6-8 \mathrm{kDa})$ against $\mathrm{MeOH}$ for $24 \mathrm{~h}$. Then $\mathrm{MeOH}$ was removed in vacuo to give G0-X SA-Y LP 11 (TFA salt) as a white solid.

G0-20SA-80LP (63\% isolated yield): ${ }^{1} \mathrm{H}$ NMR (600 MHz, $\left.\mathrm{D}_{2} \mathrm{O}, 298 \mathrm{~K}, \mathrm{ppm}\right): \delta$ $8.49-8.14(\mathrm{~m}, 5 \mathrm{H}), 7.55-7.06(\mathrm{~m}, 13 \mathrm{H}), 4.66-4.58(\mathrm{~m}, 3 \mathrm{H}), 4.32-3.98(\mathrm{~m}$, $10 \mathrm{H}), 3.81-3.71(\mathrm{~m}, 2 \mathrm{H}), 3.41-2.94(\mathrm{~m}, 29 \mathrm{H}), 2.03-1.23(\mathrm{~m}, 50 \mathrm{H})$.

G0-50SA-50LP (52\% isolated yield): ${ }^{1} \mathrm{H}$ NMR (600 MHz, $\left.\mathrm{D}_{2} \mathrm{O}, 298 \mathrm{~K}, \mathrm{ppm}\right): \delta$ $8.44-8.00(\mathrm{~m}, 3 \mathrm{H}), 7.55-7.01(\mathrm{~m}, 8 \mathrm{H}), 4.66-4.57(\mathrm{~m}, 2 \mathrm{H}), 4.35-3.96(\mathrm{~m}, 8 \mathrm{H})$, $3.81-3.69(\mathrm{~m}, 1 \mathrm{H}), 3.39-2.94(\mathrm{~m}, 20 \mathrm{H}), 2.04-1.23(\mathrm{~m}, 40 \mathrm{H})$. 
Typical procedure for synthesis of G1-X SA-Y LP 12:

In a $20 \mathrm{~mL}$ scintillation vial, G1 polymer backbone 2 (1.0 equiv.), stearic acid (quantity determined by the functionalization ratio $X, 0.8$ equiv. for $20 \%$ and 2.0 equiv. for 50\%), protected linear peptide (quantity determined by the functionalization ratio $Y, 3.2$ equiv. for $80 \%$ and 2.0 equiv. for $50 \%$ ), HATU (4.0 equiv.) and HOAt (4.0 equiv.) was dissolved in $2 \mathrm{~mL}$ anhydrous DMF. After DIPEA (8.0 equiv.) was added, the yellow reaction mixture was left to stir at room temperature overnight. The reaction mixture was then precipitated by adding the reaction solution into water. After centrifugation, the water was removed and the polymer was dissolved in a mixture of TFA $(3.0 \mathrm{~mL}), \mathrm{CH}_{2} \mathrm{Cl}_{2}(1.5 \mathrm{~mL})$, anisole $(1.5 \mathrm{~mL})$ and TIPS $(0.2 \mathrm{~mL})$. The deprotection reaction mixture was stirred at room temperature for $6 \mathrm{~h}$ under nitrogen. After removal of the solvents under reduced pressure, the residue was dissolved in $\mathrm{MeOH}$ and then precipitated in diethyl ether. After centrifugation, the supernatant was discarded and the white precipitate was dissolved in $\mathrm{MeOH}$ and purified via dialysis $(\mathrm{MWCO}=6-8 \mathrm{kDa})$ against $\mathrm{MeOH}$ for $24 \mathrm{~h}$. Then $\mathrm{MeOH}$ was removed in vacuo to give G1-X SA-Y LP 12 (TFA salt) as a white solid.

G1-20SA-80LP (64\% isolated yield): ${ }^{1} \mathrm{H}$ NMR (600 MHz, $\left.\mathrm{D}_{2} \mathrm{O}, 298 \mathrm{~K}, \mathrm{ppm}\right): \delta$ $8.51-8.04(\mathrm{~m}, 10 \mathrm{H}), 7.55-7.01(\mathrm{~m}, 26 \mathrm{H}), 4.66-4.54(\mathrm{~m}, 6 \mathrm{H}), 4.33-4.25(\mathrm{~m}$, $28 \mathrm{H}), 3.81-3.66(\mathrm{~m}, 2 \mathrm{H}), 3.40-2.95(\mathrm{~m}, 55 \mathrm{H}), 1.93-1.27(\mathrm{~m}, 104 \mathrm{H})$. 


\section{MPBP/RNA Binding Study}

\subsection{Gel electrophoresis.}

The binding of siRNA or mRNA to MPBPs was studied by agarose gel electrophoresis. Both siRNA/mRNA and MPBPs were diluted with $10 \mathrm{mM} \mathrm{pH} 7.4$ phosphate buffer. Different amount of MPBP solutions $(10 \mathrm{mg} / \mathrm{mL})$ were added to $5.0 \mu \mathrm{L} 5 \mu \mathrm{M}$ siRNA solution or $1.0 \mu \mathrm{L} 0.5 \mu \mathrm{g} / \mu \mathrm{L}$ mRNA solution to achieve different N/P ratio (the molar ratio of primary amine groups from MPBPs and phosphate groups from siRNA/mRNA, imidazole groups of histidine residues not counted because they are not protonated at $\mathrm{pH}$ 7.4). The same buffer was added to adjust the final volume to $10.0 \mu \mathrm{L}$, followed by $10 \mathrm{~min}$ incubation at room temperature. $2 \mu \mathrm{L} 6 \mathrm{X}$ RNA loading dye was added to each sample and $10 \mu \mathrm{L}$ of the mixture was loaded to each well in 1\% agarose gel with $1 \mathrm{X}$ GelRed dye. The electrophoresis was run in TBE buffer $(\mathrm{pH} \mathrm{7.9)}$ ) at $60 \mathrm{~V}$ for 90 min and the gel was visualized under a UV transilluminator. Related results are shown in Figure $\mathbf{S 2}$ and S3.

4.2 Gel electrophoresis study of mRNA protection.

(1) Following the protocol mentioned in 4.1, different MPBPs were complexed with eGFP mRNA at $\mathrm{N} / \mathrm{P}=10$ with duplicate. Two naked mRNA solutions were used as controls. To one copy of each MPBP-mRNA complex solution and naked mRNA solutions, $10 \%$ FBS (v/v) was added. The solutions were left to stand for 20 minutes at room temperature. The other copy of each MPBP-mRNA complex solution and naked mRNA solutions were used as negative controls. All solutions were subjected to agarose gel electrophoresis to examine the integrity of mRNA. As shown in Figure S4A, naked mRNA was fully degraded into small species after FBS incubation, while no small species were detected from all MPBP-mRNA 
complex solutions.

(2) Following the protocol mentioned in 4.1, different MPBPs were complexed with eGFP mRNA at N/P $=10$ and $10 \%$ FBS (v/v) was added to each complex solution. The solutions were left to stand for 20 minutes at room temperature. $7 \mu \mathrm{L}$ dextran sulfate $(0.017 \mathrm{M})$ solution was added to each complex to achieve $\mathrm{S} / \mathrm{P}=80$ (the molar ratio of sulfate groups from DS and phosphate groups from mRNA) and incubated for 5 minutes. The samples were then subjected to agarose gel electrophoresis under the aforementioned condition. As shown in Figure S4B, naked mRNA was fully degraded into small species after FBS incubation, while the RNA released from MPBP-RNA complexes was still intact.

\subsection{DLS measurements.}

The size and zeta potential of MPBP-siRNA or MPBP-mRNA complexes were measured at $633 \mathrm{~nm}$ using Zetasizer (NanoZS) dynamic light scattering instrument (Malvern Instruments, Malvern, UK) at $25^{\circ} \mathrm{C}$ with detection angle of $173^{\circ}$. Both MPBP and siRNA/mRNA were diluted in nanopure water, followed by brief vortexing. After $10 \mathrm{~min}$ incubation at room temperature, DLS measurement was taken. The solution was then diluted with $600 \mu \mathrm{L}$ PBS and subjected to zetapotential measurement. At least three measurements were taken for each sample and the mean Z-average values were reported.

\subsection{TEM characterization}

MPBP-siRNA and MPBP-mRNA complexes were prepared in $\mathrm{ddH}_{2} \mathrm{O}$ by following aforementioned protocol. For siRNA complexation, N/P $=10$ and $[\mathrm{siRNA}]=10 \mu \mathrm{M}$. For mRNA complexation, $\mathrm{N} / \mathrm{P}=10$ and $[\mathrm{mRNA}]=0.1 \mu \mathrm{g} / \mu \mathrm{L}$. 
The solution was vortexed and incubated at room temperature for 10 minutes before imaging. $8 \mu L$ sample solution was placed on a TEM grid (Ted Pella, Copper Formvar/Carbon, $200 \mathrm{mesh}$ ) and let stand for $1 \mathrm{~min}$. The solution was blotted away with a filter paper, while $15 \mu \mathrm{L} 2 \%$ Uranyl Acetate solution was pipetted on to the grid. After $1 \mathrm{~min}$, the staining process was repeated with another $15 \mu \mathrm{L} 2 \%$ Uranyl Acetate solution. All the solution was removed by a filter paper and the grid was left air dry overnight before imaging. Images were obtained on a FEI/Philips CM-20 conventional TEM operated at an accelerating voltage of 200 $\mathrm{kV}$. 


\section{Biological Studies}

5.1 siRNA transfections.

(1) Vector-siRNA complex preparation.

The TFA-salts of the various MPBPs were stored at $-20^{\circ} \mathrm{C}$ as $10 \mathrm{mg} / \mathrm{ml}$ solutions in RNase free water and prior to complexation the vectors, along with all buffers, were allowed to reach room temperature. Both negative control and targeted siRNA were diluted to $1.5 \mu \mathrm{M}$ with RNase free water. The diluted siRNA was further diluted with OptiMEM and complexed with the appropriate amount of vector solution required to achieve the desired $\mathrm{N} / \mathrm{P}$ ratio. The complex solutions were prepared at $5 \mathrm{X}$ the desired final concentration $(60 \mathrm{nM})$ and with a final volume of $60 \mu \mathrm{L}$. $20 \mu \mathrm{L}$ of the complex solution with $300 \mathrm{nM}$ siRNA was added to each well containing $80 \mu \mathrm{L}$ of OptiMEM to give a transfection media with $60 \mathrm{nM}$ siRNA. Lipofectamine RNAiMAX was used as a positive control and prepared as instructed in the product manual.

(2) Transfection in luciferase-expressing HEK-293 cells.

Transfections were performed in triplicate in a cell culture treated clear-bottom 96well plate (Corning). After passaging, the cells were plated in 96-well plates so that they were $40 \sim 50 \%$ confluent at the time of transfection. The $5 \mathrm{X}$ vector-siRNA complexes were prepared using the aforementioned protocol. The culture media was switched to $80 \mu \mathrm{L}$ OptiMEM (with or without $10 \%$ FBS) per well and $20 \mu \mathrm{L}$ of the complex solution was added to each well. The cells were cultured for 48 hours prior to analysis.

(3) Transfection analysis in luciferase-expressing HEK-293 cells.

After 48 hours of incubation post-transfection, the culture media was removed and replaced with $100 \mu \mathrm{L}$ of a $150 \mu \mathrm{g} / \mathrm{mL}$ solution of firefly D-luciferin in 
FluoroBrite ${ }^{\mathrm{TM}}$ DMEM. Without any further treatment, the cells were incubated at $37^{\circ} \mathrm{C}$ for 5 minutes after which they were imaged using an IVIS lumina II camera. The normalized luciferase knockdown was determined by comparing the overall luminescence of the samples treated with complexes containing anti-luc siRNA to those treated with complexes containing negative control siRNA.

\section{2 mRNA transfections.}

(1) Vector-mRNA complex preparation.

Before performing the mRNA transfections, the area was sterilized with bleach and RNase ZAP (Ambion), and special care was take to use RNase free products when handling the mRNA. Lipofectamine MessengerMAX was used as a positive control and prepared as instructed in the product manual. The mRNA was thawed and diluted to a concentration of $0.05 \mu \mathrm{g} / \mu \mathrm{L}$ with OptiMEM. Appropriate amount of vector solution was added to achieve the desired N/P ratio and the mixture was mixed by pipetting up and down 10 times. Finally, the mixture is diluted to $60 \mu \mathrm{L}$ with OptiMEM so that $20 \mu \mathrm{L}$ of the complex solution will contain $150 \mathrm{ng}$ of mRNA. Then $1 \mu \mathrm{L}$ of Insulin-Transferrin-Selenium (100X) was added. The mixture was then incubated at room temperature for 5 minutes.

(2) Transfection in NIH 3T3 cells and BHK cells.

Transfections were performed in triplicate in a cell culture treated clear-bottom 96well plate (Corning). After passaging, the cells were plated in 96-well plates so that they were $60 \sim 70 \%$ confluent at the time of transfection. The vector-mRNA complex solutions were prepared using the aforementioned protocol. The culture media was switched to $80 \mu \mathrm{L}$ OptiMEM (with or without $10 \%$ FBS) per well and $20 \mu \mathrm{L}$ of the complex solution was added to each well. The cells were cultured for 
24 hours prior to analysis.

(3) Transfection analysis in Fluc mRNA or Replicon mRNA (expressing Fluc) transfected cells.

24 hours post-transfection, the culture media was removed and replaced with 100 $\mu \mathrm{L}$ of a $150 \mu \mathrm{g} / \mathrm{mL}$ solution of firefly D-luciferin in FluoroBrite ${ }^{\mathrm{TM}}$ DMEM. Without any further treatment, the cells were incubated at $37^{\circ} \mathrm{C}$ for 5 minutes after which they were imaged using an IVIS lumina II camera and the luminescence was determined.

(4) Transfection analysis in eGFP mRNA or Cy5-labelled mRNA transfected cells via flow cytometry.

24 hours post-transfection, the culture media was removed and replaced with 30 $\mu \mathrm{L}$ trypsin and incubated at $37^{\circ} \mathrm{C}$ for 5 minutes. $70 \mu \mathrm{L}$ of complete media were added to the plate and the cells were transferred to a 96-well non-cell treated plate for flow cytometry. Fluorescence of the transfected cells was measured on a Becton-Dickinson LSR II flow cytometer with argon ion excitation laser. 5000 events were recorded per sample and each value reported is the average of 3 samples.

\subsection{CRISPR-Cas9 delivery}

(1) Vector-RNA (Cas9 mRNA \& sgRNA) complex preparation.

Before performing the mRNA/sgRNA transfections, the area was sterilized with bleach and RNase ZAP (Ambion), and special care was take to use RNase free products when handling the mRNA. Lipofectamine 2000 was used as a positive control and prepared as instructed in the product manual. The mRNA and sgRNA were thawed and diluted to a concentration of $0.05 \mu \mathrm{g} / \mu \mathrm{L}$ with OptiMEM. 
Appropriate amount of vector solution was added to achieve the desired N/P ratio and the mixture was mixed by pipetting up and down 10 times. Finally, the mixture is diluted to $60 \mu \mathrm{L}$ with OptiMEM so that $20 \mu \mathrm{L}$ of the complex solution will contain $100 \mathrm{ng}$ of sgRNA and $10 \mathrm{ng}$ of Cas9 mRNA. The mixture was then incubated at room temperature for 5 minutes.

(2) Transfection in eGFP-expressing NIH 3 T3 cells.

Transfections were performed in triplicate in a cell culture treated clear-bottom 96well plate (Corning). After passaging, the cells were plated in 96-well plates so that they were $50 \%$ confluent at the time of transfection. The vector-mRNA complex solutions were prepared using the aforementioned protocol. The culture media was switched to $80 \mu \mathrm{L}$ OptiMEM per well and $20 \mu \mathrm{L}$ of the complex solution was added to each well. After 24 hours, the media was changed to complete media and the cells were cultured for a further 5 days. The cells were analyzed on day 6 via flow cytometry.

\section{(3) Flow cytometry analysis}

After 6 days of incubation post-transfection, the culture media was removed and replaced with $30 \mu \mathrm{L}$ trypsin and incubated at $37{ }^{\circ} \mathrm{C}$ for 5 minutes. $70 \mu \mathrm{L}$ of complete media were added to the plate and the cells were transferred to a 96-well non-cell treated plate for flow cytometry. Fluorescence of the transfected cells was measured on a Becton-Dickinson LSR II flow cytometer with argon ion excitation laser.

\subsection{LDH cytotoxicity assay.}

NIH 3 T3 cells seeded in a 96-well plate were treated with MPBP-mRNA complexes at an N/P ratio of 15 (serum-free media) or N/P ratio of 50 (10\% FBS- 
containing media), formulated as specified above. After $24 \mathrm{~h}$ incubation with the nanoparticle complexes, $50 \mu \mathrm{L}$ of the supernatant was taken and cytotoxicity was measured using a Pierce ${ }^{\mathrm{TM}}$ LDH Cytotoxicity Assay Kit (ThermoFisher) as directed in the manual. Related results are shown in Figure S13.

5.5 Confocal microscopy studies.

(1) Confocal laser microscopy was used to track Cy5-labelled mRNA in the transfected cells. Unmodified NIH 3T3 cells were seeded at a density of 15000 cells/well on an 8-well chamber slide (Lab-Tek, Rochester, NY, polylysine treated) $24 \mathrm{~h}$ prior to transfection. Cy5-labeled mRNA was complexed with different MPBPs at an N/P of 15 and transfected to the cells under the aforementioned conditions. Confocal fluorescence microscopy was performed $4 \mathrm{~h}$ or $12 \mathrm{~h}$ posttransfection. The nucleus was stained with $1 \mu \mathrm{g} / \mathrm{mL}$ solution of Hoechst 33342 . The endosome was stained with $75 \mathrm{nM}$ LysoTracker ${ }^{\circledR}$ Green or Blue probes (200 $\mu \mathrm{L}$ per well).

(2) Confocal laser microscopy was also used to track Cy5-labelled negative control siRNA in the transfected cells. HEK-293T cells were seeded at a density of 10000 cells/well on an 8-well chamber slide (Lab-Tek, Rochester, NY, polylysine treated) $24 \mathrm{~h}$ prior to transfection. Cy5-labeled siRNA was complexed with different MPBPs at an N/P of 10 and transfected to the cells under the aforementioned conditions. Confocal fluorescence microscopy was performed $24 \mathrm{~h}$ posttransfection. The endosome was stained with $75 \mathrm{nM}$ LysoTracker ${ }^{\circledR}$ Blue probes (200 $\mu \mathrm{L}$ per well).

(3) All confocal images were acquired using a Zeiss LSM 700 inverted laserscanning confocal microscope. A 20X plan apochromatic numerical aperture of 0.8 
DIC II objective was used for cellular uptake imaging experiments. A 63X oil objective was used for endosomal escape imaging experiments. A $639 \mathrm{~nm}$ laser and a 606-700 $\mathrm{nm}$ band-pass filter were used to obtain the images of Cy5-labelled mRNA. A $405 \mathrm{~nm}$ laser and a 400-498 nm band-pass filter were used to obtain the images of the Hoechst 33342 counter-stained nuclei. The fluorescent images were scanned separately and overlaid together with the differential interference contrast image (DIC). The cells were scanned as a z-stack of two-dimensional images $(1024 \times 1024$ pixels $)$ and an image cutting approximately through the middle of the cellular height was selected to present the intracellular RNA localization. 


\section{Flow Cytometry Output}

6.1 eGFP mRNA transfection in serum-free media

Untreated
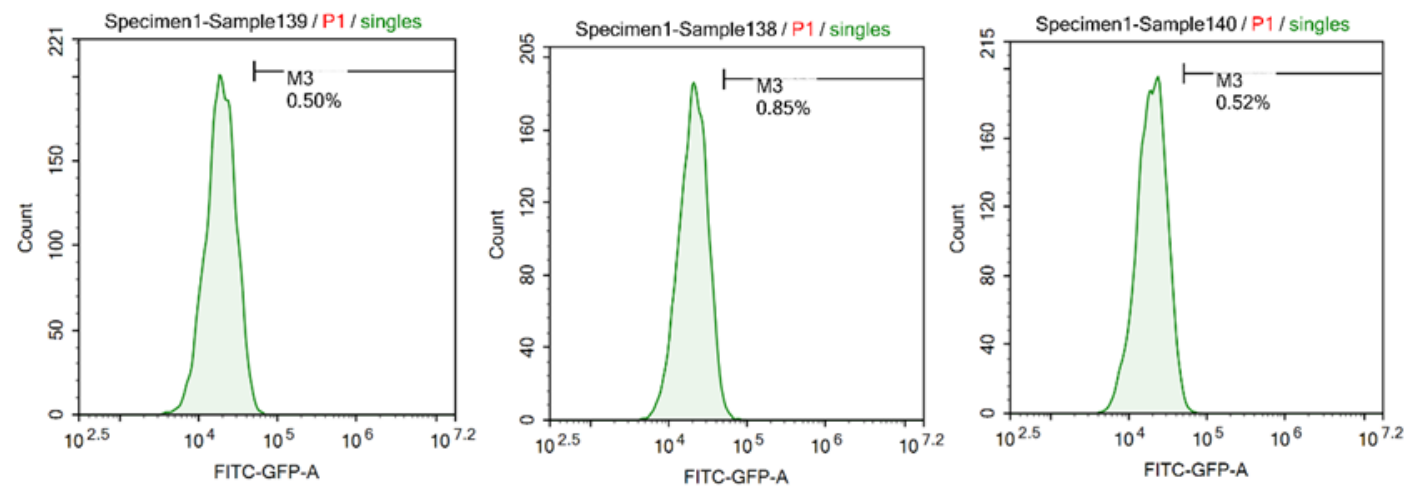

\begin{tabular}{cccc}
\hline Sample & Count & \% of All & Mean FITC-GFP \\
\hline 1 & 5000 & 0.50 & 22410 \\
2 & 5000 & 0.85 & 20908 \\
3 & 5000 & 0.52 & 21544 \\
\hline
\end{tabular}

mRNA only
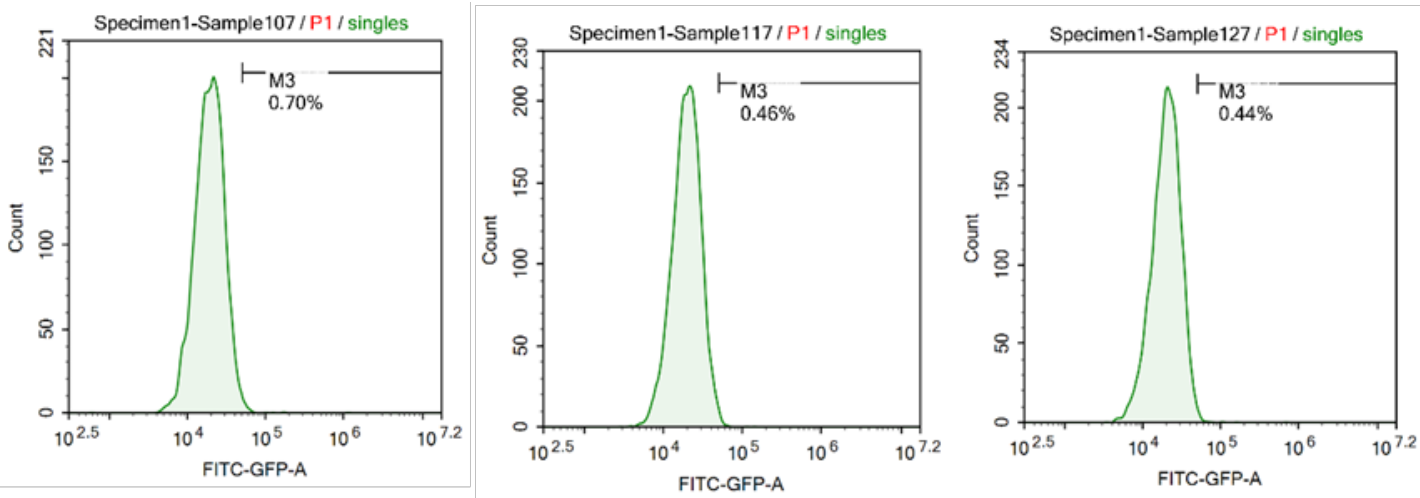

\begin{tabular}{cccc}
\hline Sample & Count & \% of All & Mean FITC-GFP \\
\hline 1 & 5000 & 0.70 & 21356 \\
2 & 5000 & 0.46 & 21457 \\
3 & 5000 & 0.44 & 22012 \\
\hline
\end{tabular}




\section{LF MM}
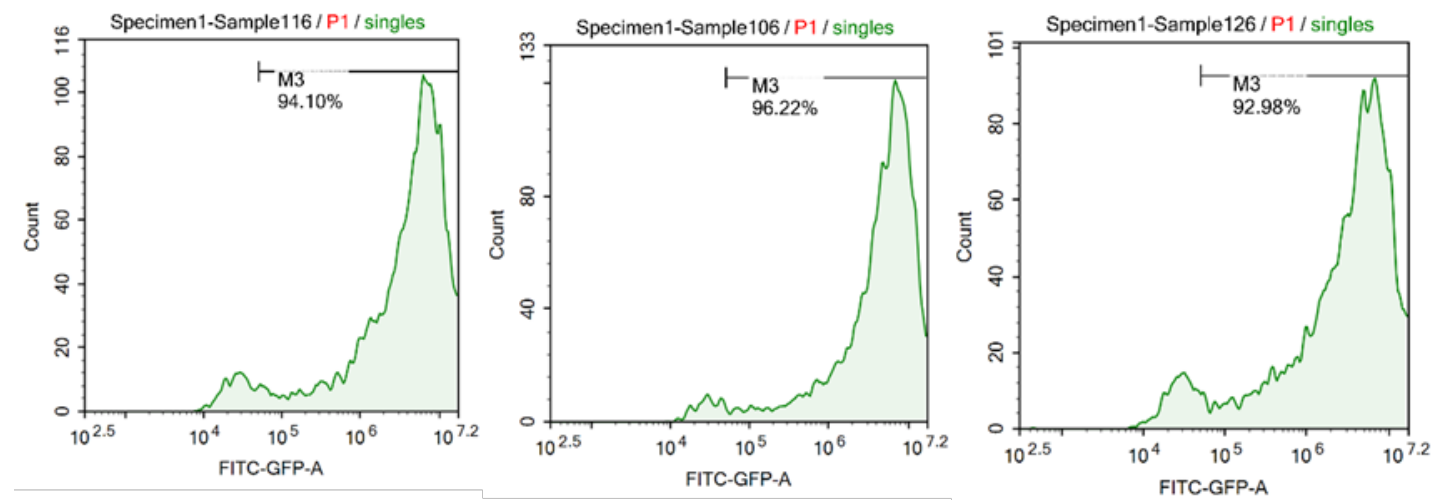

\begin{tabular}{cccc}
\hline Sample & Count & \% of All & Mean FITC-GFP \\
\hline 1 & 5000 & 94.10 & 6324327 \\
2 & 5000 & 96.22 & 6092067 \\
3 & 5000 & 92.98 & 5234940 \\
\hline
\end{tabular}

\section{G0-100LP}
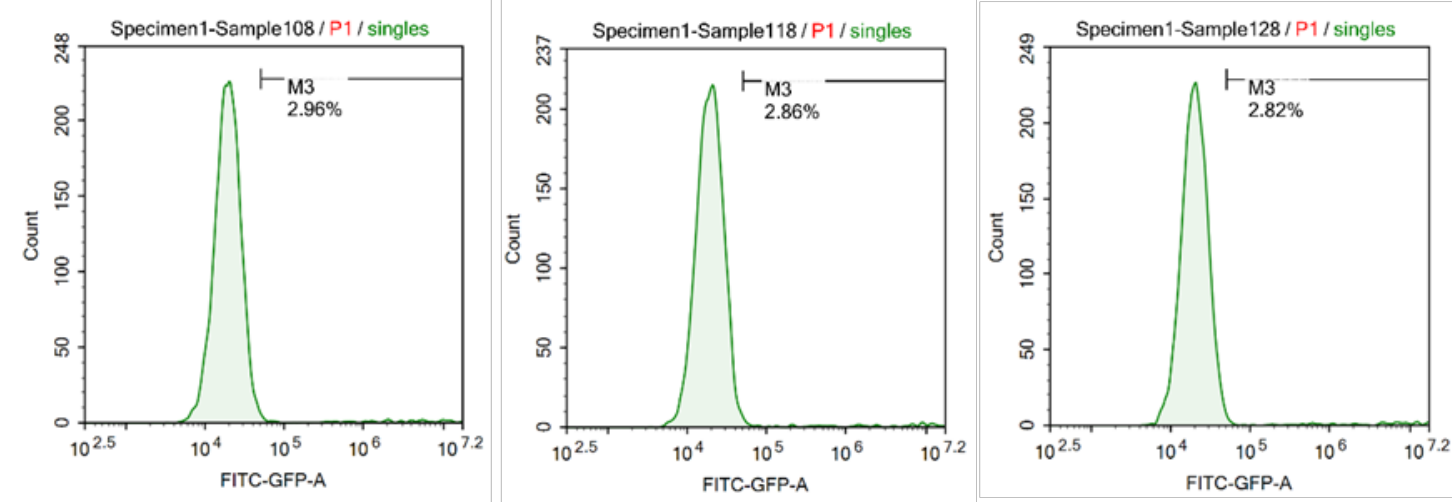

\begin{tabular}{cccc}
\hline Sample & Count & \% of All & Mean FITC-GFP \\
\hline 1 & 5000 & 2.96 & 143835 \\
2 & 5000 & 2.86 & 156423 \\
3 & 5000 & 2.82 & 161359 \\
\hline
\end{tabular}


G0-20TEG-80LP
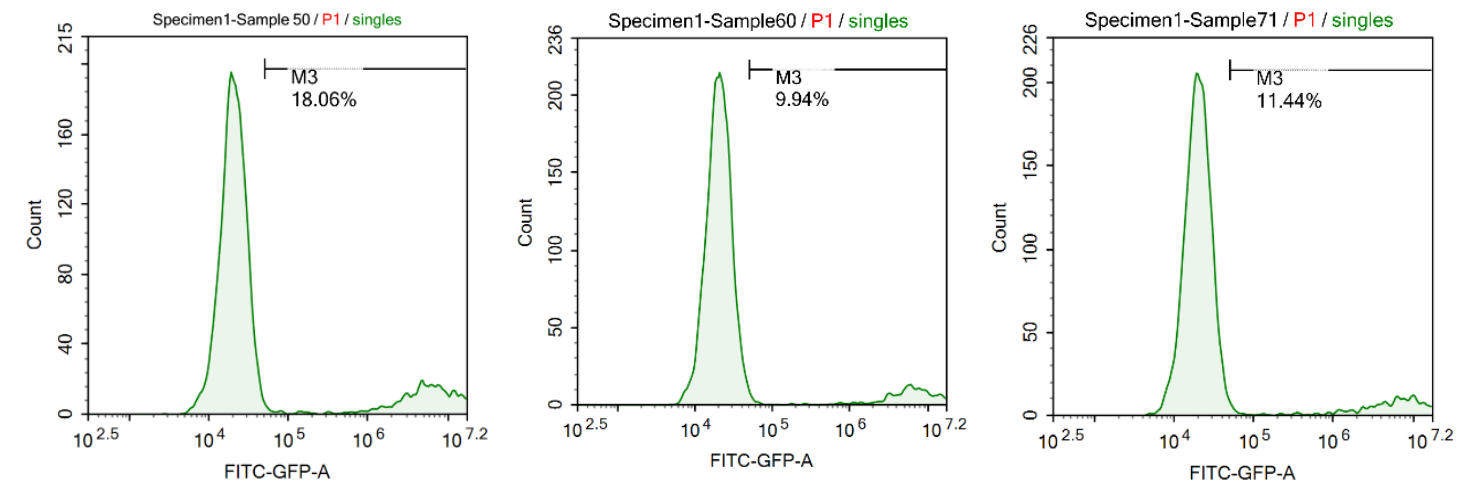

\begin{tabular}{cccc}
\hline Sample & Count & \% of All & Mean FITC-GFP \\
\hline 1 & 5000 & 18.06 & 1563883 \\
2 & 5000 & 9.94 & 822601 \\
3 & 5000 & 11.44 & 939790 \\
\hline
\end{tabular}

\section{G0-50TEG-50LP}
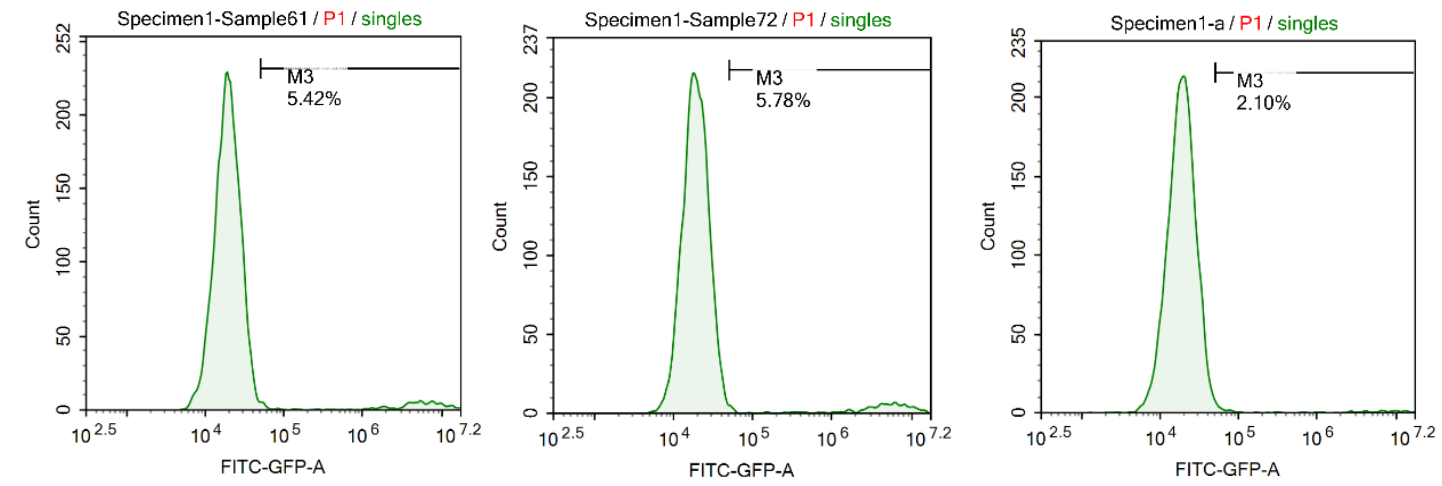

\begin{tabular}{cccc}
\hline Sample & Count & \% of All & Mean FITC-GFP \\
\hline 1 & 5000 & 5.42 & 61233 \\
2 & 5000 & 5.78 & 80527 \\
3 & 5000 & 2.10 & 121996 \\
\hline
\end{tabular}


G0-20SA-80LP
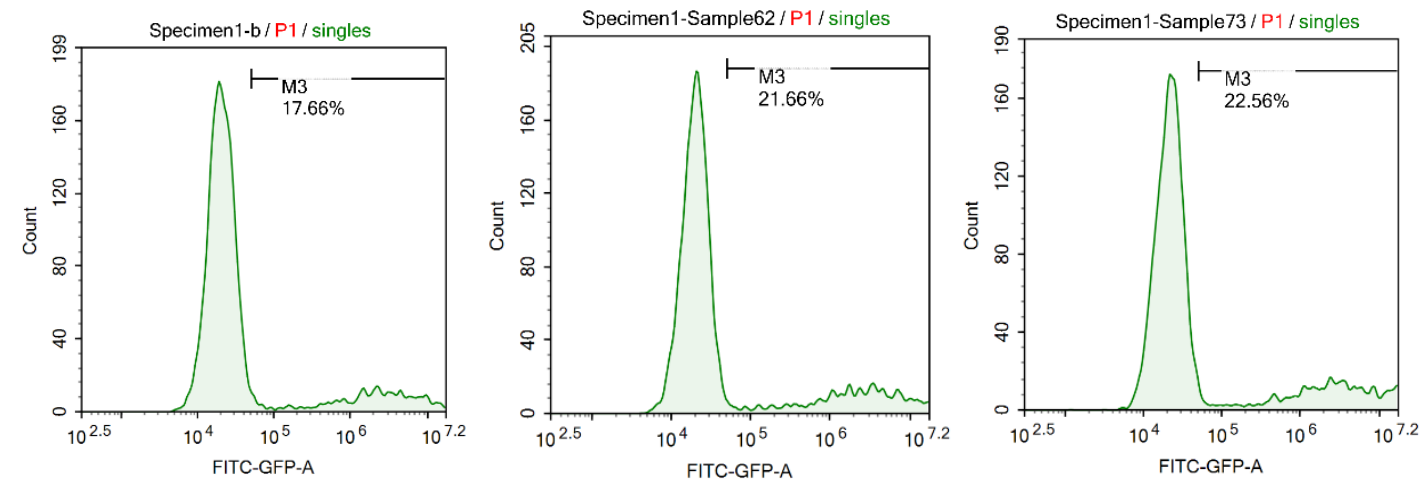

\begin{tabular}{cccc}
\hline Sample & Count & \% of All & Mean FITC-GFP \\
\hline 1 & 5000 & 17.66 & 756082 \\
2 & 5000 & 21.66 & 1000737 \\
3 & 5000 & 22.56 & 1161848 \\
\hline
\end{tabular}

\section{G0-50SA-50LP}
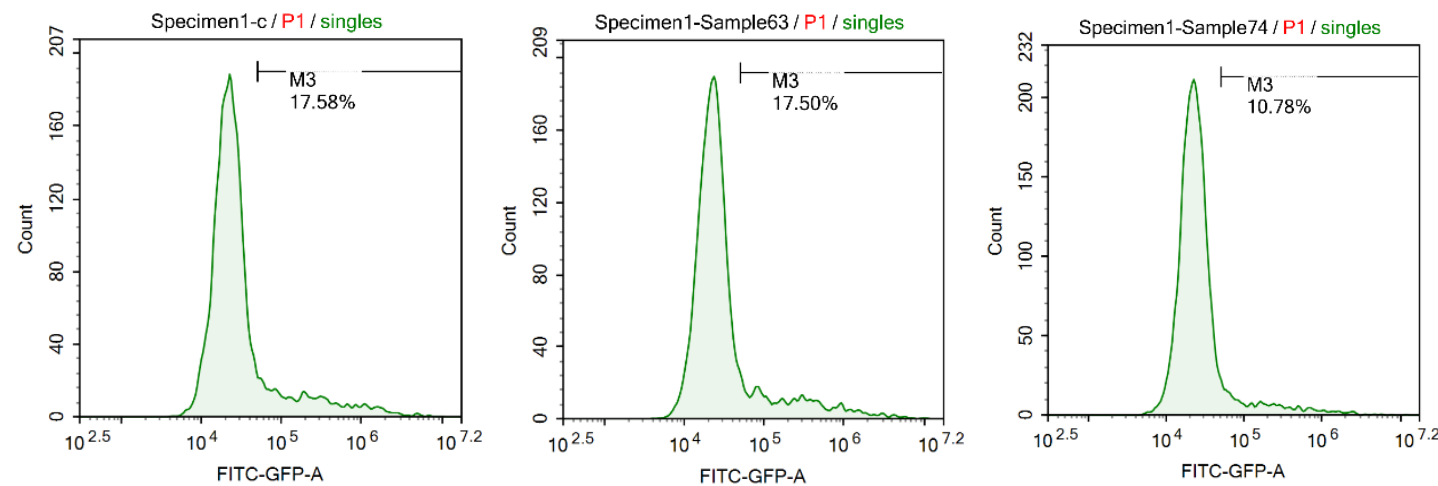

\begin{tabular}{cccc}
\hline Sample & Count & \% of All & Mean FITC-GFP \\
\hline 1 & 5000 & 17.58 & 116702 \\
2 & 5000 & 17.50 & 123622 \\
3 & 5000 & 10.78 & 70883 \\
\hline
\end{tabular}




\section{G1-100LP}
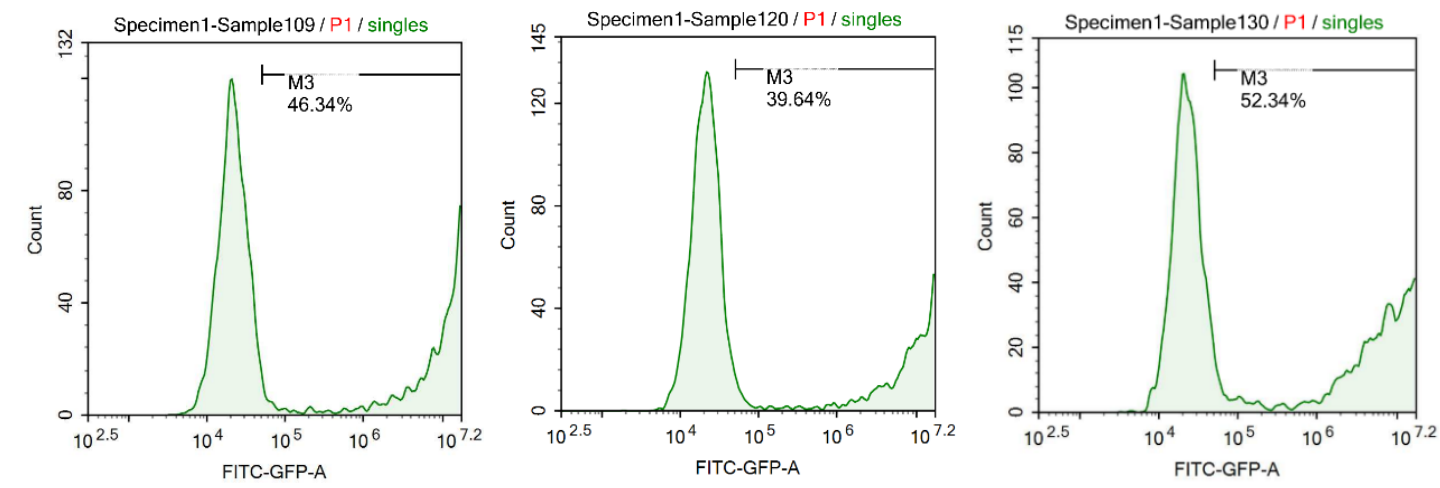

\begin{tabular}{cccc}
\hline Sample & Count & \% of All & Mean FITC-GFP \\
\hline 1 & 5000 & 46.34 & 7240389 \\
2 & 5000 & 39.64 & 6094296 \\
3 & 5000 & 52.34 & 7575724 \\
\hline
\end{tabular}

\section{G1-20TEG-80LP}
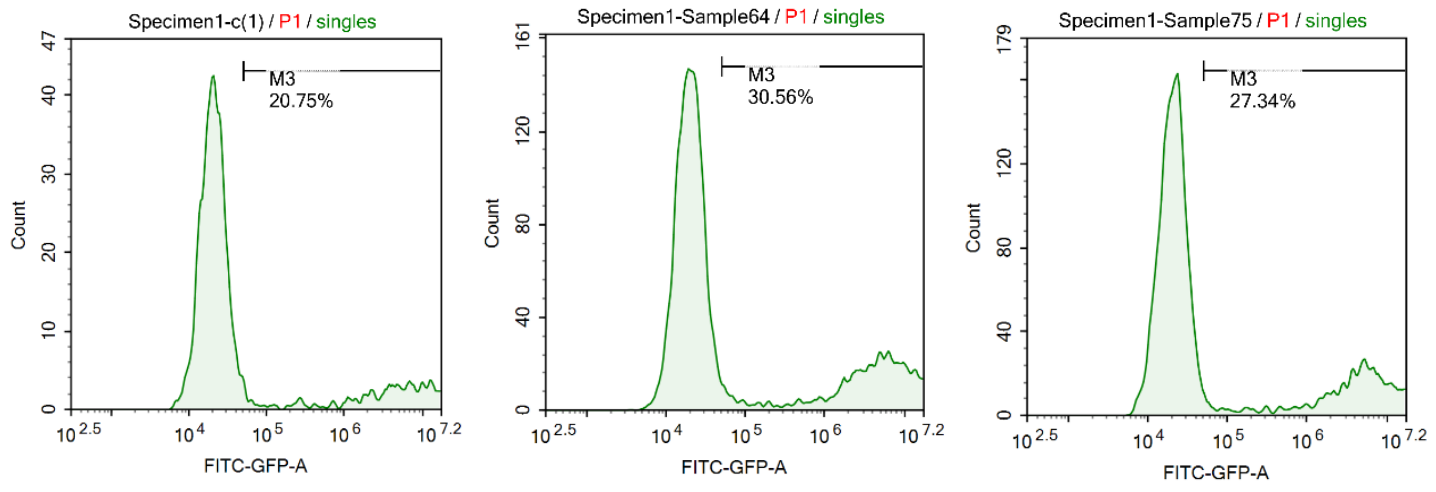

\begin{tabular}{cccc}
\hline Sample & Count & \% of All & Mean FITC-GFP \\
\hline 1 & 5000 & 20.75 & 1537838 \\
2 & 5000 & 30.56 & 2214018 \\
3 & 5000 & 27.34 & 1996336 \\
\hline
\end{tabular}




\section{G1-50TEG-50LP}
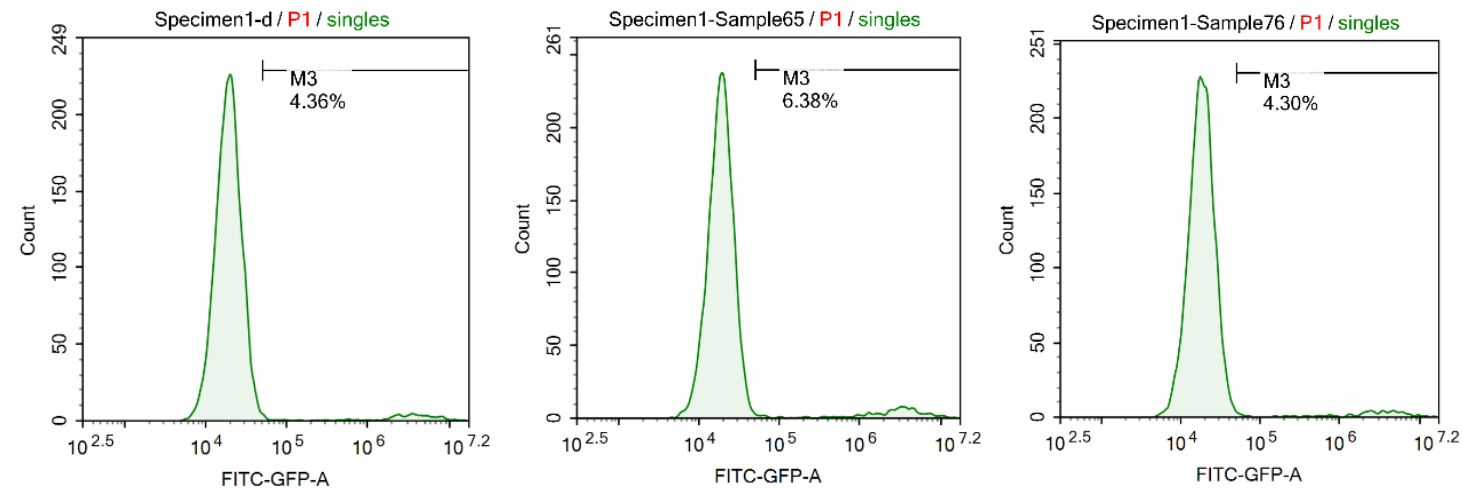

\begin{tabular}{cccc}
\hline Sample & Count & \% of All & Mean FITC-GFP \\
\hline 1 & 5000 & 4.36 & 188241 \\
2 & 5000 & 6.38 & 247591 \\
3 & 5000 & 4.30 & 168589 \\
\hline
\end{tabular}

\section{G1-20SA-80LP}
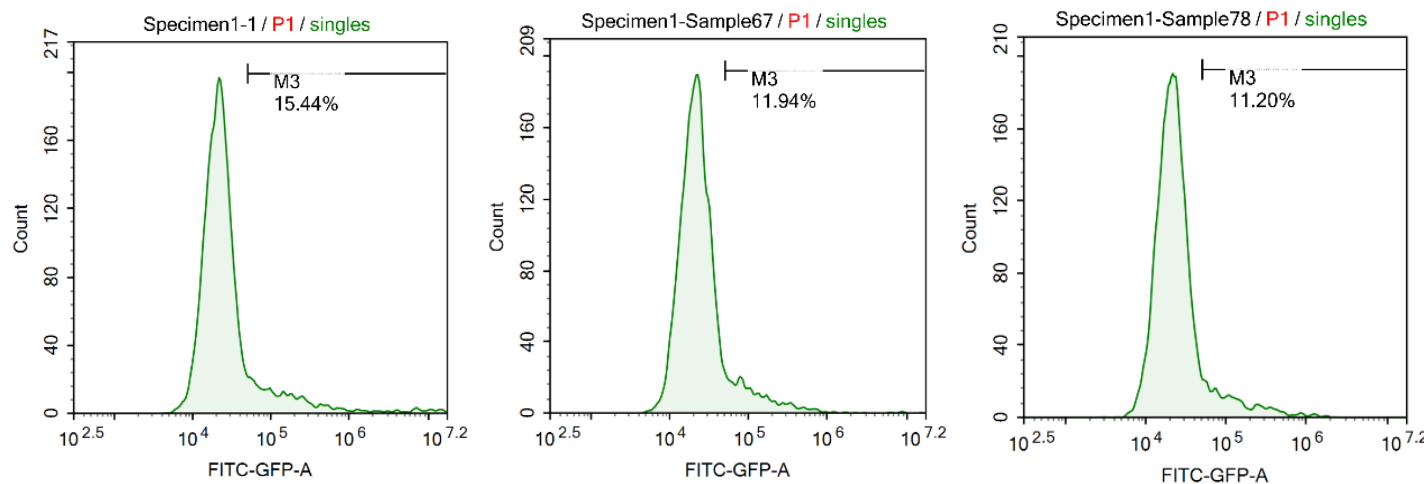

\begin{tabular}{cccc}
\hline Sample & Count & \% of All & Mean FITC-GFP \\
\hline 1 & 5000 & 15.44 & 152264 \\
2 & 5000 & 11.94 & 74424 \\
3 & 5000 & 11.20 & 42282 \\
\hline
\end{tabular}


G2-100LP
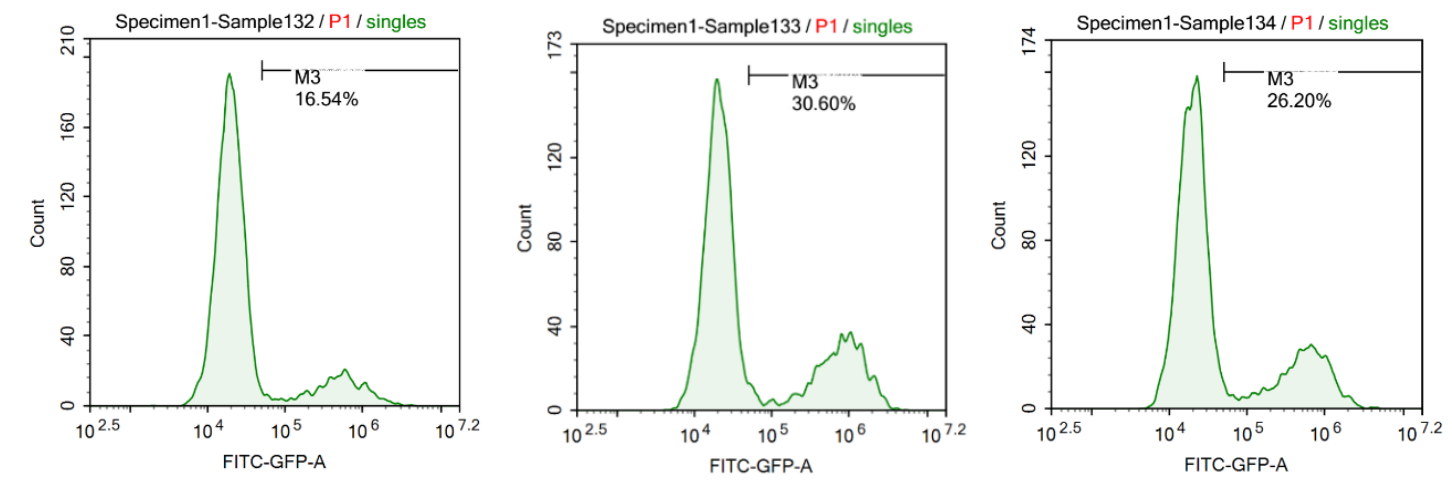

\begin{tabular}{cccc}
\hline Sample & Count & \% of All & Mean FITC-GFP \\
\hline 1 & 5000 & 16.54 & 122083 \\
2 & 5000 & 30.60 & 293665 \\
3 & 5000 & 26.20 & 190229 \\
\hline
\end{tabular}

\section{2 eGFP mRNA transfection in 10\% FBS-containing media}

\section{Untreated}
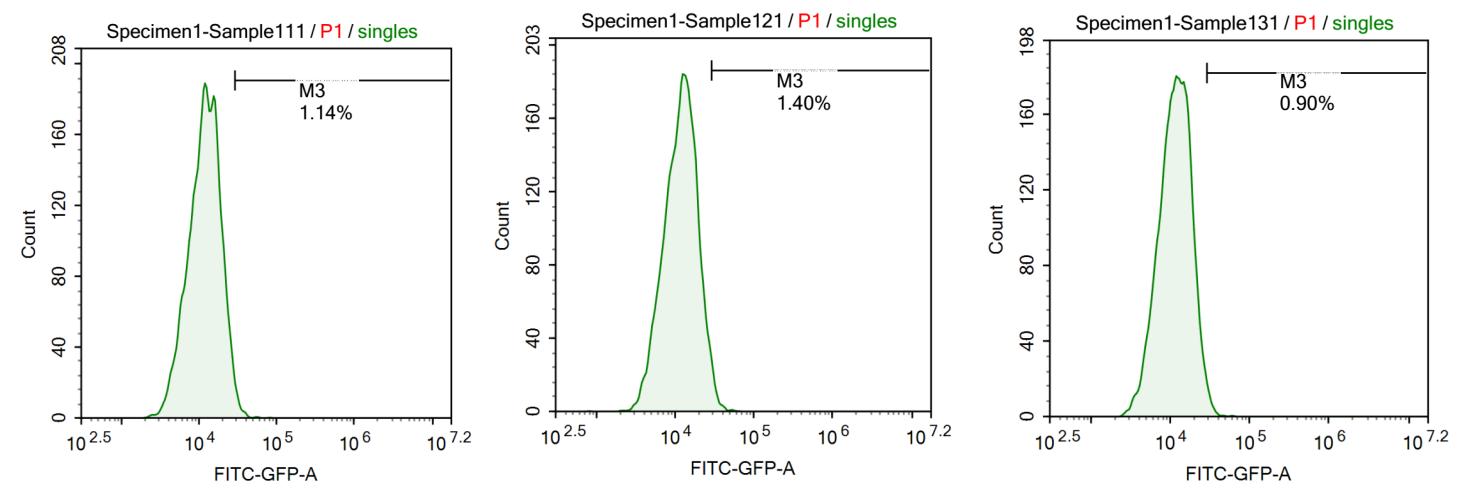

\begin{tabular}{cccc}
\hline Sample & Count & \% of All & Mean FITC-GFP \\
\hline 1 & 5000 & 1.14 & 18735 \\
2 & 5000 & 1.40 & 13250 \\
3 & 5000 & 0.90 & 12835 \\
\hline
\end{tabular}


mRNA only
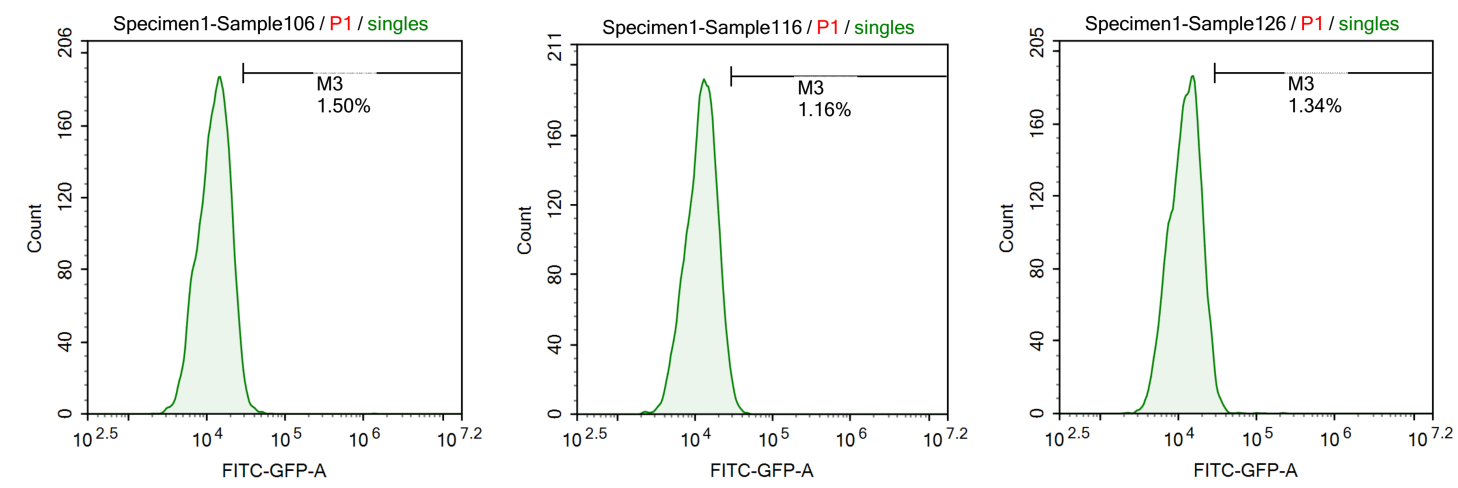

\begin{tabular}{cccc}
\hline Sample & Count & \% of All & Mean FITC-GFP \\
\hline 1 & 5000 & 1.50 & 14210 \\
2 & 5000 & 1.16 & 13471 \\
3 & 5000 & 1.34 & 13791 \\
\hline
\end{tabular}

\section{LF MM}
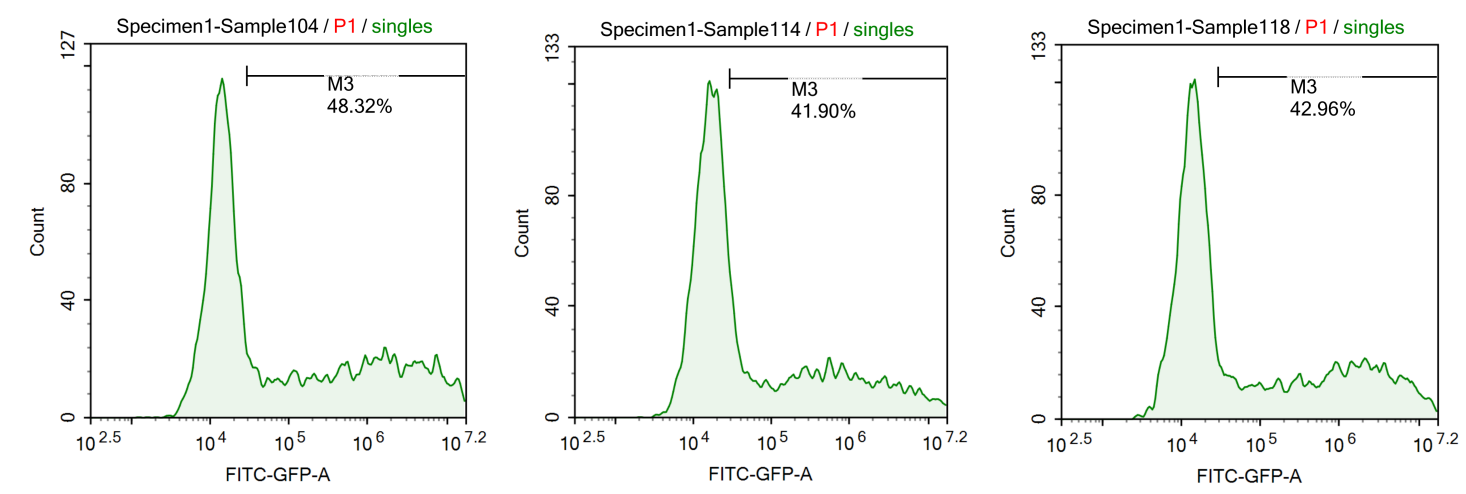

\begin{tabular}{cccc}
\hline Sample & Count & \% of All & Mean FITC-GFP \\
\hline 1 & 5000 & 48.32 & 1582084 \\
2 & 5000 & 41.90 & 893936 \\
3 & 5000 & 42.96 & 1126860 \\
\hline
\end{tabular}


G0-100LP


\begin{tabular}{cccc}
\hline Sample & Count & \% of All & Mean FITC-GFP \\
\hline 1 & 5000 & 6.14 & 225490 \\
2 & 5000 & 7.28 & 297331 \\
3 & 5000 & 8.28 & 400630 \\
\hline
\end{tabular}

G0-20TEG-80LP
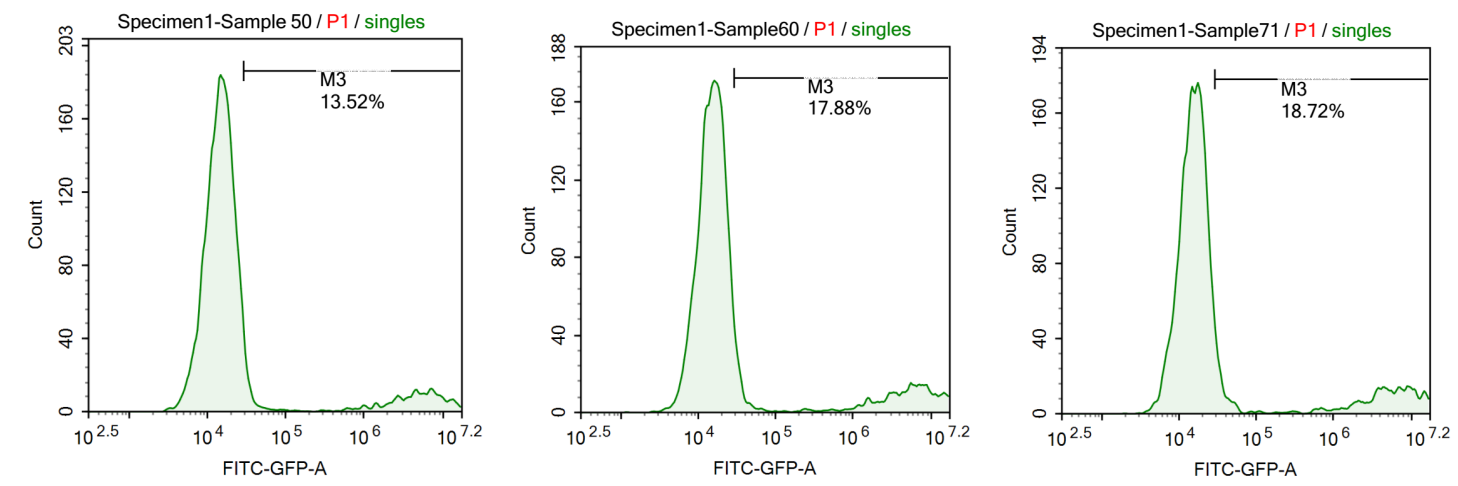

\begin{tabular}{cccc}
\hline Sample & Count & \% of All & Mean FITC-GFP \\
\hline 1 & 5000 & 13.52 & 685989 \\
2 & 5000 & 17.88 & 958579 \\
3 & 5000 & 18.72 & 1049797 \\
\hline
\end{tabular}


G0-50TEG-50LP


\begin{tabular}{cccc}
\hline Sample & Count & \% of All & Mean FITC-GFP \\
\hline 1 & 5000 & 10.16 & 298567 \\
2 & 5000 & 7.20 & 235771 \\
3 & 5000 & 7.04 & 261280 \\
\hline
\end{tabular}

\section{G0-20SA-80LP}
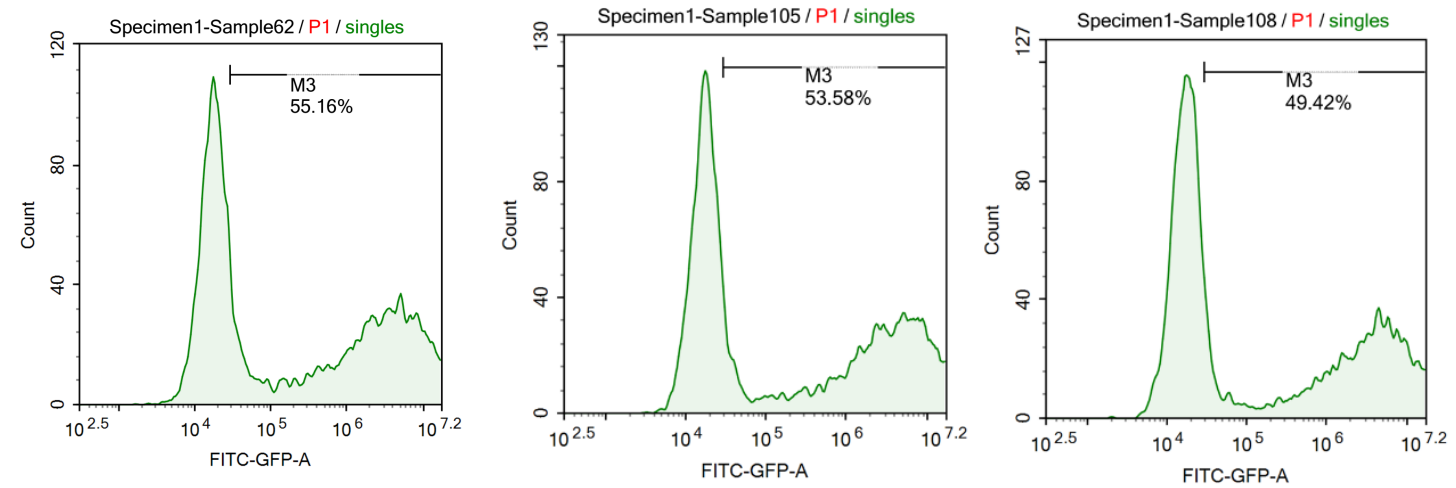

\begin{tabular}{cccc}
\hline Sample & Count & \% of All & Mean FITC-GFP \\
\hline 1 & 5000 & 55.16 & 2268149 \\
2 & 5000 & 53.58 & 2836431 \\
3 & 5000 & 49.42 & 2532842 \\
\hline
\end{tabular}




\section{G0-50SA-50LP}
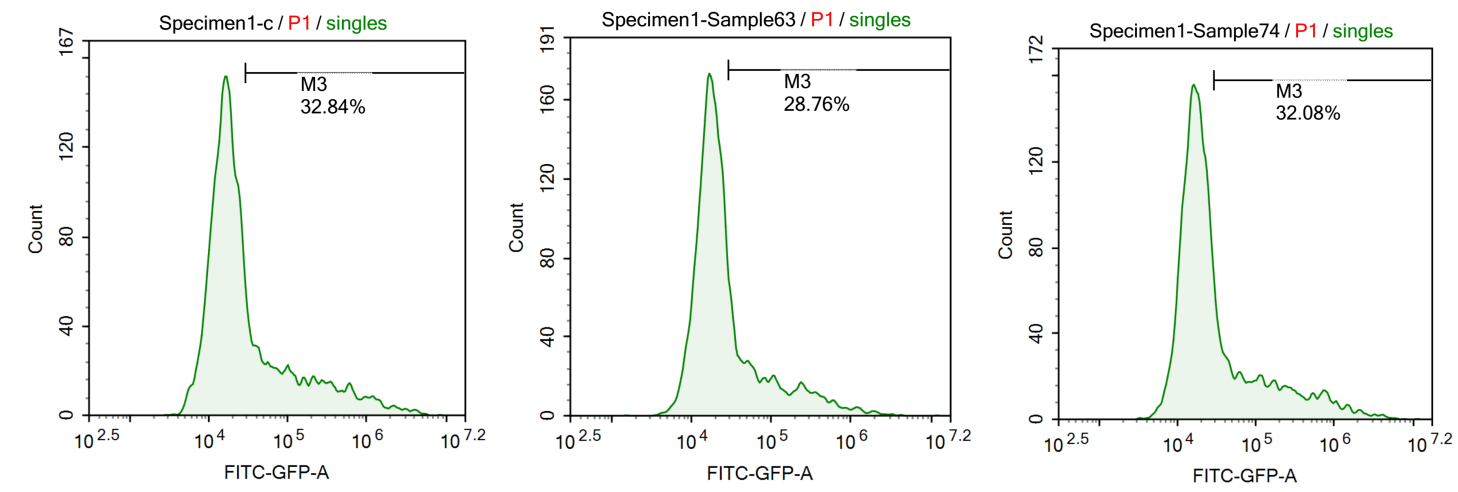

\begin{tabular}{cccc}
\hline Sample & Count & \% of All & Mean FITC-GFP \\
\hline 1 & 5000 & 32.84 & 143484 \\
2 & 5000 & 28.76 & 81912 \\
3 & 5000 & 32.08 & 137334 \\
\hline
\end{tabular}

\section{G1-100LP}
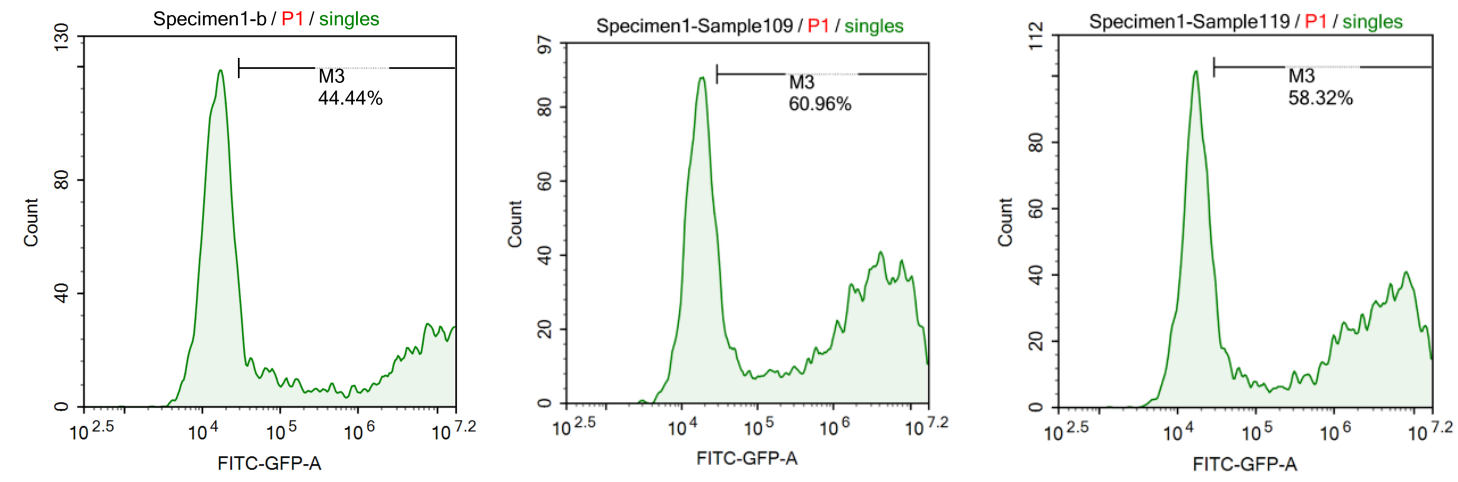

\begin{tabular}{cccc}
\hline Sample & Count & \% of All & Mean FITC-GFP \\
\hline 1 & 5000 & 44.44 & 3077175 \\
2 & 5000 & 60.96 & 2631080 \\
3 & 5000 & 58.32 & 2831390 \\
\hline
\end{tabular}




\section{G1-20TEG-80LP}


\begin{tabular}{cccc}
\hline Sample & Count & \% of All & Mean FITC-GFP \\
\hline 1 & 5000 & 42.46 & 2075207 \\
2 & 5000 & 44.22 & 2084895 \\
3 & 5000 & 43.60 & 2398933 \\
\hline
\end{tabular}

\section{G1-50TEG-50LP}
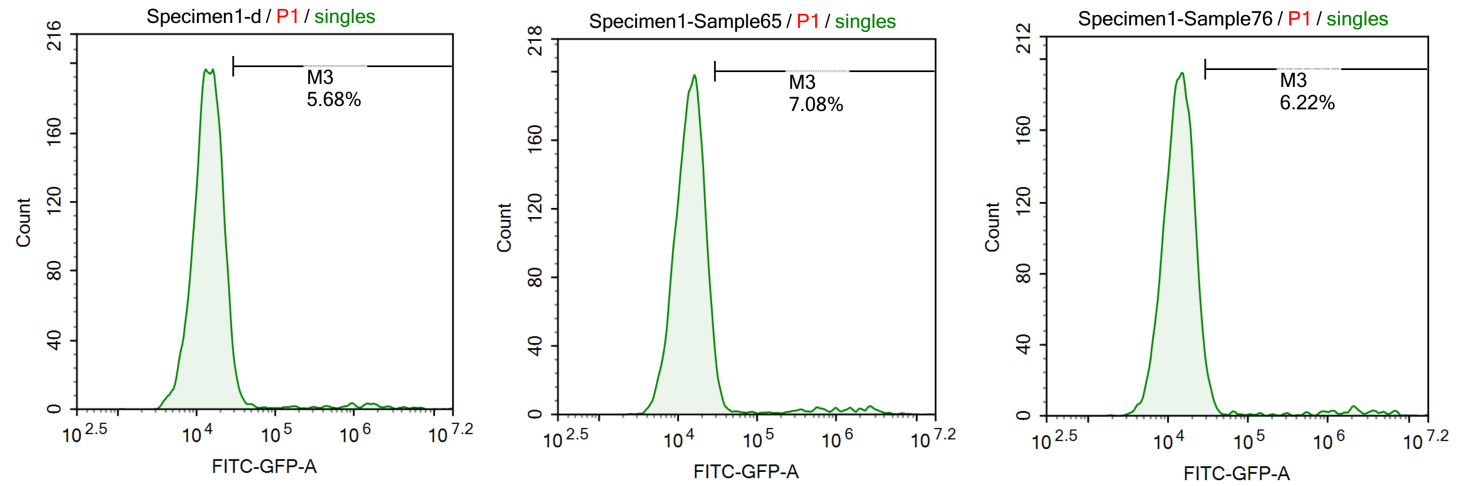

\begin{tabular}{cccc}
\hline Sample & Count & \% of All & Mean FITC-GFP \\
\hline 1 & 5000 & 5.68 & 71726 \\
2 & 5000 & 7.08 & 88078 \\
3 & 5000 & 6.22 & 107803 \\
\hline
\end{tabular}




\section{G1-20SA-80LP}
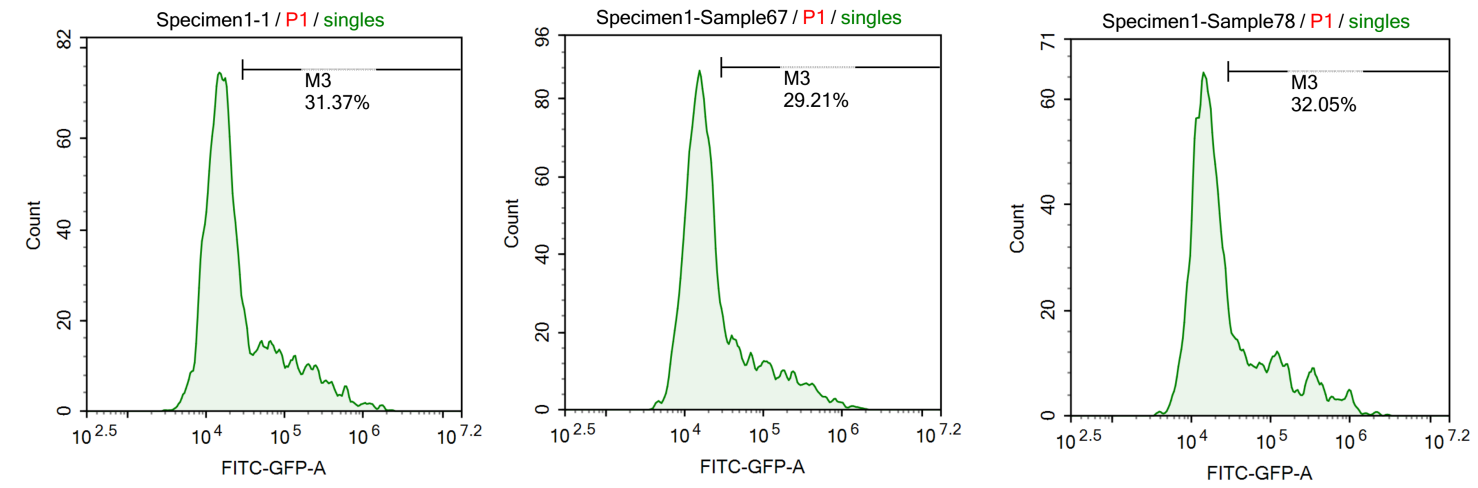

\begin{tabular}{cccc}
\hline Sample & Count & \% of All & Mean FITC-GFP \\
\hline 1 & 5000 & 31.37 & 72255 \\
2 & 5000 & 29.21 & 63708 \\
3 & 5000 & 32.05 & 85301 \\
\hline
\end{tabular}

\section{G2-100LP}
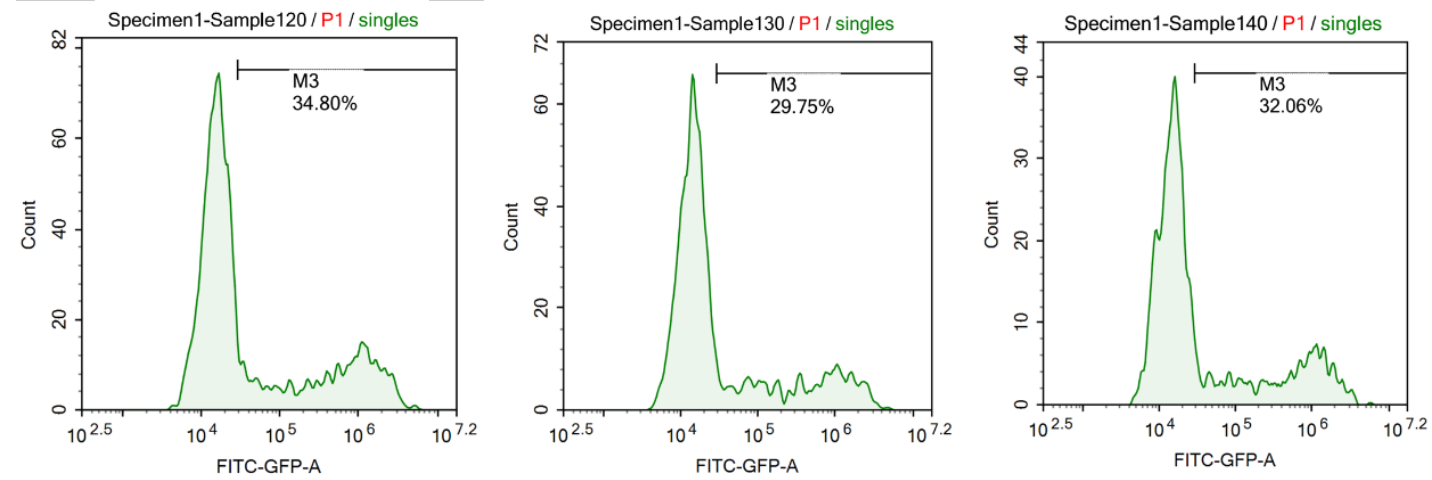

\begin{tabular}{cccc}
\hline Sample & Count & \% of All & Mean FITC-GFP \\
\hline 1 & 5000 & 34.80 & 316001 \\
2 & 5000 & 29.75 & 240382 \\
3 & 5000 & 32.06 & 268352 \\
\hline
\end{tabular}




\subsection{Co-delivery of Cas9 mRNA and sgRNA}

\section{Cas9 mRNA/sgRNA}
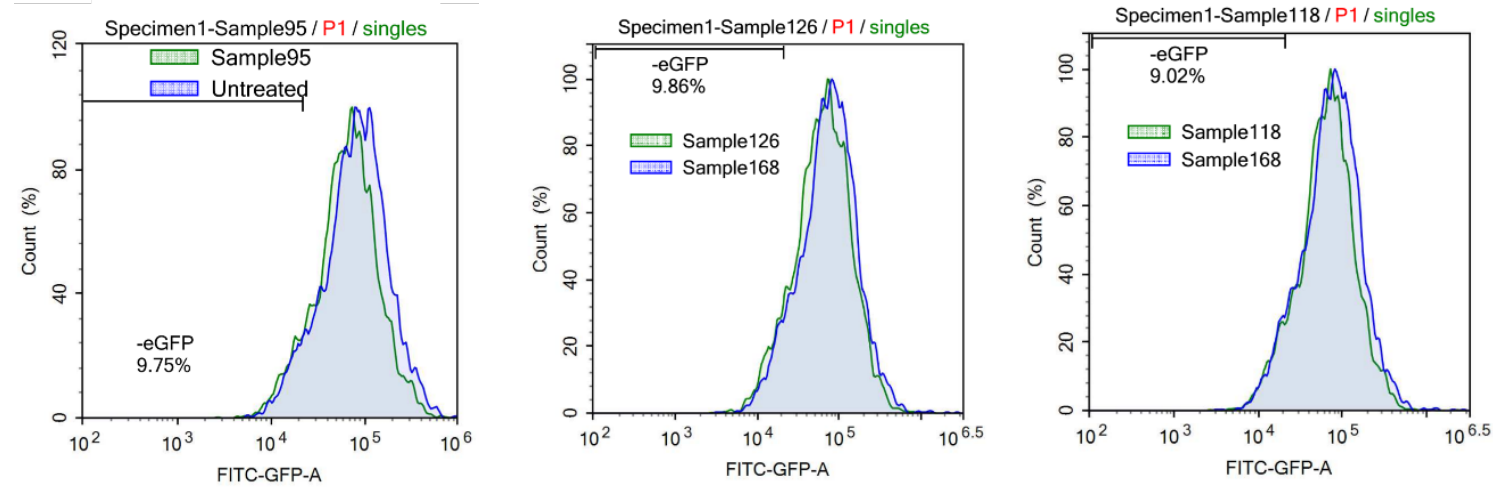

\section{LF 2000}
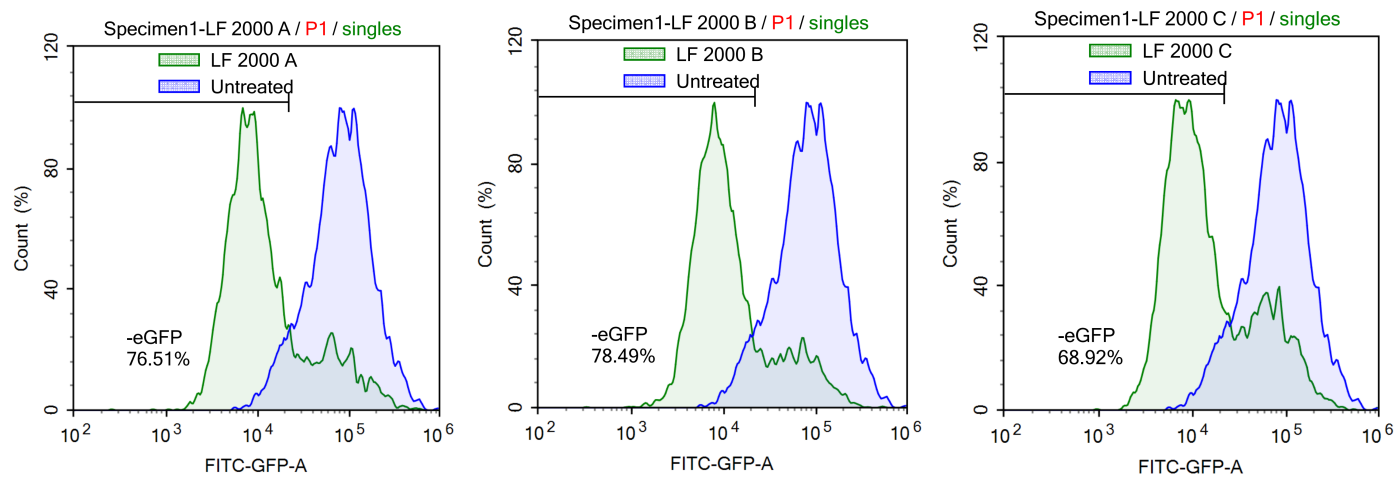

G0-20SA-80LP
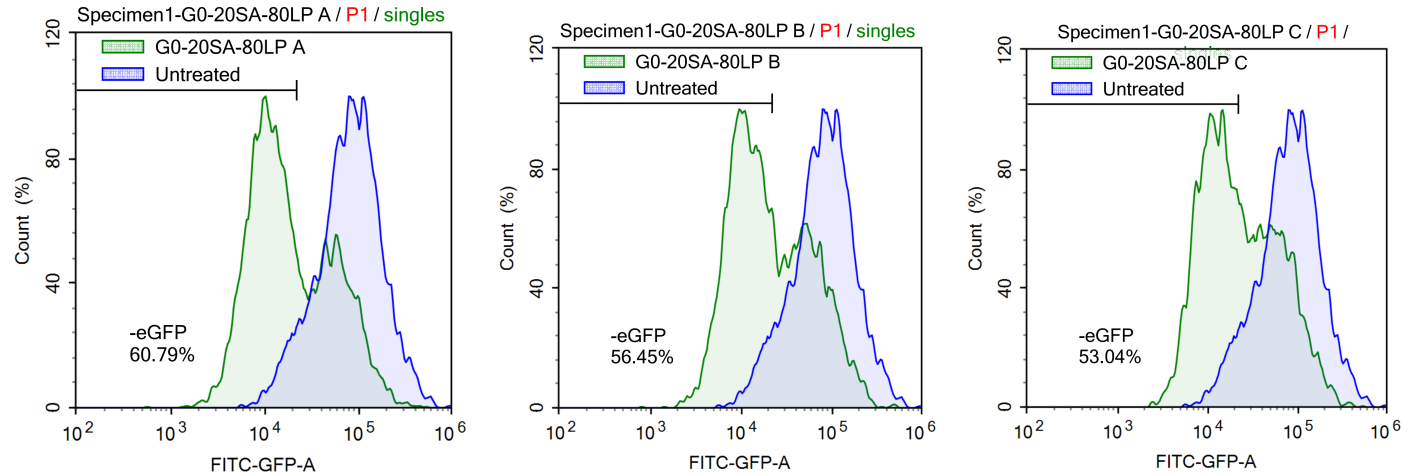


\section{G1-100LP}
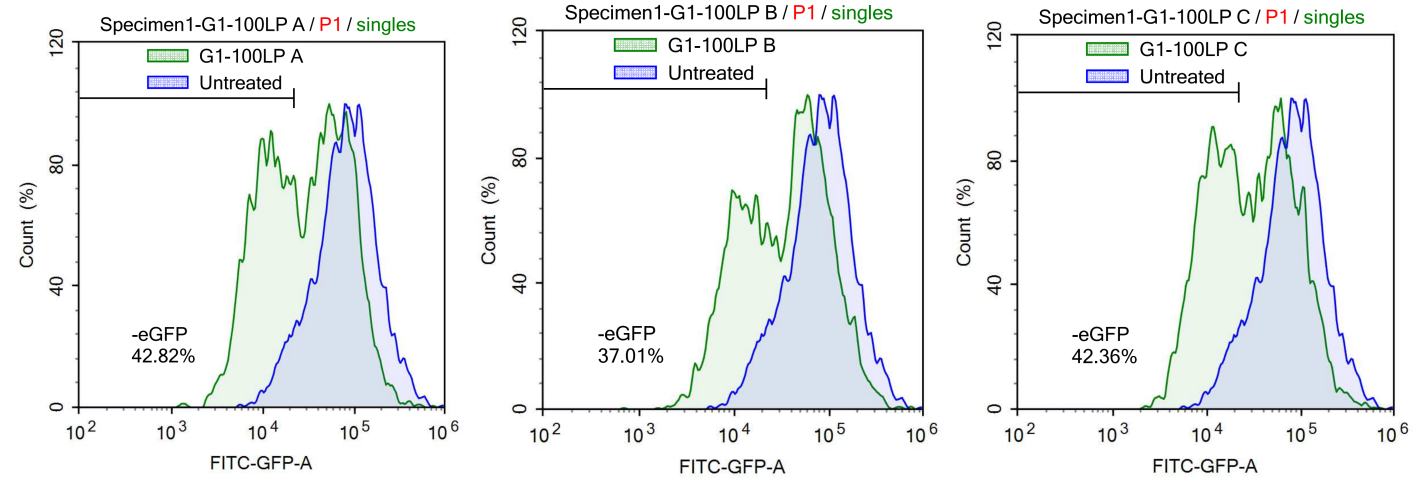

\section{G1-20TEG-80LP}
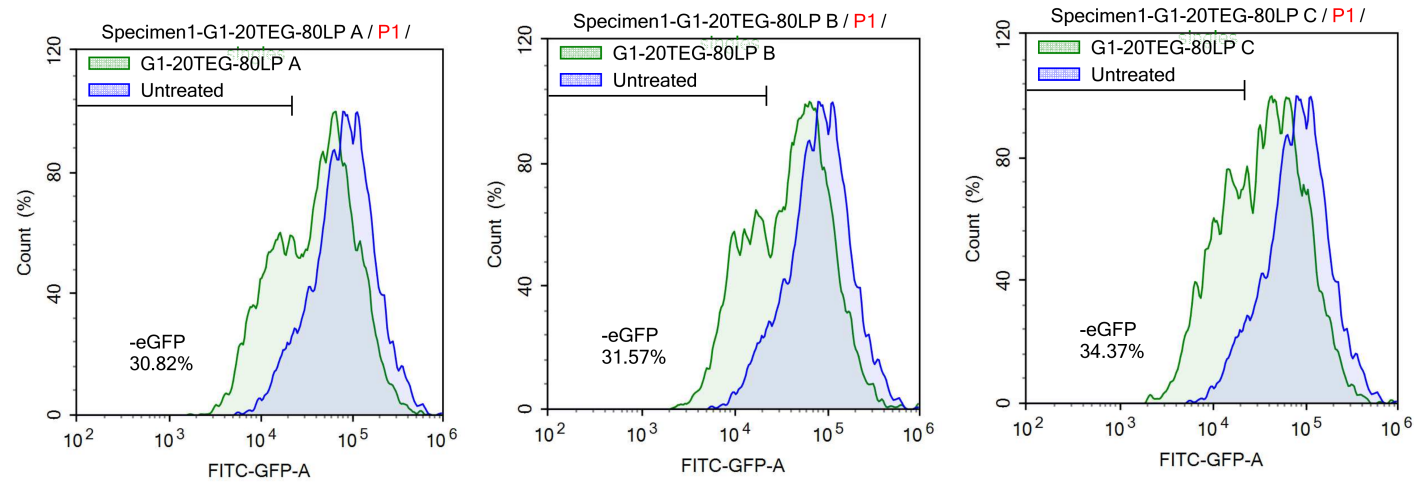

\section{G1-20SA-80LP}
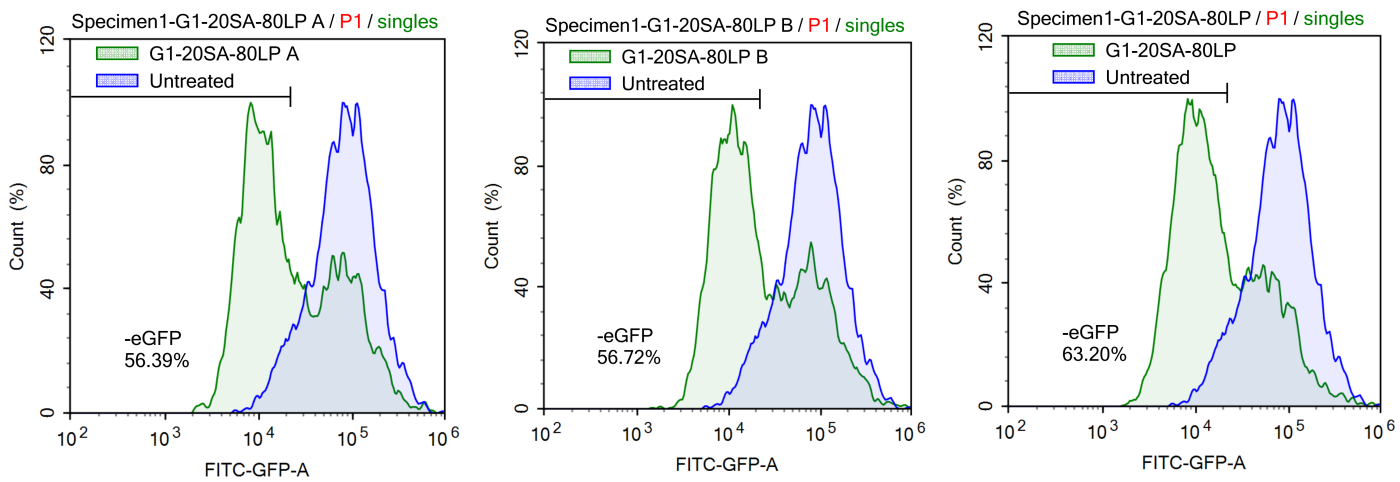


\section{7. ${ }^{1} \mathrm{H}$ NMR Spectra}

\section{G0-20 TEG polymer backbone}

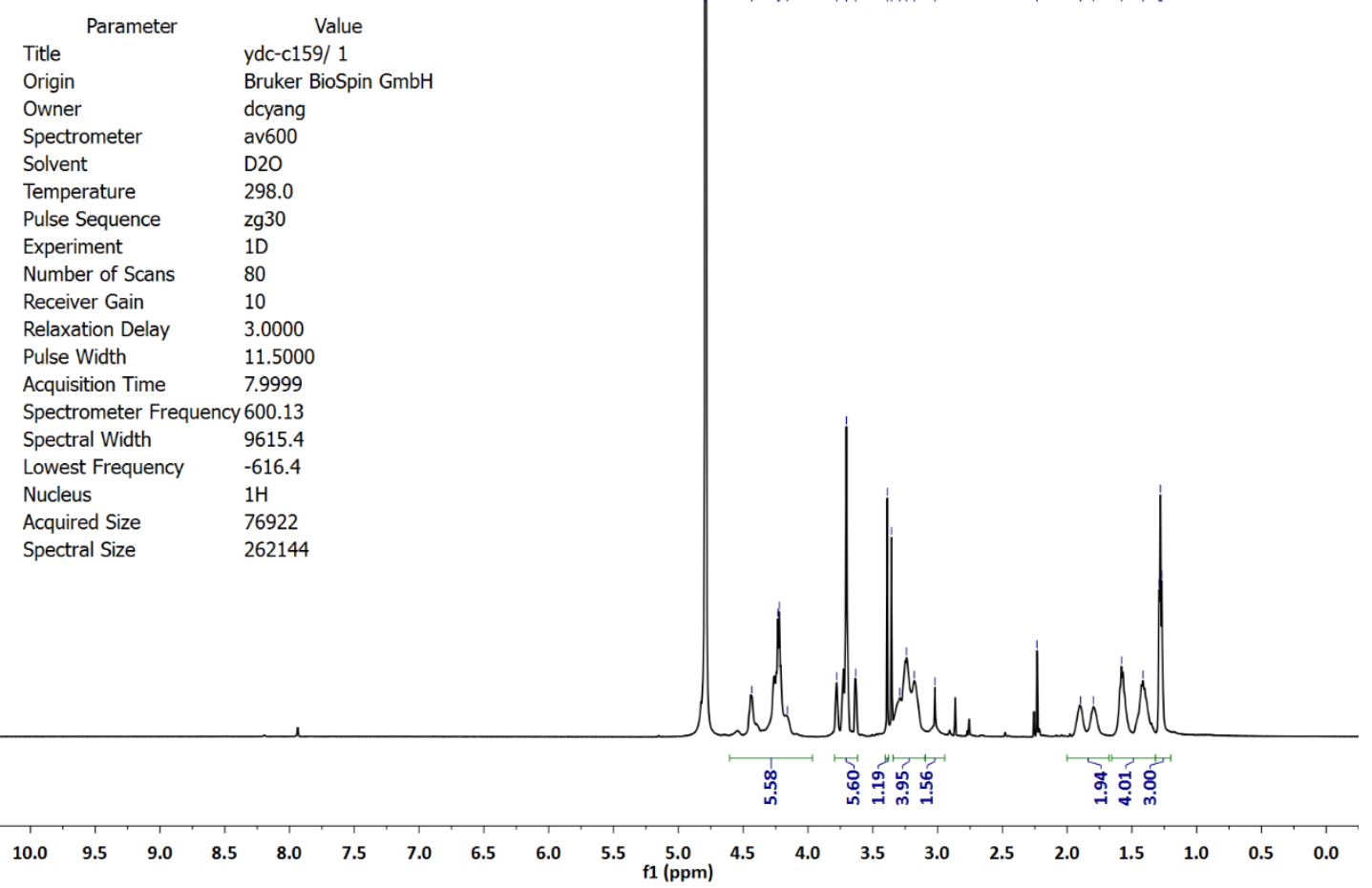

\section{G0-50 TEG polymer backbone}

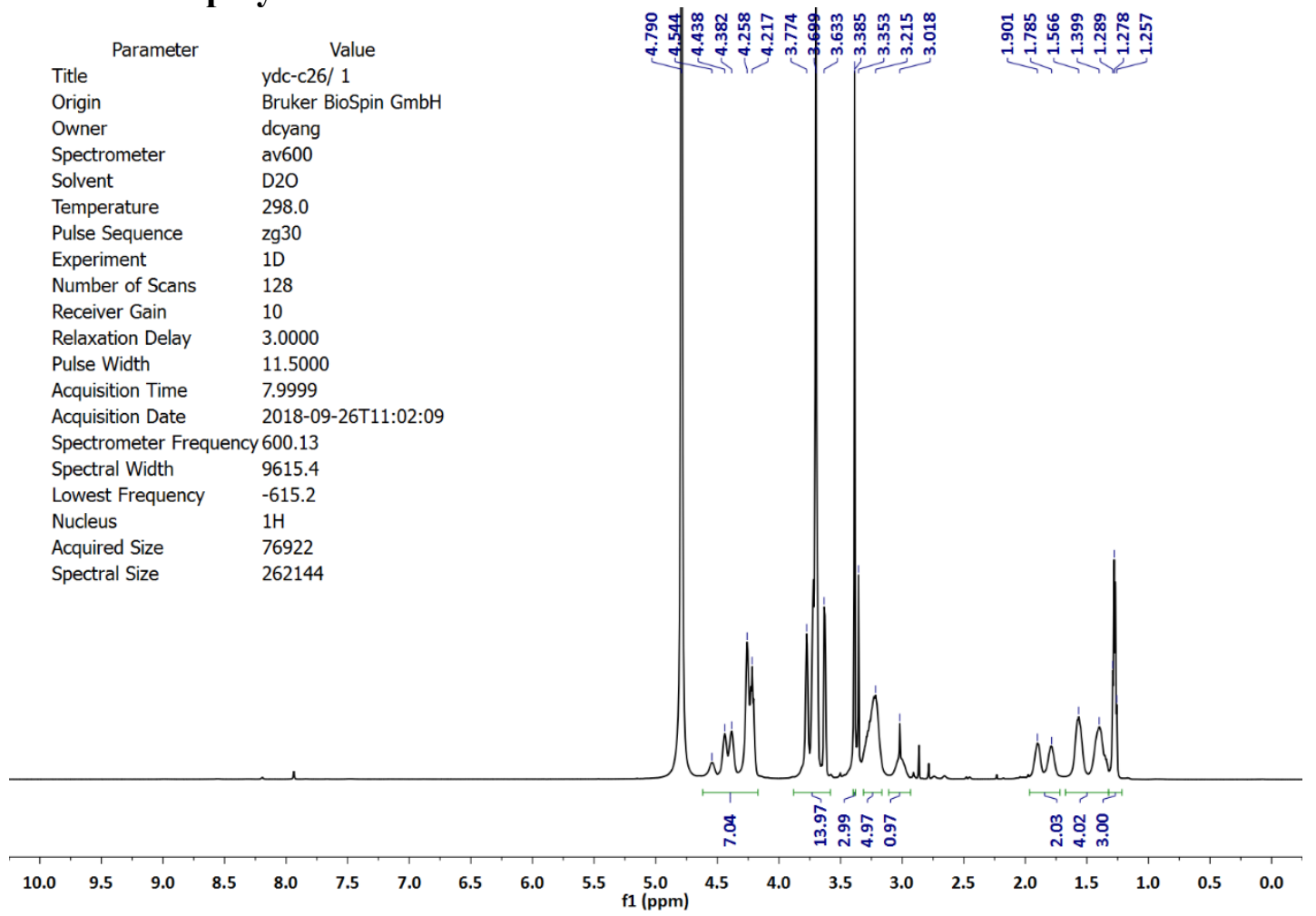




\section{G1-20 TEG polymer backbone}

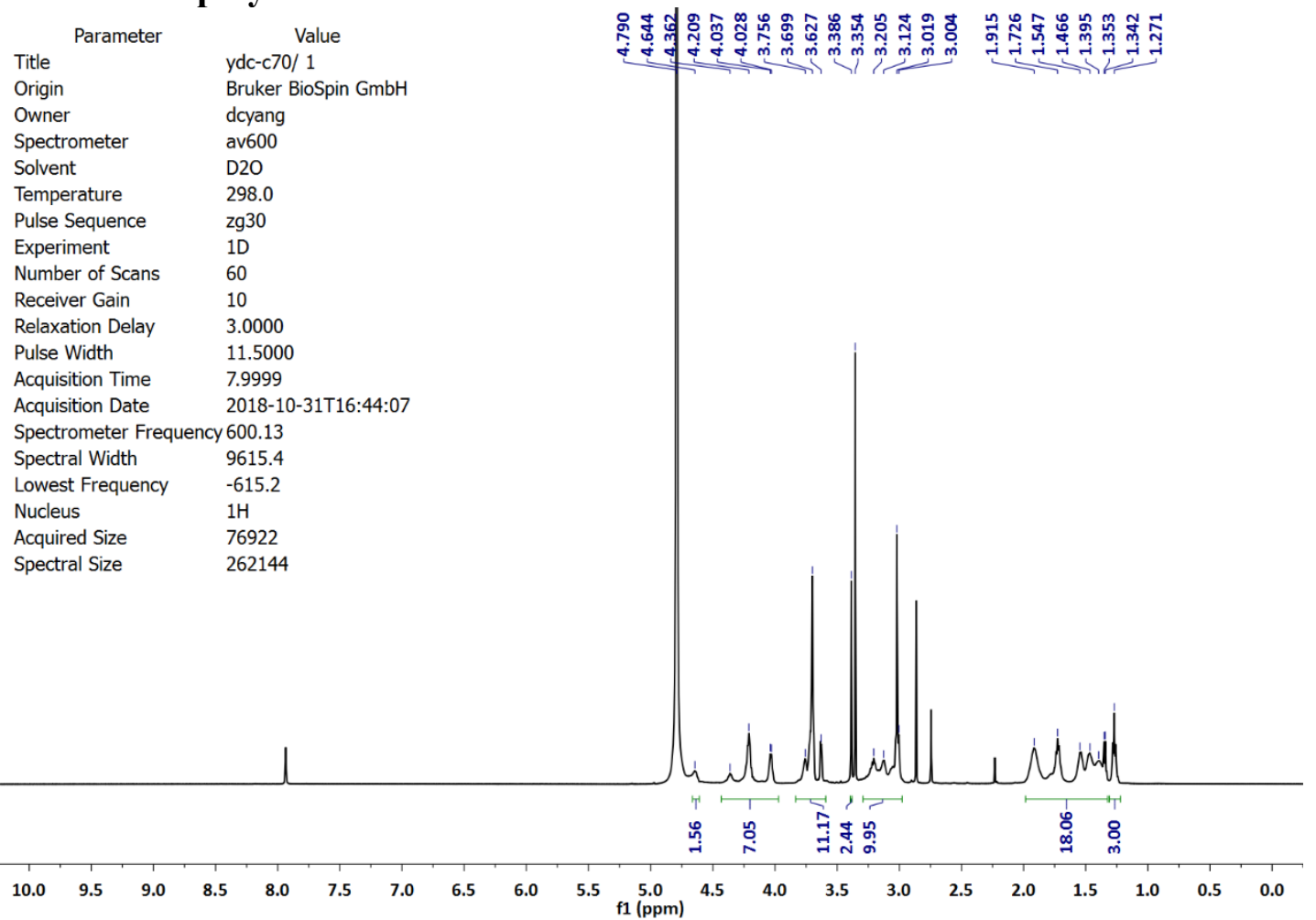

\section{G1-50 TEG polymer backbone}

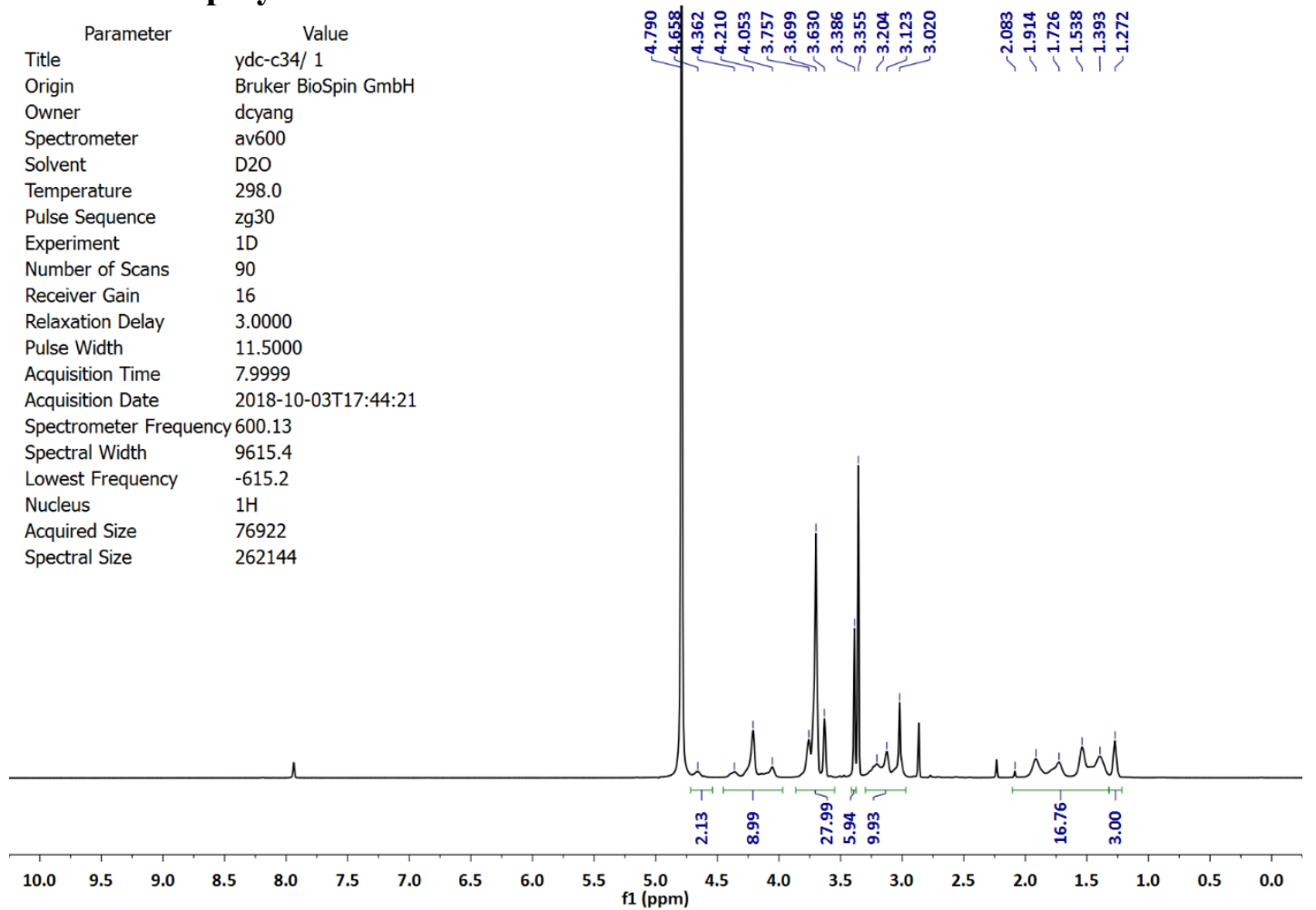




\section{G0-100LP}

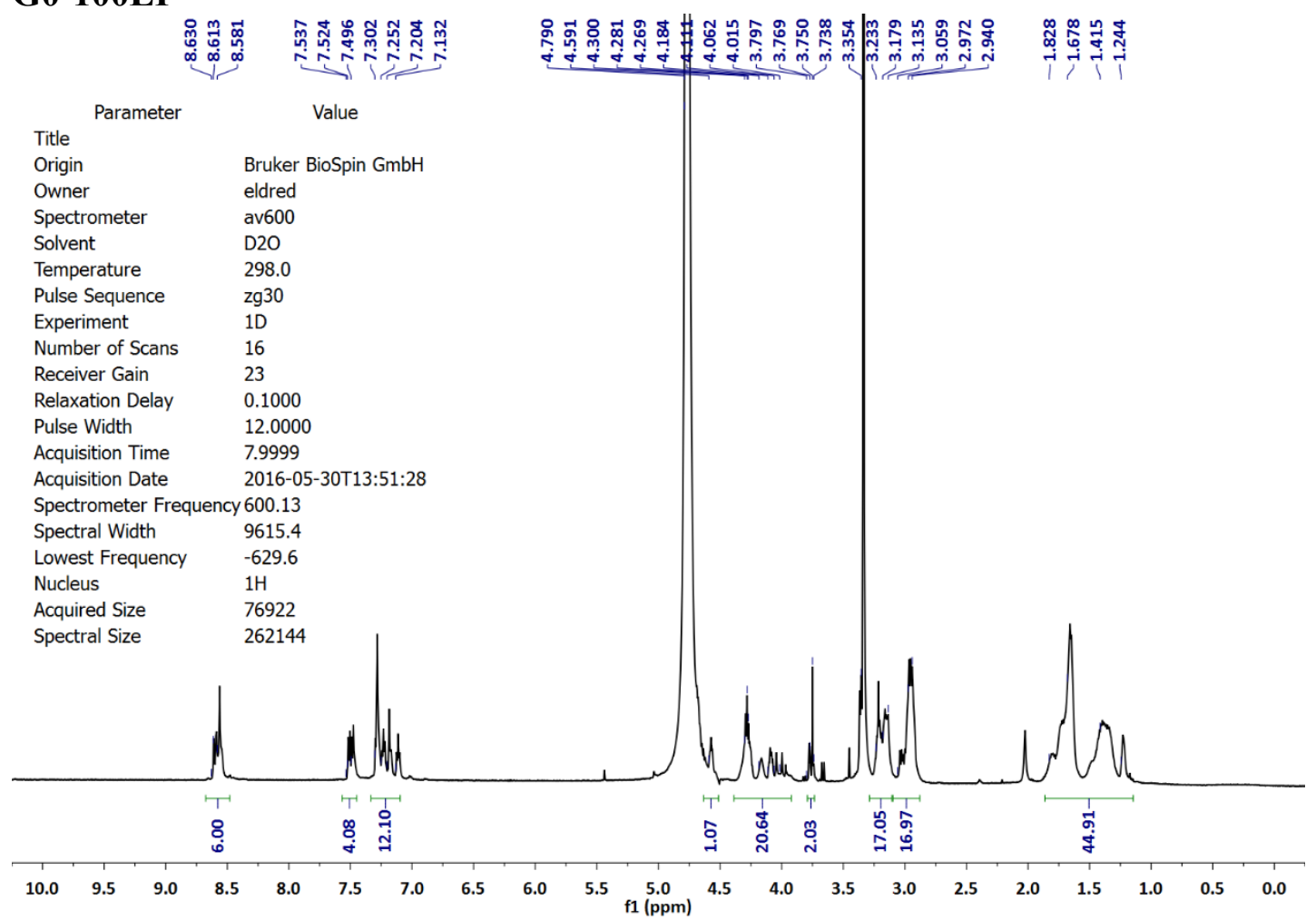

\section{G1-100LP}

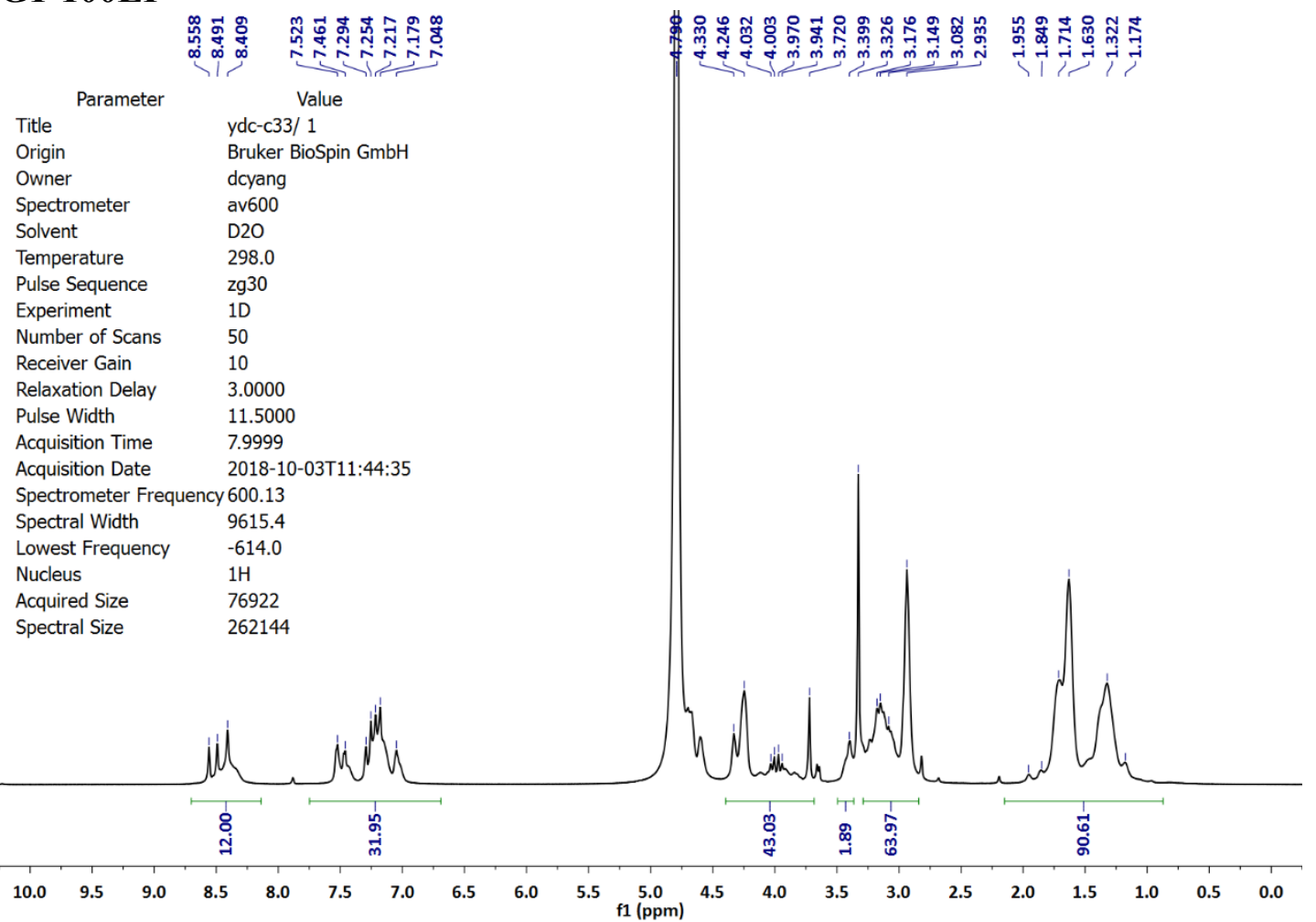




\section{G2-100LP}

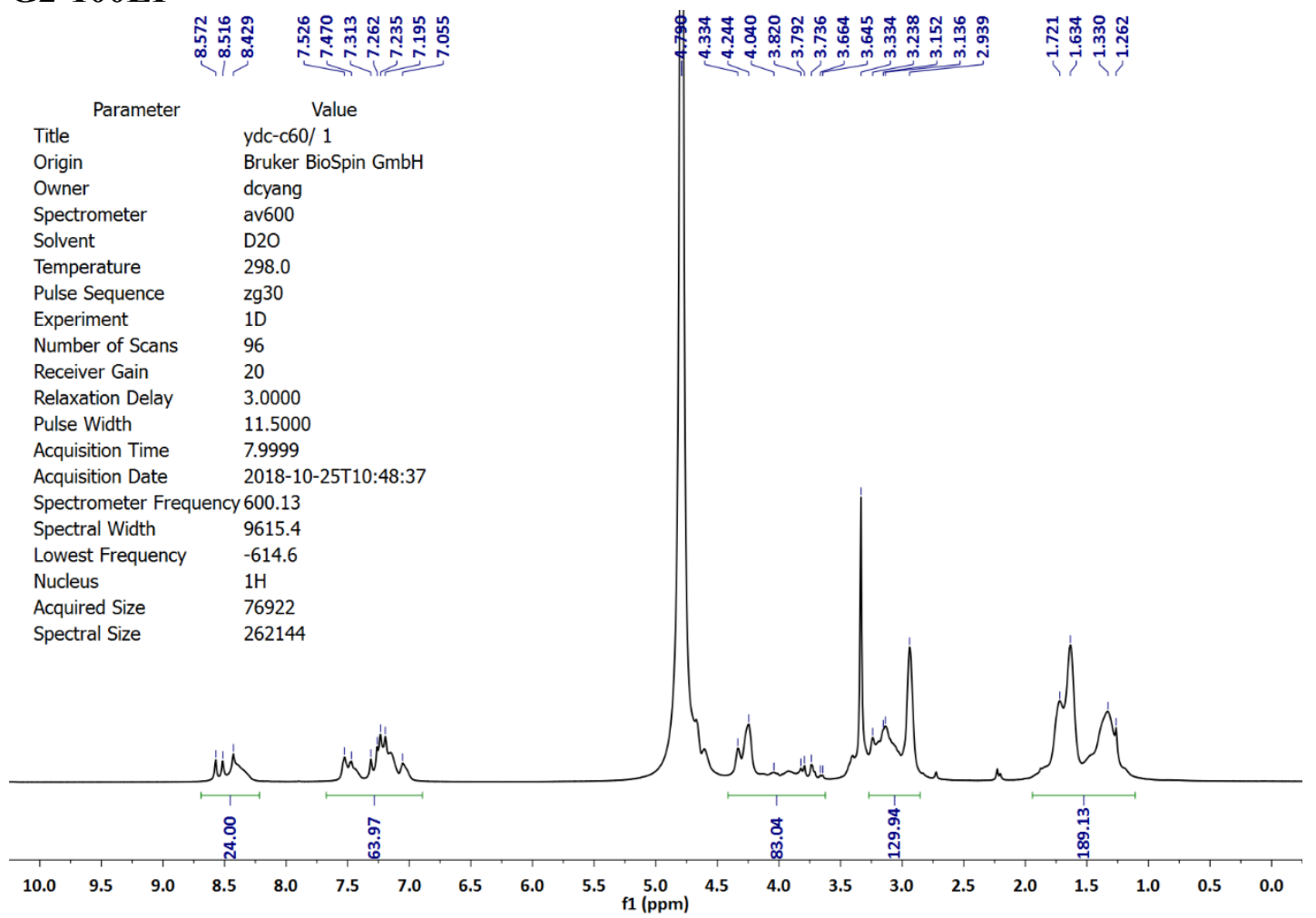

\section{G0-20 TEG-80 LP}

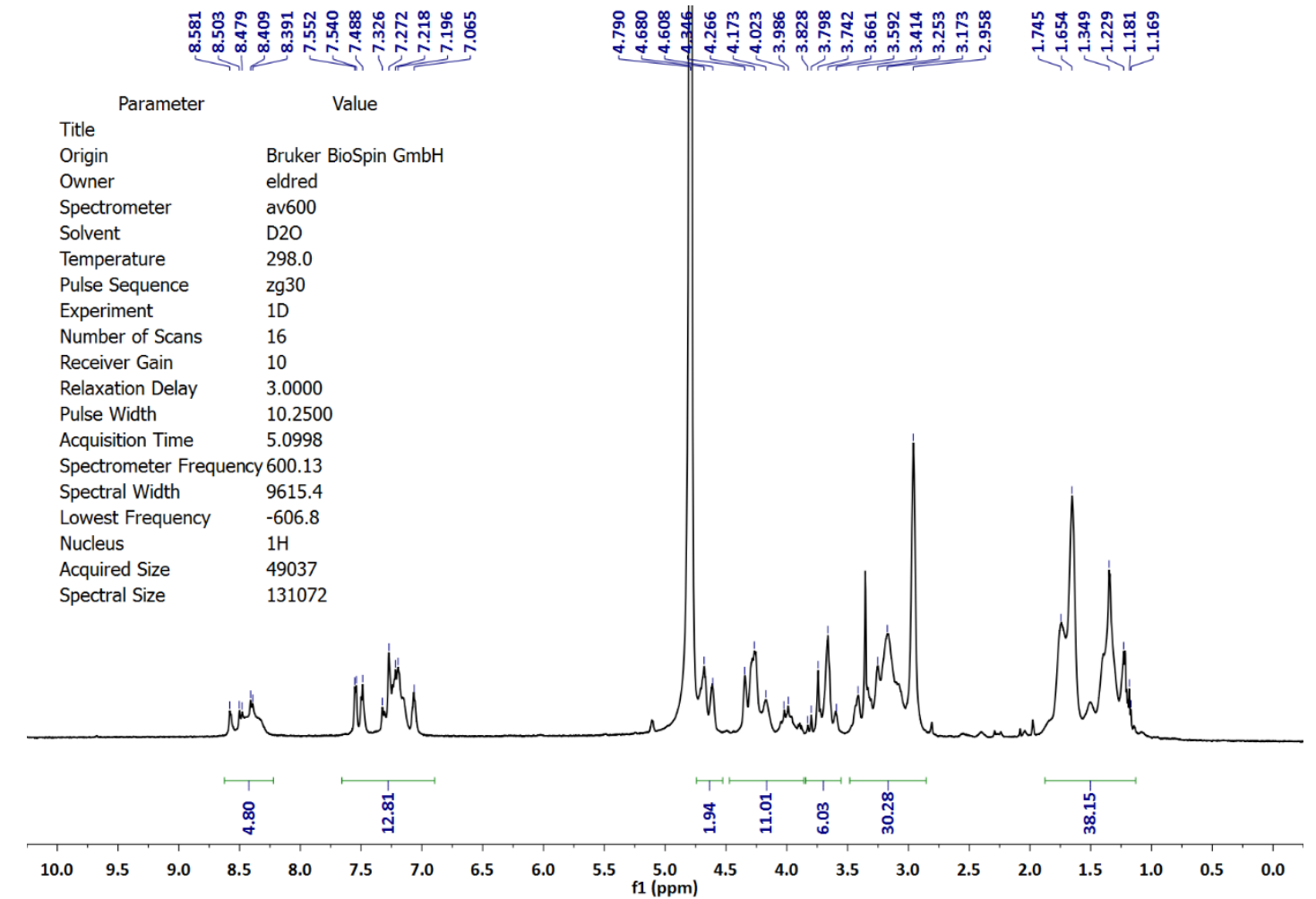


G0-50 TEG-50 LP

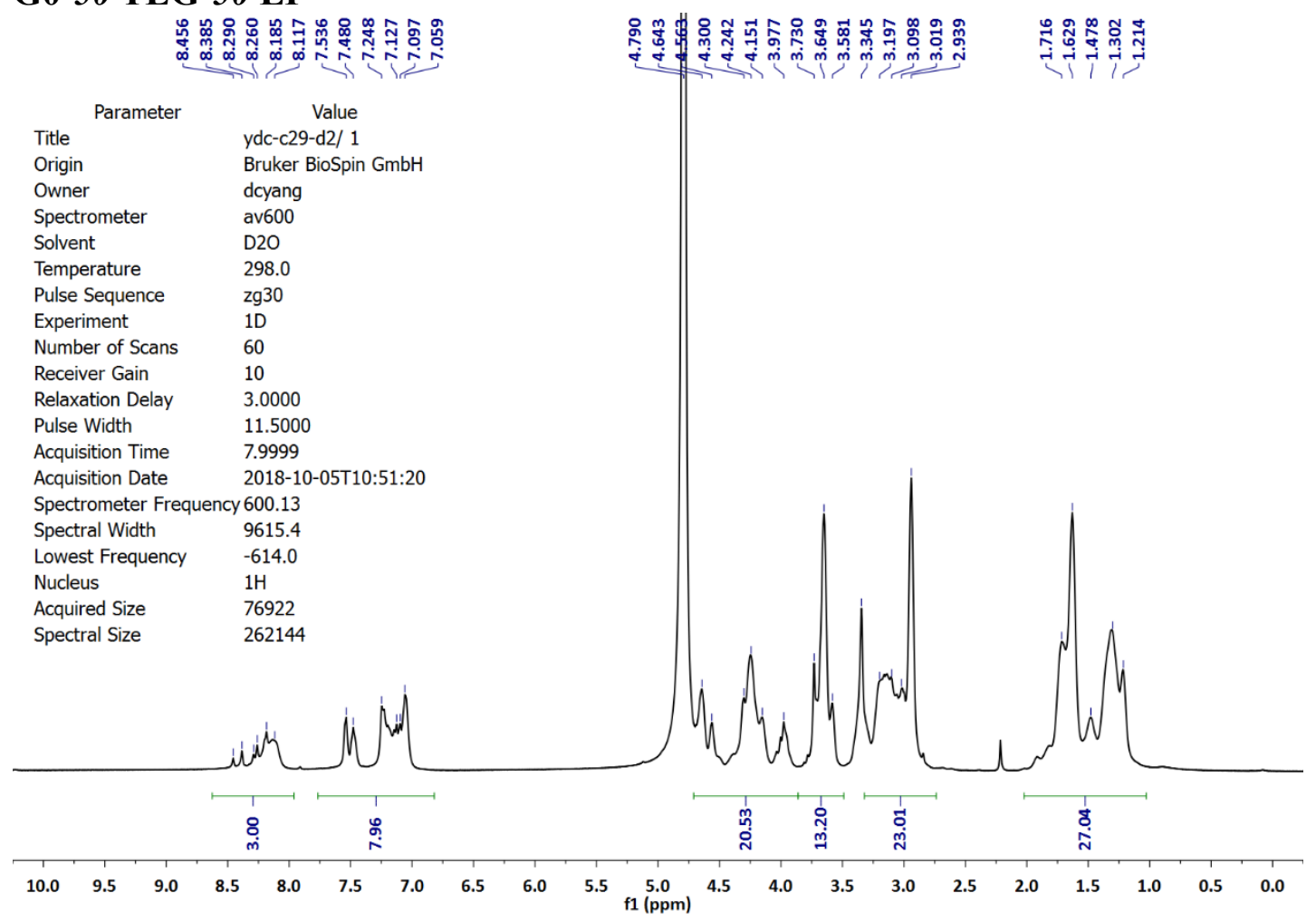

\section{G1-20 TEG-80 LP}

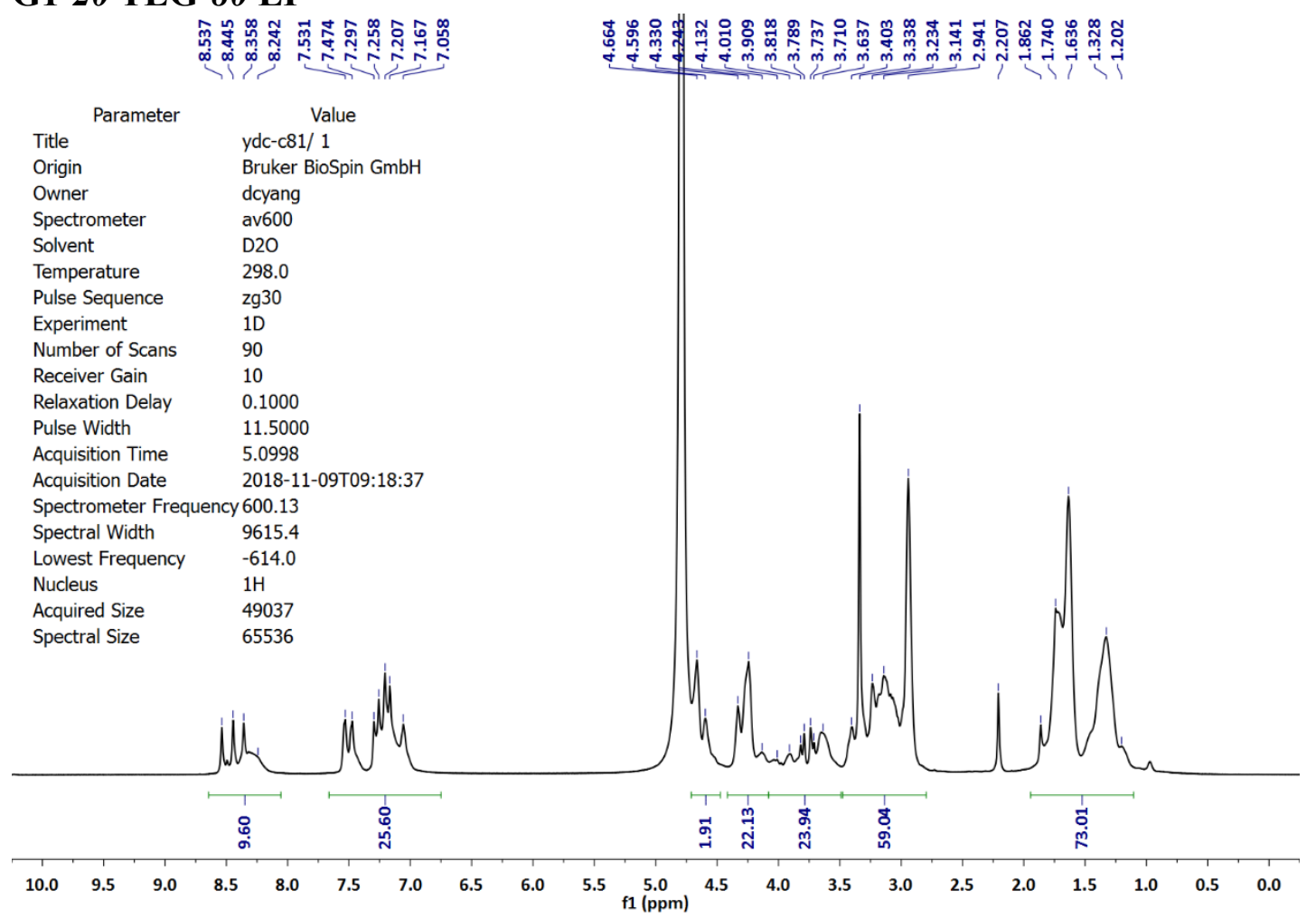




\section{G1-50 TEG-50 LP}



\section{G0-20 SA-80 LP}

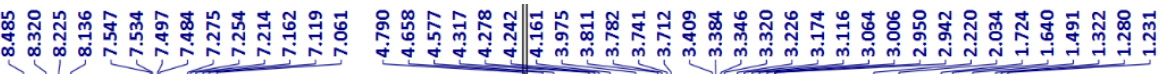

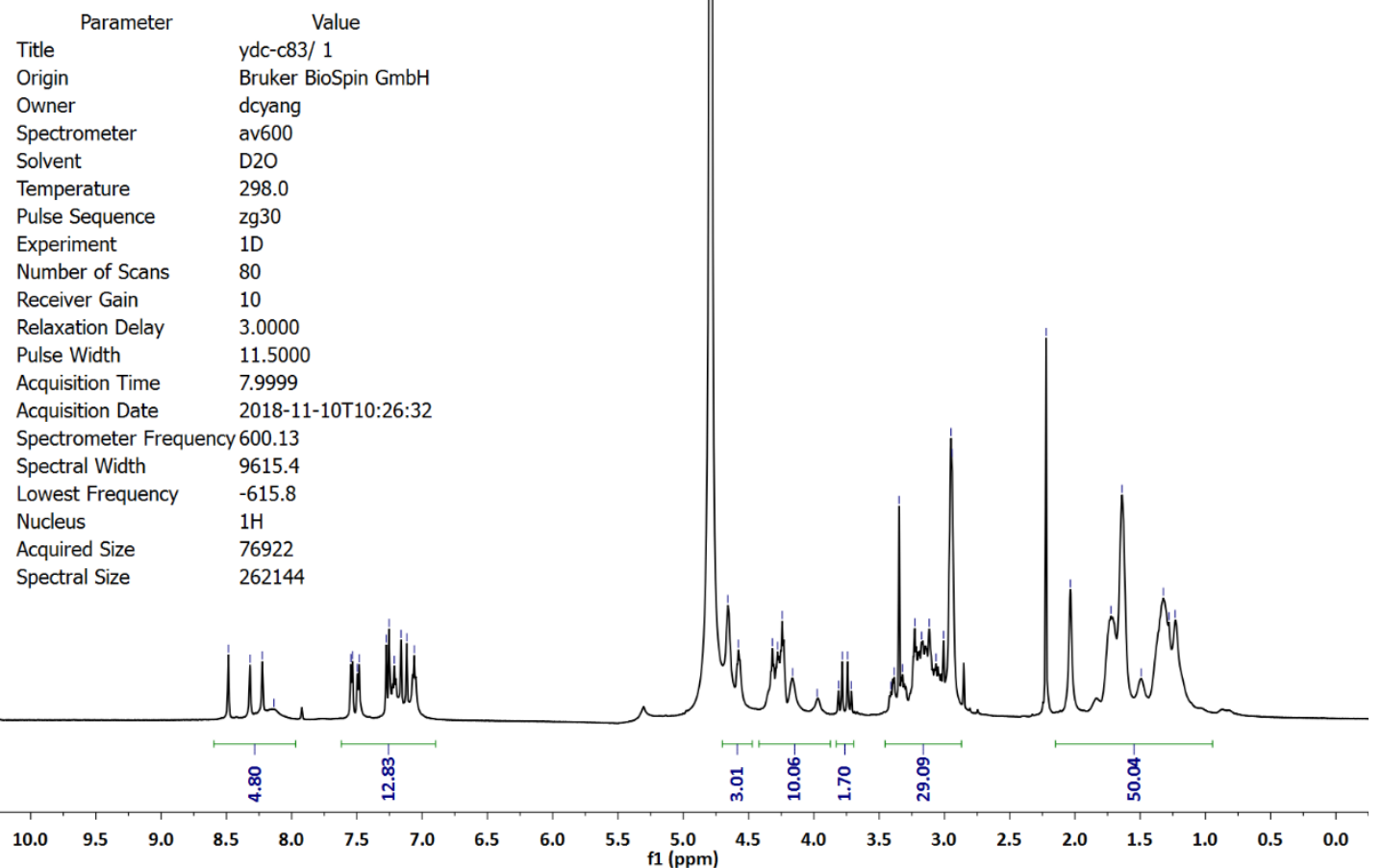




\section{G0-50 SA-50 LP}

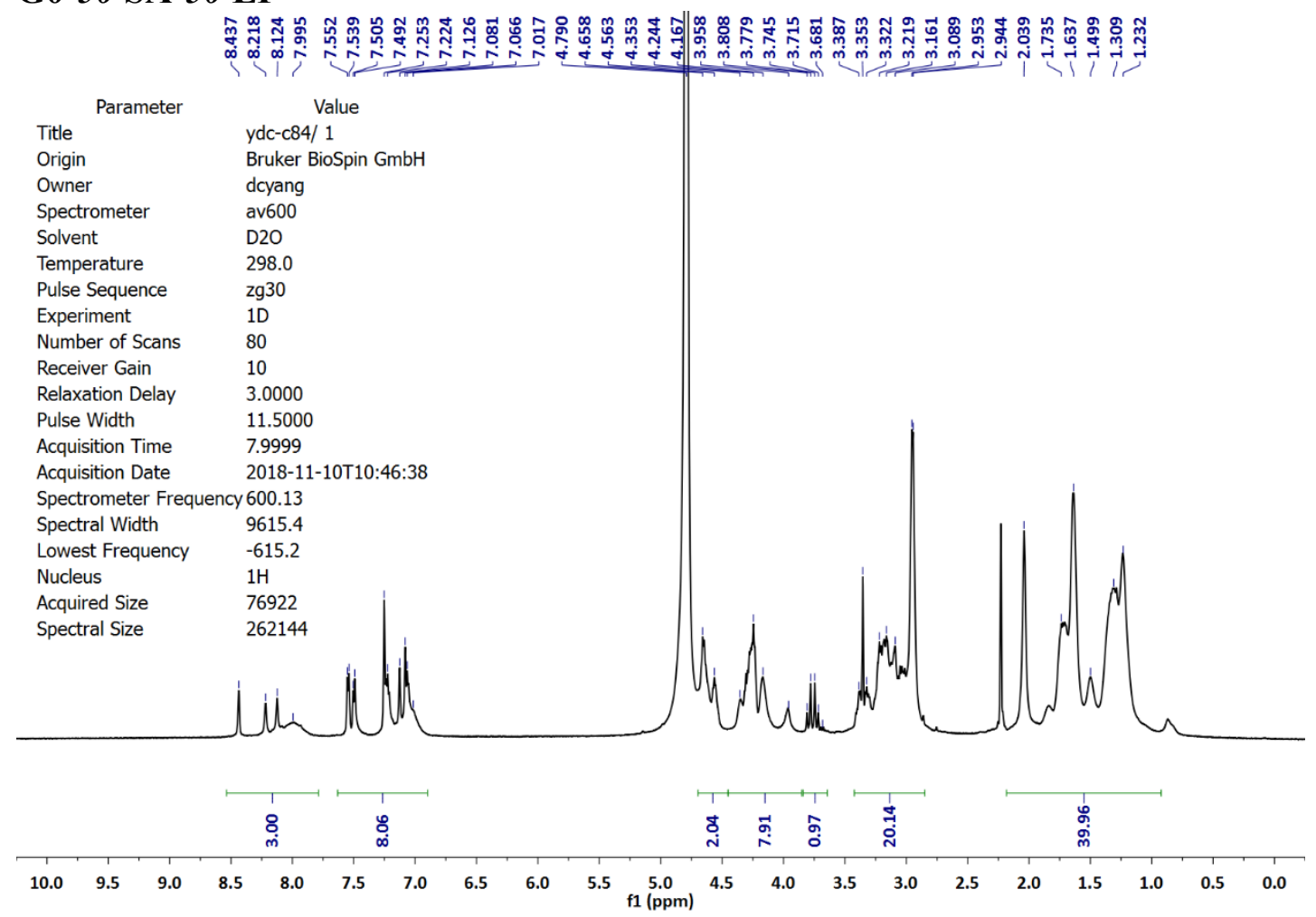

\section{G1-20 SA-80 LP}

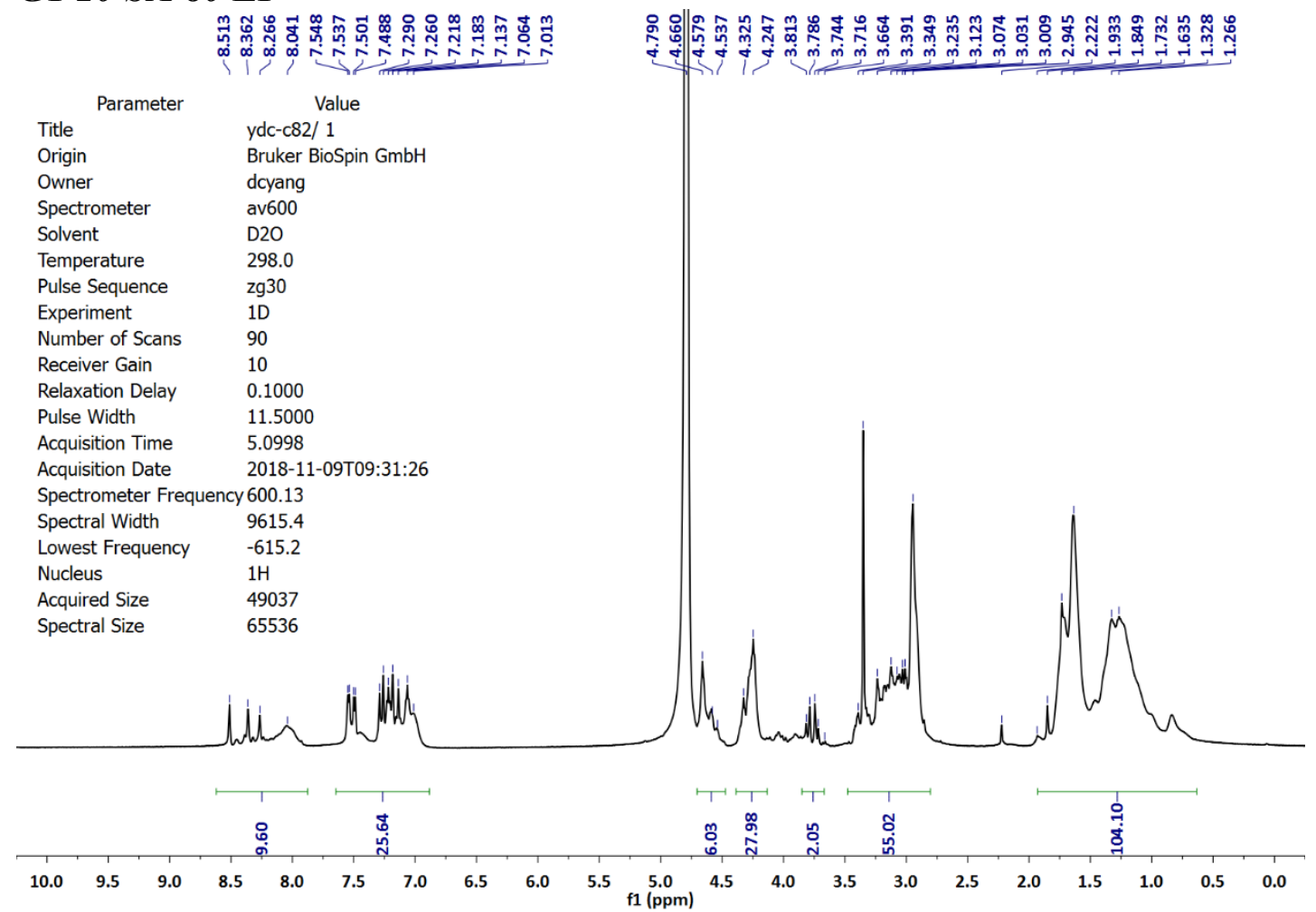




\section{References}

(1). (a) Sanjana, N. E.; Shalem, O.; Zhang, F. Improved vectors and genome-wide libraries for CRISPR screening. Nat. Methods 2014, 11 (8), 783-784. (b) Sancak, Y.; Peterson, T. R.; Shaul, Y. D.; Lindquist, R. A.; Thoreen, C. C.; Bar-Peled, L.; Sabatini, D. M. The Rag CTPases Bind Raptor and Mediate Amino Acid Signaling to mTORC1. Science, 2008, 320, 1496-1501.

(2). (a) Zeng, H.; Little, H. C.; Tiambeng, T. N.; Williams, G. A.; Guan, Z. Multifunctional dendronized peptide polymer platform for safe and effective siRNA delivery. J. Am. Chem. Soc. 2013, 135 (13), 4962-4965. (b) Oldenhuis, N. J.; Eldredge, A. C.; Burts, A. O.; Ryu, K. A.; Chung, J.; Johnson, M. E.; Guan, Z. Biodegradable Dendronized Polymers for Efficient mRNA Delivery. ChemistrySelect 2016, 1 (15), 4413-4417.

Bef 